\title{
Dynamics of Dense Cores in the Perseus Molecular Cloud
}

\author{
Helen Kirk ${ }^{1,2}$, Doug Johnstone ${ }^{1,2}$, and Mario Tafalla ${ }^{3}$
}

\begin{abstract}
We survey the kinematics of over one hundred and fifty candidate (and potentially starforming) dense cores in the Perseus molecular cloud with pointed $\mathrm{N}_{2} \mathrm{H}^{+}(1-0)$ and simultaneous $\mathrm{C}^{18} \mathrm{O}(2-1)$ observations. Our detection rate of $\mathrm{N}_{2} \mathrm{H}^{+}$is $62 \%$, rising to $84 \%$ for JCMT SCUBAselected targets. In agreement with previous observations, we find that the dense $\mathrm{N}_{2} \mathrm{H}^{+}$targets tend to display nearly thermal linewidths, particularly those which appear to be starless (using Spitzer data), indicating turbulent support on the small scales of molecular clouds is minimal. For those $\mathrm{N}_{2} \mathrm{H}^{+}$targets which have an associated SCUBA dense core, we find their internal motions are more than sufficient to provide support against the gravitational force on the cores. Comparison of the $\mathrm{N}_{2} \mathrm{H}^{+}$integrated intensity and SCUBA flux reveals fractional $\mathrm{N}_{2} \mathrm{H}^{+}$abundances between $10^{-10}$ and $10^{-9}$. We demonstrate that the relative motion of the dense $\mathrm{N}_{2} \mathrm{H}^{+}$gas and the surrounding $\mathrm{C}^{18} \mathrm{O}$ gas is less than the sound speed in the vast majority of cases $(\sim 90 \%)$. The point-to-point motions we observe within larger extinction regions appear to be insufficient to provide support against gravity, although we sparsely sample these regions.
\end{abstract}

Subject headings: infrared: ISM: continuum - ISM: individual (Perseus) - ISM: structure - stars: formation - submillimetre

\section{INTRODUCTION}

Stars form in the densest regions of a hierarchy of structures that exist within a molecular cloud. Supersonic motions dominate on the largest scales (e.g., Larson 1981) but appear to be much reduced on the smallest scale, that of a preprotostellar core (e.g., Benson \& Mvers 1989). Understanding what physical processes are at play at each scale ranging from the largest to the smallest is a challenge that both observers and theorists face. The challenge is complicated by the fact that each molecular cloud possesses different properties - local environment has a strong effect on the star formation process. Some molecular clouds, such as Taurus, display isolated star-forming cores which are quiescent and have a low star forma-

\footnotetext{
${ }^{1}$ Department of Physics \& Astronomy, University of Victoria, Victoria, BC, V8P 1A1, Canada; hkirk@uvastro.phys.uvic.ca

${ }^{2}$ National Research Council of Canada, Herzberg Institute of Astrophysics, 5071 West Saanich Road, Victoria, BC, V9E 2E7, Canada

${ }^{3}$ Observatorio Astronómico Nacional (IGN), Alfonso XII 3, E-28014 Madrid, Spain
}

tion efficiency, while others such as Orion display clustered star-forming cores and have more turbulent motions and a higher star formation efficiency (e.g., Cohen \& Kuhi 1979). While clustering increases the complexity of a region and hence the difficulty in understanding what processes are at play, the majority of stars appear to form in environments which are clustered to some degree, and hence it is important to study such regions to understand the impact of clustering. In this paper, we examine the Perseus molecular cloud - a cloud which is less clustered and confused than structure in the Orion molecular cloud, but is not as isolated and quiescent as the Taurus molecular cloud. The Perseus molecular cloud consists of a chain of distinct, well-known small clustered environments in which stars are forming - e.g., NGC1333 and IC348 Bally et al. in prep). There is a wealth of data uniformly spanning this cloud, courtesy of the Spitzer 'c2d' Survey (Evans et al. 2003) and the COMPLETE (CoOrdinated Molecular Probe Line, Extinction, and Thermal Emission) Survey (see Ridge et al. 2006, for a summary of the publicly available data). The 
continuum data from the latter survey (SCUBA thermal dust emission and 2MASS near-IR extinction) allow for the determination of the (column) density structure of the cloud. In particular, we (Kirk, Johnstone, \& Di Francesco 2006, hereafter Paper I) characterized the environments in which dense cores (which could eventually evolve to form a star) were themselves able to form. In doing so, we determined a set of constraints on the column density structure of the cloud which simulations should match. The goal of the present work is to extend that set of density constraints to a set of dynamical constraints.

To sample the behaviour of the dense gas in cores across the molecular cloud, we performed pointed $\mathrm{N}_{2} \mathrm{H}^{+}$observations on a set of locations including candidate dense cores from submillimetre data, points of high visual extinction from the Palomar plates, and peaks of large-scale extinction from 2MASS data. With the addition of the Spitzer data (Jørgensen et al. 2007), we are able to differentiate between unevolved dense starless cores and their more evolved protostellar bretheren. We couple these data with the existing continuum data discussed above in order to determine the dynamical behaviour of the dense gas within the cloud on a variety of scales. Our data do not provide the resolution or full sampling of some other recent surveys (e.g., Walsh et al. 2007), but have the advantage of providing (sparse) sampling across a much larger area, and are thus complimentary to these other works.

\section{SOURCE CATALOG}

\subsection{SCUBA submillimetre}

The Perseus molecular cloud has been mapped over roughly $\sim 3.5$ square degrees in the submillimetre (sensitive to thermal radiation by dust grains) at $850 \mu \mathrm{m}$ with the Submillimetre Common User Bolometer Array (SCUBA) at the James Clerk Maxwell Telescope in Hawaii. In Paper I, we identified approximately fifty cores in the SCUBA data using a $6^{\prime \prime}$ sampled map of all existing data in the cloud. The majority of these data were archival (see Hatchell et al. 2005), but also included some 'fast scan' maps (with insufficient integration time to allow for the typical $3^{\prime \prime}$ sampling) taken as part of the COMPLETE project (Ridge et al. 2006). Paper I compared the prop- erties of the SCUBA cores to the environment they inhabit through comparison to near IR extinction data with $2.5^{\prime}$ resolution (see discussion of these data below), hence the consistent areal coverage was of greater importance than resolution. All of the submillimetre cores were found in regions of previously identified star-formation (e.g., B1, NGC1333), and none were found in the fast-scan mapped regions. For our current project, we utilize maps created with a finer $3^{\prime \prime}$ sampling which allows for better separation of close cores and determination of core properties such as radius. Appendix A discusses the re-reduction of the data we performed, and presents a full source catalog. We identify seventy two submillimetre cores above our usual S/N level (these cores are also used in Jørgensen et al. 2007), as well as 15 additional potential submillimetre cores which do not satisfy our S/N criteria.

The original $6^{\prime \prime}$ sampled map formed the basis of our target list of dense cores to observe in $\mathrm{N}_{2} \mathrm{H}^{+}(1-0)$. We supplemented this with a list of potential SCUBA cores which fell below the detection threshold of our core-identification procedure in order to have as complete a list as possible. This resulted in 89 dense core targets. These target positions are listed in Table 1 along with the associated better-defined SCUBA core from this paper.

\subsubsection{Spitzer $\mathcal{E}$ young protostars}

The Perseus molecular cloud was also one of the clouds surveyed by the Spitzer 'c2d' project (Evans et al. 2003). While the submillimetre wavelengths covered by SCUBA are sensitive to the dusty envelopes of both starless cores and enshrouded protostars, the IR wavelengths probed by Spitzer, particularly the shorter wavelengths, are sensitive to the central accreting object and hence young protostars. Thus Spitzer observations are ideal in distinguishing between starless cores and their more evolved bretheren. The full Spitzer dataset is described in Jørgensen et al. (2006) and Rebull et al. (in press), while a catalogue identifying young protostellar candidates using a combination of Spitzer and SCUBA data is presented in Jørgensen et al. (2007). Note that the work of Jørgensen et al. (2007) utilizes the $3^{\prime \prime}$ sampled SCUBA core list included in Appendix A. Table 1 also shows whether the targets are asso- 
ciated with a young protostar as detected with Spitzer.

A second comprehensive catalog listing the protostellar and starless cores in Perseus has also recently been published by Hatchell et al. (2007) where the sources were classified using SEDs fit to IRAS, Spitzer, SCUBA, and Bolocam observations. A significant difference between the two catalogs is that the Hatchell catalog used only the shorter wavelength Spitzer IRAC data, while the Jørgensen catalog relied primarily on the longer wavelength Spitzer MIPS data. The bulk of the two protostellar catalogs agree, but the Jørgensen catalog contains five protostars not in the Hatchell catalog and the Hatchell catalog contains seventeen protostars not in the Jørgensen catalog.

Of the five sources only in the Jørgensen catalog, one was outside the region included in the Hatchell catalog, two were classified as starless cores in the Hatchell catalog, and the remaining two had submillimetre emission below the threshold for identification. The Jørgensen catalog had three criteria for classification as a protostar - a set of colour criteria for a source across the IRAC $(3.6,4.5,5.8 \mu \mathrm{m})$ and MIPS $(24 \mu \mathrm{m})$ bands, spatial coincidence of a MIPS $24 \mu \mathrm{m}$ source with a SCUBA core, or detection of a SCUBA core with a high central concentration (see Appendix A for the definition of concentration). None of the seventeen protostars only identified in the Hatchell catalog are associated with a high submillimetre central concentration, therefore inclusion in the Jørgensen catalog would require a detection in the MIPS $24 \mu \mathrm{m}$ band plus fulfilment of either the colour criteria or SCUBA core association. We searched the Spitzer data (Rebull et al. in press; Jørgensen et al. 2006; Evans et al. 2003) around each of the seventeen protostars only in the Hatchell catalog. Twelve of the seventeen did not have MIPS detections with a signal to noise above five (seven of these had close SCUBA cores while five did not). Of the remaining five, none had close SCUBA cores or colours satisfying the colour criteria of the Jørgensen catalog. Of the sources only in the Jørgensen catalog, we observed four of the five and all had detections (our sources $\# 21,22,74$, and 95). Of the sources only in the Hatchell catalog, we observed ten of the seventeen and had detections for seven (our sources \#92, 94, 101, 109, 110, 121, and 150).
A range of linewidths, centroid velocities, and peak intensities were found for these sources, therefore any potential mis-classification is unlikely to bias our results.

\subsection{Extinction - 2MASS}

From the COMPLETE Survey, we also have a map of the total column density created from extinction measures derived using the NICER technique (Lombardi \& Alves 2001) on the 2MASS dataset (Ridge et al. 2006; Alves \& Lombardi 2007). This technique utilizes near infrared reddening of background stars in three wavelength bands (two colour indices) in order to determine the total column density of dust. The resolution of this map is $2.5^{\prime}$ and spans the range of $\mathrm{A}_{V}=3$ - 11 within the region mapped by SCUBA (Figures 2 and 3 of Paper I). Paper I analyzed these extinction data and identified structures in the column density on two scales. We utilized the maxima in the smaller-scale structures (the 'extinction cores' of Paper I) to identify a further 24 targets for our $\mathrm{N}_{2} \mathrm{H}^{+}$survey. In later sections of this paper, we utilize the larger-scale structures ('extinction supercores' of Paper I) to define the environments in which the dense cores inhabit. The extinction target positions, along with the associated information from the extinction and submillimetre maps are given in Table 1 .

\subsection{Palomar Plates}

The final extension to the dense core candidate target list was taken from visually-selected targets in the red POSS-II Palomar plates. We focussed on plates in regions devoid of SCUBA cores in order to maximize the extent of our coverage of environments within the cloud. This provided an additional 44 targets. The information on these targets is given in Table 1.

Figure 11 shows all of the targets we selected overlaid on the extinction map of the Perseus molecular cloud.

\section{OBSERVATIONS AND DATA RE- DUCTION}

We made pointed observations of the 157 targets using the $30 \mathrm{~m}$ IRAM telescope in Pico Veleta, Spain. We observed $\mathrm{N}_{2} \mathrm{H}^{+}(1-0)$ in both polarizations using the $(\mathrm{AB}) 100 \mathrm{GHz}$ receivers and 
simultaneously observed $\mathrm{C}^{18} \mathrm{O}(2-1)$ in both polarizations using the (CD) $230 \mathrm{GHz}$ receivers, in both cases utilizing frequency switching. We used the VESPA correlator and smoothed to $0.05 \mathrm{~km} / \mathrm{s}$ channels. The beamsize is $\sim 25^{\prime \prime}$ for $\mathrm{N}_{2} \mathrm{H}^{+}$and $\sim 11^{\prime \prime}$ for $\mathrm{C}^{18} \mathrm{O}$. Each observation was made for 2 minutes and had an $\mathrm{rms}$ of $\mathrm{T}_{A}^{*} \sim 0.1 \mathrm{~K}$. We made multiple pointings on some of the cores to better resolve spectral features or search for a signal to a higher sensitivity. We made four-point maps (offsets of $25^{\prime \prime}$ in RA and dec around the central pointing) around some of the targets in order to distinguish extended structures and search for cores offset from the assumed position. In the interests of minimizing observing time, this was done for only a subsample (62) of the cores.

We detected signal in $\mathrm{N}_{2} \mathrm{H}^{+}$in $62 \%$ of our targets at the central position, with the rate rising to $84 \%$ for the SCUBA-selected targets. Since $\mathrm{N}_{2} \mathrm{H}^{+}$is a 'late time' molecular ion, not attaining significant abundance until after $\sim 10^{5}$ yrs (Aikawa et al. 2003), this implies most of the SCUBA sources are at least this old.

Virtually every target had a $\mathrm{C}^{18} \mathrm{O}$ detection (96\%). All but one of the spectra with signal in $\mathrm{N}_{2} \mathrm{H}^{+}$had a corresponding detection in $\mathrm{C}^{18} \mathrm{O}$. Examination of the one rogue case revealed that higher than average noise in the $\mathrm{C}^{18} \mathrm{O}$ spectrum was likely responsible for the lack of a detection.

Table 2 shows the full break-down of the detection rates and numbers for the various target selection methods. There are several factors which likely go into the vast difference in success rates for the different selection criteria. Both the 2MASS and Palomar plate-selected targets have greater uncertainties attached to a potential core's position than the SCUBA-selected cores. The 2MASS map has a resolution of $2.5^{\prime}$ and thus is insensitive to the small density peak of an individual core, rather, it represents a smoothed average of any large- plus small-scale dense structures along the line of sight. The Palomar plates have better resolution $\left(1^{\prime \prime}\right)$ but are only sensitive to a few magnitudes of visual extinction. Our detection efficiency for this portion of the survey is similar to the $\mathrm{NH}_{3}$ survey of Benson \& Mvers (1989) which used the original Palomar plates to identify candidate cores.

$\mathrm{N}_{2} \mathrm{H}^{+}$has a critical density of $\sim 10^{5} \mathrm{~cm}^{-3}$ (Tafalla et al. 2002) and thus is sensitive to only the densest gas within molecular clouds. The SCUBA-selected and Palomar-selected targets were all chosen on the basis of apparent (column) density enhancements which would indicate the site of a dense core. While this was not the case for the 2MASS-selected targets (the resolution allowed only for the identification of peaks in the large-scale structure), those 2MASS-selected targets which had detections all lie on or close to structure visible in the SCUBA observations. Hence all of the targets where we detected $\mathrm{N}_{2} \mathrm{H}^{+}$ are likely to be dense cores rather than less dense gas unassociated with any small-scale structure.

\subsection{Fitting the Spectra}

We reduced the $\mathrm{N}_{2} \mathrm{H}^{+}$and $\mathrm{C}^{18} \mathrm{O}$ data from IRAM using CLASS 11. First, we fit a baseline to each spectrum individually using a 4 th order polynomial. The resultant spectra were then folded and summed where multiple pointings existed.

To fit the seven components of the $\mathrm{N}_{2} \mathrm{H}^{+}$(1$0)$ spectra, we used CLASS's HyperFine Split fitting routine, with the relative frequencies and optical depths for $\mathrm{N}_{2} \mathrm{H}^{+}$taken from Caselli et al. (1995) and a frequency of $93176.258 \mathrm{MHz}$ for the $\mathrm{N}_{2} \mathrm{H}^{+}\left(\mathrm{JF}_{1} \mathrm{~F}=101-012\right)$ 'isolated' component (Lee. Myers \& Tafalla 2001).

In some cases $\left(20 \mathrm{~N}_{2} \mathrm{H}^{+}\right.$spectra), two separate components were clearly required for a good fit. We interpret these spectra as belonging to two separate entities, rather than a central dip caused by self-absorption. Appendix B discusses the evidence for this interpretation of these cores.

Table 3 shows the best-fit line parameters found using CLASS for the $\mathrm{N}_{2} \mathrm{H}^{+}$spectra - the centroid velocity, velocity dispersion (measured in terms of FWHM), the total optical depth, the baseline level (alternatively, the standard deviation in regions with no line emission), and the line rms (alternatively the standard deviation in the fitting residuals where there is line emission). All fits were visually inspected; those of poor reliability due to low $\mathrm{S} / \mathrm{N}$ are noted in the final column these have reasonable centroid velocities but poor dispersions since noise limits the determination of the extent of the line. We include the less secure fits only in the analysis of centroid velocities. The

\footnotetext{
${ }^{1}$ See http://www. iram.fr/IRAMFR/GILDAS
} 
integrated intensities were also measured for each spectrum using the tdv function 2 in CLASS. We integrated over a range of -9 to $+8 \mathrm{~km} / \mathrm{s}$ around the centroid velocity fit (in order to include all hyperfine components), and take the error in the integrated intensity to be $B \times \delta V / \sqrt{N}$, where B is the spectrum's rms (baseline level), $\delta V$ is the velocity range $\left(17 \mathrm{~km} \mathrm{~s}^{-1}\right)$ and $\mathrm{N}$ the number of spectral channels summed over (541).

To fit the single-line $\mathrm{C}^{18} \mathrm{O}(2-1)$ spectra, we used CLASS's Gaussian fitting routine, and assumed a rest frequency of $219560.354 \mathrm{MHz}$ (Müller et al. 2001). These spectra often had complex shapes not well approximated by a single Gaussian. $\mathrm{C}^{18} \mathrm{O}$ traces less dense gas than $\mathrm{N}_{2} \mathrm{H}^{+}$and thus could be expected to more often trace multiple structures along the line of sight. The Gaussian profile, however, is a simple approximation for the lines and provides a rough estimate on relevant properties. In cases where fitting a second Gaussian made a marked improvement to the fit, we did so (66 spectra). We fit a third component in only one case (a cross position) where three distinct and separate features were visible. Figure 2 shows three $\mathrm{C}^{18} \mathrm{O}$ spectra as an example of some of the types of profiles observed - the first displays an obvious single Gaussian profile, the second a clear doubleGaussian profile and the third a more complicated structure which we fit with a single Gaussian.

Table 4 shows the best-fit parameters found by CLASS for the $\mathrm{C}^{18} \mathrm{O}$ spectra - the centroid velocity, velocity dispersion (measured in FWHM units), integrated intensity, peak intensity, baseline (the standard deviation where there is no line emission), and line rms (the standard deviation of the fitting residuals where there is line emission). Similarly to our procedure for the $\mathrm{N}_{2} \mathrm{H}^{+}$lines, we take the error in the integrated intensity (not included in the table) to be $B \times \delta V / \sqrt{N}$ where $\mathrm{B}$ is the baseline, $\delta V$ is twice the FWHM and $\mathrm{N}$ the number of spectral channels summed over (each spectral channel is $0.0267 \mathrm{~km} \mathrm{~s}^{-1}$ ).

\footnotetext{
${ }^{2}$ The tdv function, a part of the spectral cube package, calculates the integrated intensity of individual spectra between two user-specified velocities, similar to the print area command.
}

\subsection{Other Considerations - Pointing Ac- curacy}

In the analysis below, we utilize only the measurements from the central pointing and ignore the offset cross pointings that we have on a subsample of the targets in order to treat the entire sample consistently. The observations of cross-positions are useful in allowing us to determine how accurately we determined the $\mathrm{N}_{2} \mathrm{H}^{+}$core centres during target selection and how much error or bias might be introduced to our results from using only a single pointing. We leave a full discussion of these issues for Appendix C, but note the result that we find little evidence our results are affected by any errors or bias introduced by using a single pointing.

\section{NON-THERMAL MOTIONS WITHIN DENSE $\mathrm{N}_{2} \mathrm{H}^{+}$CORES}

The one-dimensional thermal velocity dispersion expected for $\mathrm{N}_{2} \mathrm{H}^{+}$is given by

$$
\sigma_{T, n}=\sqrt{\frac{k_{B} T}{\mu_{n} m_{H}}}
$$

where $k_{B}$ is the Boltzmann constant, $\mathrm{T}$ is the temperature, $\mu_{n}$ is the molecular weight of $\mathrm{N}_{2} \mathrm{H}^{+}$in atomic units (29) and $m_{H}$ the mass of a hydrogen atom. We assume a temperature of $15 \mathrm{~K}$, which lies within the range of temperatures we derived from Bonnor-Ebert modelling of SCUBA cores in the Perseus molecular cloud (Paper I). This corresponds to a sound speed of $0.065 \mathrm{~km} / \mathrm{s}$ for $\mathrm{N}_{2} \mathrm{H}^{+}$. The non-thermal component of the velocity dispersion is then given by

$$
\sigma_{N T, n}=\sqrt{\sigma_{o b s, n}^{2}-\sigma_{T, n}^{2}}
$$

where $\sigma_{o b s, n}$ is the observed velocity dispersion. The level of internal turbulence, the ratio of nonthermal velocity dispersion to the mean thermal velocity dispersion of the gas, is then :

$$
f_{\text {turb }}=\frac{\sigma_{N T, n}}{c_{s}}
$$

where we take a mean molecular weight of 2.33 , which yields a sound speed of $0.23 \mathrm{~km} / \mathrm{s}$ in the mean gas.

We use the same procedure to calculate the level of non-thermal motions observed in our $\mathrm{C}^{18} \mathrm{O}$ 
data, with $\mu_{C}=30$ and a corresponding sound speed of $0.064 \mathrm{~km} / \mathrm{s}$.

The error in $f_{\text {turb }}$ is small for either line since the linewidths are determined to better than $5 \%$ in most cases.

Recent ammonia observations (Rosolowsky et al, in prep), which include all of our targets, show a spread in temperatures between 10 and $15 \mathrm{~K}$, with the mean near $12 \mathrm{~K}$. The non-thermal motions we measure would only become $\sim 10 \%$ larger and the turbulent fraction $\sim 10-35 \%$ larger with the adoption of the ammonia temperatures. We maintain our use of $15 \mathrm{~K}$ for consistency with Paper I.

Maps of dense cores show that they are surrounded by a less dense envelope. In targets where we detected an $\mathrm{N}_{2} \mathrm{H}^{+}$signal, we expect a surrounding envelope to also exist. Due to chemical effects, $\mathrm{C}^{18} \mathrm{O}$ is expected to trace a larger scale than $\mathrm{N}_{2} \mathrm{H}^{+}$even with its smaller beamsize due to the higher frequency of the transition $-\mathrm{C}^{18} \mathrm{O}$ (with critical density $\sim 10^{3} \mathrm{~cm}^{-3}$, e.g., Ungerechts et al. 1997) freezes out at densities of $10^{5} \mathrm{~cm}^{-3}$ where $\mathrm{N}_{2} \mathrm{H}^{+}$is detectable (e.g., Tafalla et al. 2002). Therefore, in a dense core, $\mathrm{C}^{18} \mathrm{O}$ measures are weighted to the outer parts while $\mathrm{N}_{2} \mathrm{H}^{+}$measures are weighted to the denser inner parts. Hence in targets where we detect both $\mathrm{N}_{2} \mathrm{H}^{+}$and $\mathrm{C}^{18} \mathrm{O}$, the $\mathrm{C}^{18} \mathrm{O}$ can be thought of as tracing the envelope of the dense $\mathrm{N}_{2} \mathrm{H}^{+}$core. From our single pointing observations, we are unable to determine whether this surrounding less dense gas is found distinctly around each dense core (each core has a unique envelope) or on a larger scale (several cores sharing a common envelope). We therefore use the term envelope broadly in our discussion of results. In targets where we only detect $\mathrm{C}^{18} \mathrm{O}$, we do not have sufficient information to determine if the emission originates from an envelope-like region.

Previous observations of dense cores and their surroundings have shown that the dense gas (observed in $\mathrm{N}_{2} \mathrm{H}^{+}$or $\mathrm{NH}_{3}$ ) traces a 'coherent core' with a close-to-constant velocity dispersion of slightly above the thermal value (Benson \& Mvers 1989; Barranco \& Goodman 1998; Goodman et al. 1998; Jijina et al. 1999; Caselli et al. 2002). Additionally, the dense core appears kinematically distinct from the surrounding less dense gas (traced by $\mathrm{OH}$ or $\mathrm{C}^{18} \mathrm{O}$ ) which displays an increasing velocity dispersion with size (Barranco \& Goodman
1998; Goodman et al. 1998). We therefore expect that the velocity dispersion we measure in our $\mathrm{N}_{2} \mathrm{H}^{+}$pointed observations represents the value that would be present across the entire coherence length of the core $(\sim 0.1 \mathrm{pc}$ for low-mass isolated cores in Goodman et al. 1998). Figure 3 which plots the distribution of the level of internal turbulence $\left(f_{\text {turb }}\right)$ measured in $\mathrm{N}_{2} \mathrm{H}^{+}$, shows that indeed most of the dense cores have little nonthermal motion.

Any dense cores which have evolved to the protostellar phase might be expected to display a greater fraction of non-thermal motions - either infall our outflow motion would be expected to broaden the line width observed. We analyze the subset of dense $\mathrm{N}_{2} \mathrm{H}^{+}$cores which are not associated with protostars from the Spitzer catalog (also plotted in Figure 3) and find that, as expected, this subset does tend to display even less turbulent motions. The mean and standard deviation of the turbulent fraction is $0.6 \pm 0.3$ and $1.0 \pm 0.4$ for the starless cores and protostellar cores respectively.

The turbulent fractions we find for starless cores and protostars are consistent with previous dense core surveys (e.g. Benson \& Myers 1989; Jijina et al. 1999). While Jijina et al. (1999) do observe higher turbulent fractions in cores belonging to more massive and turbulent molecular clouds such as Orion, the turbulent fractions we observe are consistent with the range Jijina et al. (1999) find in cores in molecular clouds with properties similar to Perseus.

The results are in contrast, however, to the simulation of Klessen et al. (2005) who find that their large-scale-driven turbulence model only has $\sim 50 \%$ of the cores with $f_{\text {turb }} \leq 1$; the smallscale-driven simulation has a much smaller fraction again. The distribution of cores in the Klessen et al. 2005) simulation are also plotted in Figure 3. displaying a significant tail to the distribution of $f_{\text {turb }}$ of cores not found in our observations.

The turbulent fraction is also affected by association with young stellar clusters. Caselli \& Mvers (1995) analyzed ammonia cores in the Orion B molecular cloud and found an inverse relationship between core linewidth and distance to the nearest stellar cluster. There are three young star clusters near the Perseus molecular cloud - in NGC1333, IC348, and the Perseus OB association 
(e.g. Hatchell et al. 2005). We note our observations are consistent with a similar trend - the most turbulent cores are found in NGC1333 and IC348 (the Perseus OB association lies farther from the cores we observed).

We can perform a similar turbulent fraction analysis with the $\mathrm{C}^{18} \mathrm{O}$ observations (adapting the velocity dispersion equations above). The $\mathrm{C}^{18} \mathrm{O}$ observations are sensitive to a lower density regime and so trace larger structures which display a higher level of turbulent motion than the densest parts of the core displays (see Figure 4). This is also consistent with previous observations (e.g., Benson \& Myers 1989). The results from the Klessen et al. (2005) model are also plotted for reference. Although the model is a much closer match to these observations, the model 'observations' were designed to match to a dense-gas tracer such as $\mathrm{N}_{2} \mathrm{H}^{+}$. The core boundaries used to define the 'observable area' of the cores in the simulation, the half-maximum column density contour Klessen et al. 2005) better match the extent of densities traced by $\mathrm{N}_{2} \mathrm{H}^{+}$than by $\mathrm{C}^{18} \mathrm{O}$. It is interesting to note that our $\mathrm{C}^{18} \mathrm{O}$ targets show much less variation in their distribution of $\mathrm{f}_{\text {turb }}$ between those which are and are not associated with a protostar than the dense $\mathrm{N}_{2} \mathrm{H}^{+}$cores do. The mean and standard deviation are $1.2 \pm 0.6$ and $1.8 \pm 0.7$ for pointings not associated and associated with protostars respectively. This may indicate that at the early stages of protostellar evolution, protostars do not affect the bulk of their envelopes in a significant manner!

\section{CORE VERSUS ENVELOPE MO- TIONS}

As discussed earlier, for the pointings which have both $\mathrm{N}_{2} \mathrm{H}^{+}$and $\mathrm{C}^{18} \mathrm{O}$ detections, the $\mathrm{N}_{2} \mathrm{H}^{+}$ traces the dynamics of the dense core, while the $\mathrm{C}^{18} \mathrm{O}$ traces the dynamics of the surrounding less dense gas.

Previous studies using maps of $\mathrm{N}_{2} \mathrm{H}^{+}$and $\mathrm{C}^{18} \mathrm{O}$ have shown that cores do not move ballistically within their envelopes (i.e. centroid velocity differences between $\mathrm{N}_{2} \mathrm{H}^{+}$and $\mathrm{C}^{18} \mathrm{O}$ are smaller than the $\mathrm{C}^{18} \mathrm{O}$ linewidth) and most have subsonic core-to-envelope motions (e.g., Walsh et al. 2004, 2007). The Walsh et al. (2004) survey examined mostly single isolated cores, rather than those in clustered regions, while the Walsh et al. (2007) survey spanned a clustered region of dense cores (NGC1333, which is included in our larger-area sample although at lower resolution). Unfortunately, the Walsh et al. (2007) results are less certain since their $\mathrm{C}^{18} \mathrm{O}$ beamsize was significantly larger than their $\mathrm{N}_{2} \mathrm{H}^{+}$beamsize. Thus our survey is ideal in providing a large statistical measure of core-envelope motions within a clustered environment.

We separately analyze the relative core to envelope motions of the starless and protostellar cores. In starless cores, the relative motions should be induced by the molecular cloud and the core formation process. In protostellar cores, the relative motions between core and envelope could be complicated by outflows or processes which decouple the core from its envelope. Figure 5 shows our results for the starless cores and protostars separately - both have a high fraction of relative velocities which are less than the sound speed.

Ayliffe et al. (2007) has argued that the previous analyses of Walsh et al. (2004, 2007) biases results towards small velocity differences due to the method of analysis. In instances where multiple $\mathrm{CO}$ velocities were found along the line of sight, the velocity component closest to the $\mathrm{N}_{2} \mathrm{H}^{+}$ core velocity was assumed to be the one associated with the core. Here, we demonstrate that taking the closest $\mathrm{CO}$ velocity component is reasonable and does not introduce significant bias. Most of the cores in our observations had only a single velocity component fit. For these, we compared the difference in centroid velocity between the $\mathrm{N}_{2} \mathrm{H}^{+}$and $\mathrm{C}^{18} \mathrm{O}$, as shown in Figure 5. This figure demonstrates that the vast majority of cores (nearly 90\%) have differences less than the sound speed of the ambient medium (dotted lines), and the remaining cores have differences which are not much larger. Note that some of the $\mathrm{N}_{2} \mathrm{H}^{+}$cores in this plot were fit to two velocity components; we considered these two velocity components as separate entities (i.e., plotted as two distinct cores). The velocity differences found for the two $\mathrm{N}_{2} \mathrm{H}^{+}$ velocity cores versus the surrounding $\mathrm{C}^{18} \mathrm{O}$ tend to be larger than for the other cores (since both $\mathrm{N}_{2} \mathrm{H}^{+}$velocities are compared to the same $\mathrm{C}^{18} \mathrm{O}$ velocity). The $\mathrm{CO}$ linewidth for the two velocity $\mathrm{N}_{2} \mathrm{H}^{+}$cores also tends to be broader than average. All of the cores have an error in the centroid ve- 
locity of around several hundredths of a $\mathrm{km} \mathrm{s}^{-1}$, indicating that the majority of the differences in velocities observed are real.

Figure 6] shows the absolute difference in $\mathrm{N}_{2} \mathrm{H}^{+}$ to $\mathrm{C}^{18} \mathrm{O}$ centroid velocity in dense cores where two $\mathrm{C}^{18} \mathrm{O}$ velocity components were fit, again split into starless cores and protostars. The velocity differences here are ordered in terms of the largest-difference component (squares), while the smallest-difference component is denoted by diamonds or asterisks. Clearly the two CO velocity components are not correlated, as is expected since the second CO component merely lies along the same line of sight. The cores which happen to have a second $\mathrm{C}^{18} \mathrm{O}$ velocity component along the same line of sight should possess a similar distribution of core-to-envelope relative velocities as along lines of sight where only a single $\mathrm{C}^{18} \mathrm{O}$ velocity component was observed - i.e., velocity differences smaller than the sound speed in the vast majority of cases. As can be seen from Figure 6. in almost every case this implies the closer CO velocity component is the only sensible one to associate with the dense core; in the rare instance of ambiguity, the resultant number of cores with each velocity difference will be little affected.

Assuming in all cases that the closest velocity $\mathrm{C}^{18} \mathrm{O}$ component is the one associated with the $\mathrm{N}_{2} \mathrm{H}^{+}$profile peak, we find that in the majority of dense cores, the core-to-envelope velocity tends to be smaller than thermal, $(88 \%$ and $83 \%$ for the starless and protostellar cores respectively). In the Walsh et al. (2004) survey of mostly isolated cores, they find only one out of 35 cores (or $3 \%$ ) with a core-to-envelope velocity exceeding the sound speed. The Walsh et al. (2007) survey of cores in NGC1333 found an rms core-to-envelope velocity of $0.53 \mathrm{~km} / \mathrm{s}$; nearly half of their cores have differences greater than the sound speed of the medium. Our survey includes the NGC1333 cores but finds much lower differences (we have rms velocity differences of $0.16 \mathrm{~km} / \mathrm{s}$ for the starless cores and $0.18 \mathrm{~km} / \mathrm{s}$ for the protostars when both the one- and two- velocity component $\mathrm{CO}$ spectra are included). This may indicate that the Walsh et al. (2007) survey results were biased by the much larger beamsize for $\mathrm{C}^{18} \mathrm{O}\left(50^{\prime \prime}\right)$ than $\mathrm{N}_{2} \mathrm{H}^{+}\left(10^{\prime \prime}\right)$ which could have sampled a large fraction of material not associated with the individual dense core's envelope.
As discussed in Walsh et al. (2004), small relative motions between cores and envelopes could be interpreted as an indication of quiescence on small scales, and as such would appear to argue against a competitive accretion scenario for star formation, where dense cores gain most of their mass by sweeping up material as they move through the cloud. Recent analysis of simulations by Ayliffe et al. (2007), however, show that the competitive accretion scenario is not necessarily incompatible with the observations. Ayliffe et al. (2007) analyzed the competitive accretion simulations of Bate et al. (2003) and demonstrated that the simulated observations also show core to envelope motions are not ballistic. There were, however, differences between the simulated observations and the Walsh et al. (2004) results at later times in the simulation (such as the $\mathrm{N}_{2} \mathrm{H}^{+}$linewidth becoming larger than the $\mathrm{C}^{18} \mathrm{O}$ linewidth), which were attributed to the clustered environment of the simulation, versus the isolated cores observed. Since our observations probe cores forming in a clustered environment (and include protostars), we can make a stronger comparison with the Ayliffe et al. (2007) results at later times. Ayliffe et al. (2007) do find the majority of their sources have velocity differences less than the sound speed at all time steps, however, they have a more significant tail out to large velocity differences (around $0.5 \mathrm{~km} / \mathrm{s}$ or higher). They find the dispersion in the velocity difference ranges from 0.25 to $0.27 \mathrm{~km} / \mathrm{s}$, or 0.18 to $0.24 \mathrm{~km} / \mathrm{s}$ after smoothing to the Walsh et al. (2004) resolution. It should also be noted that the $\mathrm{N}_{2} \mathrm{H}^{+}$linewidth becomes equal to or larger than the $\mathrm{C}^{18} \mathrm{O}$ linewidth at 1.1 times the free-fall time and beyond, contradicting our observations ( $\S 4)$ and that of many previous studies. Thus while the simulation of competitive accretion analyzed by Ayliffe et al. (2007) has promise in reproducing core-to-envelope dynamics it does not simultaneously reproduce all observations.

Our results show no indication that the coreto-envelope motions significantly change between the starless and protostellar stages of evolution.

On an even smaller scale, Jørgensen et al. (2007) examined the location of YSOs within SCUBA cores and showed that they lie within $15^{\prime \prime}$ of the SCUBA core centre. These small separations imply that the YSOs have motions smaller 
than the thermal velocity relative to the SCUBA core they were born in. The picture that emerges from the combination of these results is that the central source, core, and envelope are quiescent.

\section{CORE-TO-CORE MOTIONS}

We next examine how the $\mathrm{N}_{2} \mathrm{H}^{+}$cores move with respect to each other to gain an understanding of the dynamics on larger scales within the cloud.

We can use our extinction map of the Perseus molecular cloud to define the larger regions in which the dense $\mathrm{N}_{2} \mathrm{H}^{+}$cores inhabit. In Paper I, we identify large-scale structure in the extinction map which we will term 'extinction regions' here to prevent confusion (the regions are referred to as 'extinction super cores' in Paper I). Starless cores within each extinction region should be coupled to the surrounding gas in the region, and hence the motion of the starless cores should reflect the motion of the ambient material. Protostellar cores may have become decoupled from their parental material, and hence are a less reliable tracer of the dynamics occuring in the region.

We analyze the motions within each extinction region and determine whether the regions appear to have sufficient velocity dispersion to provide support against gravity. We adopt the commonly used formulation of

$$
\sigma_{\text {grav }}=\sqrt{G M_{\text {ext }} / 5 R_{\text {ext }}}
$$

as the velocity dispersion required in 1-D to prevent collapse (see for example Bertoldi \& McKee 1992). We estimate the total mass and size of each region from the extinction data (Paper I); these data are provided in Table 5. The above formula technically only applies to a uniform density sphere, but different density structures and object shapes change the required velocity dispersion by factors of order unity (Walsh et al. 2007; Bertoldi \& McKee 1992). Regions which display $\sigma_{o b s}=\sigma_{\text {grav }}$ are often said to be in approximate virial equilibrium, although to have true virial equilibrium, the 'surface terms' of the virial equation must be included (e.g., Dib et al. 2007).

Motions providing support for the extinction region could originate on either the small or large scale. The former would be measurable through internal core motions, while the latter through core-to-core motions. In the case of the densest material probed by $\mathrm{N}_{2} \mathrm{H}^{+}$, the internal core motions are of order the thermal motions of a gas at $\sim 15 \mathrm{~K}$. If the extinction regions were in virial equilibrium, they would require effective temperatures of up to several hundred Kelvin to prevent gravitational collapse ( Paper I); therefore, internal thermal motions cannot provide the bulk of the support required and hence most of the support must originate in large scale motions. We measure the dispersion in centroid velocities of the $\mathrm{N}_{2} \mathrm{H}^{+}$starless cores within each extinction region to determine the amount of support that can be provided by large scale motions traced by the cores. We add the contribution of thermal motions (which has little effect except for the smallest core-to-core velocity dispersions). This total support is plotted in Figure 7 in terms of the ratio of observed velocity dispersion to that which is required for virial equilibrium. The horizontal axis plots the mass within each extinction region.

In the case of the material probed by $\mathrm{C}^{18} \mathrm{O}$, small-scale motions could provide a larger contribution to overall support, since the internal velocity dispersions are often several times larger than the sound speed and are closer in magnitude to the point-to-point velocity differences. In order to account for both of these contributions and also to decrease potential errors from the difficulty in fitting each $\mathrm{C}^{18} \mathrm{O}$ spectrum, we sum all of the spectra within an extinction region and fit the sum with a single Gaussian thus measuring the total velocity dispersion within each region. We correct the thermal component of the velocity dispersion to be that of the mean gas, rather than $\mathrm{C}^{18} \mathrm{O}$. These results are shown in the plot as blue open diamonds.

Table 5 also summarizes the relevant information for each extinction region - the number of non-protostellar cores detected in $\mathrm{N}_{2} \mathrm{H}^{+}$and $\mathrm{C}^{18} \mathrm{O}$ in each region and the velocity dispersions measured with both molecules.

Variations by a factor on the order of one could be expected between the estimated and true velocity dispersion required for gravitational support - the extinction regions do not have a spherical geometry, several extinction regions have a small number of cores to calculate the velocity dispersion from, the cores do not span the entire extent of the extinction regions, and the conversion between extinction and mass has some uncertainty. 
It should also be noted that there is a velocity gradient across the Perseus molecular cloud - we leave a detailed analysis of the core motions relative to the overall cloud gradient for a future paper, and do not attempt to correct for it when calculating the velocity dispersions used here. With these considerations in mind, we find that the extinction regions tend to display velocity dispersions lower than required for 'virial equilibrium', with the starless cores possessing lower dispersions in $\mathrm{N}_{2} \mathrm{H}^{+}$than in $\mathrm{C}^{18} \mathrm{O}$, but the measurements do not rule out 'virial equilibrium'.

\section{ENVIRONMENTAL EFFECT ON DENSE CORES}

Most $(84 \%)$ of the SCUBA cores have associated $\mathrm{N}_{2} \mathrm{H}^{+}$. For these cores, we can examine whether the SCUBA core properties have an effect on their internal dynamics. Since $\mathrm{N}_{2} \mathrm{H}^{+}$requires $\sim 10^{5}$ years to form (Aikawa et al. 2003), the SCUBA cores must be at least this old, and hence are at an advanced stage of evolution, consistent with the results of Jørgensen et al. (2007).

\subsection{Concentration}

The 'peakiness' or central concentration of a core gives an indication of the importance of selfgravity of the core. The concentration is defined in terms of observable measures in equation (A1). Concentration can be thought of as an approximate proxy for evolutionary state with high concentration objects being more evolved (Walawender et al. 2005, 2006; Johnstone \& Bally 2006; Jørgensen et al. 2007) - in the framework of a Bonnor Ebert sphere model, any object with concentration above 0.72 is unstable to gravitational collapse, furthermore, heating from a central source also leads to an increase in concentration. Figure 8 shows the variation in observed core velocity dispersion with SCUBA concentration for both protostellar and starless cores. The mean concentration and velocity dispersion are lower in the starless cores than the protostars, with protostars of higher velocity dispersion also possessing high concentrations. The mean and standard deviation of the concentration is $\mathrm{C}=$ $0.4 \pm 0.1$ and $\mathrm{C}=0.6 \pm 0.2$ for the starless and protostellar cores respectively. The velocity dispersion observed for cores associated with a SCUBA source is $0.20 \pm 0.08 \mathrm{~km} / \mathrm{s}$ for the starless cores and $0.25 \pm 0.09 \mathrm{~km} / \mathrm{s}$ for the protostars. The scatter in the velocity dispersion of the starless cores is mostly due to two starless cores with unusually high internal turbulence levels ( $>1.5$ ); excluding these two cores, the velocity dispersion becomes $0.18 \pm 0.04 \mathrm{~km} / \mathrm{s}$. These two starless cores are in NGC1333 where the region is highly clustered, making it more difficult to determine accurate core properties as well as determine if there is an associated protostar. The velocity dispersion for those cores which are not associated with a SCUBA source (primarily targets selected from the Palomar plates) tend to be even lower - the mean and standard deviation is $0.14 \pm 0.04 \mathrm{~km} / \mathrm{s}$.

\subsection{Total Flux}

We next examine the relationship between internal turbulence level with the total flux of the SCUBA core. Figure 9 shows SCUBA core total flux versus the velocity dispersion for both the starless and protostellar cores. No trend is apparent for the starless cores (diamonds), while there appears to be a weak trend of higher flux corresponding to higher velocity dispersion in the protostars (asterisks). If we split the protostars into those with fluxes greater than $5 \mathrm{Jy}$ and less than $5 \mathrm{Jy}$, we find the mean and standard deviation are $0.31 \pm 0.10 \mathrm{~km} / \mathrm{s}$ and $0.23 \pm 0.07 \mathrm{~km} / \mathrm{s}$ respectively. The symbols intersected by crosses show the mean and standard deviation for the protostars and starless cores, indicating that the protostars tend to have higher flux than the starless cores. This could be the result of slightly higher central temperatures in the protostellar cores.

If we assume a constant temperature of $15 \mathrm{~K}$, a dust opacity of $0.02 \mathrm{~g}^{-1} \mathrm{~cm}^{2}$ at $850 \mu \mathrm{m}$ and a distance to the Perseus molecular cloud of $250 \mathrm{pc}$ (e.g., Cernis 1993), we can convert the observed SCUBA flux into mass as $1 \mathrm{Jy}=0.48 \mathrm{M}_{\odot}$ (see Paper I). Note that due to the non-negligible uncertainties in all of the above quantities, the mass is only accurate to a factor of roughly 6 . Even with the large uncertainty, we can use the mass and radius measured for each SCUBA core to estimate the internal velocity dispersion required to provide support against gravity, which we again take to be $\sigma_{\text {grav }}=\sqrt{G M_{C} / 5 R_{C}}$ (c.f. eq. [4]).

The velocity dispersion of the mean gas can be calculated by correcting for a thermal component 
with a molecular weight of 2.33 rather than 29 for $\mathrm{N}_{2} \mathrm{H}^{+}$. We can then compare the total gas velocity dispersion to that predicted for virial equilibrium (from the SCUBA observations). Figure 10 shows the square of the ratio of the observed velocity dispersion to the virial velocity versus SCUBA flux for the starless cores and protostars. 'Virial equilibrium' would occur for a ratio of 1 (dotted line). All of the $\mathrm{N}_{2} \mathrm{H}^{+}$cores have higher velocity dispersions than predicted by the virial equation, with those at small SCUBA fluxes displaying the largest difference. The cores farthest from 'virial equilibrium' would require the SCUBA mass to be underestimated by a factor of ten or more if they were truly in virial equilibrium, far larger than our uncertainties allow. Many of the cores would be far from virial equilibrium even if their observed velocity dispersion were purely thermal - the dashed and dot-dashed lines show the relationships for a $15 \mathrm{~K}$ thermal core velocity dispersion and assuming core radii of $10^{\prime \prime}$ and $60^{\prime \prime}$ respectively (bounding the observed range of SCUBA core radii).

The above analysis ignores the contribution of external pressure in the virial equilbrium calculation which for sub-Jeans mass objects keeps the internal motions thermal even though gravity alone does not require internal motions of this magnitude. In Paper I, we find that the SCUBA cores in Perseus are well fit by Bonnor-Ebert spheres with external pressures in the range of $5.5 \leq \log _{10} \mathrm{P}_{\text {ext }} / \mathrm{k}_{B} \leq 6.0$. For a 'typical' core of roughly one solar mass and $50^{\prime \prime}$ in extent, when the external pressure is included in calculating virial equilibrium, the square of the virial velocity rises by a factor of approximately 1.3 to 2 of what it was without considering the external pressure, which would make most of the higher flux cores in approximate virial equilibrium. Similarly, a critical $\mathrm{BE}$ sphere, which has $\mathrm{R}_{\text {crit }}=0.41 \frac{G M}{c_{s}^{2}}$ Hartmann 1998), requires $\sqrt{5 \times 0.41}$, or roughly 1.4 , times the velocity dispersion one would naively assume. Note that observing a line width and converting to mass using the virial equation without accounting for surface pressure will overestimate the enclosed mass of an equilibrium core. See also Dib et al. (2007).

Our results thus show that while we observe velocity dispersions that are several times larger than what is predicted by the traditional 'virial equilibrium' measures, when the external pressure on the dense cores from the ambient cloud is accounted for, the agreement is reasonable for the higher flux cores. This is in contrast with some previous observations which tend to find velocity dispersions which are consistent with 'virial equilibrium' without accounting for any external pressure - for example, the low mass dense core survey of Caselli et al. (2002). Some previous studies, however, have shown that external pressure is required for virial equilibrium, e.g., in the Horsehead nebula (Ward-Thompson et al. 2006).

The turbulent simulations of Klessen et al. (2005) predict a relationship between virial and observed mass - their large-scale-driven simulation (which more closely matches our other observations) shows that the starless cores have virial masses which are greater by up to a factor of thirty than the actual mass. Unlike our observations, however, the simulation shows that protostars have virial masses which are several times less than the actual mass. Klessen et al. (2005) points out that the virial mass estimates for protostars are underestimated due to the lack of velocity resolution of the gas in the central sink cell, but that this will have a small effect on the measured velocity dispersion since a small fraction of the core mass is contained within the sink cell.

\subsection{Variation of Line Intensity}

$\mathrm{N}_{2} \mathrm{H}^{+}$and $\mathrm{C}^{18} \mathrm{O}$ observations can also serve as a probe of the chemistry of the dense cores. $\mathrm{N}_{2} \mathrm{H}^{+}$ is only able to form in significant amounts after $\mathrm{C}^{18} \mathrm{O}$ freezeout has occurred, as the two molecules form via competing reactions. While $\mathrm{N}_{2} \mathrm{H}^{+}$is observed to be a good dense gas tracer for densities of $10^{5}-10^{6} \mathrm{~cm}^{-3}$ (Tafalla et al. 2002), it may freeze out onto dust grains at densities above this (Crapsi et al. 2005). $\quad \mathrm{C}^{18} \mathrm{O}$ on the other hand, should be depleted at high densities. At later stages of evolution once a central protostar has formed, the situation is expected to reverse, with the central region heating, causing the liberation of $\mathrm{CO}$ and destruction of $\mathrm{N}_{2} \mathrm{H}^{+}$. Our SCUBA observations allow us to estimate the (column) density of the dense cores independently of our IRAM observations which may be affected by chemistry. Using the same flux to mass conversion factors discussed above, we can convert the SCUBA flux into a column density $-1 \mathrm{Jy}^{\text {beam }^{-1}}$ corresponds to $0.24 \mathrm{~g} \mathrm{~cm}^{-2}$ or $\sim 10^{22} \mathrm{~cm}^{-2}$. Making the further 
assumption that the cores are roughly spherical and have a diameter of $\sim 50^{\prime \prime}$ in the plane of the sky, this corresponds to a density of $\sim 10^{6} \mathrm{~cm}^{-3}$.

Figure 11 shows the total SCUBA flux within the IRAM beam for each observation versus the integrated intensity measured in both $\mathrm{N}_{2} \mathrm{H}^{+}$and $\mathrm{C}^{18} \mathrm{O}$. The $\mathrm{N}_{2} \mathrm{H}^{+}$integrated intensity shows some correlation with the total SCUBA flux for both the starless and protostellar cores. The $\mathrm{C}^{18} \mathrm{O}$ integrated intensity possibly shows a very weak correlation with SCUBA flux below $~ 1$ Jy and no correlation above this. This is consistent with denser cores being dominated by central freeze out (i.e., even with increasing column density, the $\mathrm{C}^{18} \mathrm{O}$ integrated intensity remains constant).

We also examine the ratio between the $\mathrm{C}^{18} \mathrm{O}$ and $\mathrm{N}_{2} \mathrm{H}^{+}$integrated intensities - a low ratio, for example, would be indicative of freezeout. Figure 12 shows the total SCUBA flux observed in each IRAM beam versus the ratio of integrated intensity measured in $\mathrm{C}^{18} \mathrm{O}$ and $\mathrm{N}_{2} \mathrm{H}^{+}$. This figure shows that high $\mathrm{C}^{18} \mathrm{O}$ to $\mathrm{N}_{2} \mathrm{H}^{+}$ratios mostly occur for starless cores, and only at smaller SCUBA fluxes, i.e., where the density is lowest and hence there is little to no freeze out. All high flux SCUBA cores have low $\mathrm{C}^{18} \mathrm{O}$ to $\mathrm{N}_{2} \mathrm{H}^{+}$ratios. Due to the large relative error in the $\mathrm{N}_{2} \mathrm{H}^{+}$integrated intensity for these cores, the error in the ratio is often greater than $100 \%$. Note that following the results of $\S 5$, in the few cases where two $\mathrm{C}^{18} \mathrm{O}$ components were associated with an $\mathrm{N}_{2} \mathrm{H}^{+}$dense core, the integrated intensity of the component with the closest velocity is plotted.

We can also calculate the $\mathrm{N}_{2} \mathrm{H}^{+}$column density from the integrated intensity, assuming an excitation temperature of $15 \mathrm{~K}$ and correcting for the optical depth. We use eq. (10) of Shirley et al. (2005), and find a column density of

$N_{N_{2} H^{+}}=1.47 \times 10^{7} \frac{\langle\tau\rangle}{1-e^{-\langle\tau\rangle}} \int T_{A}^{*} d V \times \frac{F_{\text {eff }}}{B_{\text {eff }}} \mathrm{cm}^{-2}$

where $\langle\tau\rangle$ is the mean optical depth of the hyperfine transitions (CLASS's hfs fitting routine fits $\left.\tau_{\text {tot }}=7\langle\tau\rangle\right), \int T_{A}^{*} d V$ is the integrated intensity in $\mathrm{K} \mathrm{m} \mathrm{s}^{-1}$, and $F_{\text {eff }}=0.95$ and $B_{\text {eff }}=0.77$ are beam efficiency parameters available from the IRAM 30m website. Our minimum observable column density is $\sim 10^{11} \mathrm{~cm}^{-2}$.

Figure 13 shows the $\mathrm{N}_{2} \mathrm{H}^{+}$column density de- rived versus the total column density derived from the total SCUBA flux measured in the IRAM beam. The relative error in the total column densities is $\sim 30 \%$ (the calibration error of SCUBA data), with an absolute error close to a factor of six due to uncertainties in constants used to convert flux to mass. The errors in the $\mathrm{N}_{2} \mathrm{H}^{+}$column density vary substantially, mostly due to errors in the optical depth determined; the median error is $30 \%$. The noise in the SCUBA map is $\sim 10$ mJy beam $^{-1}$, which translates to a minimum observable total column density of $\sim 10^{21} \mathrm{~cm}^{-2}$.

Overplotted on Figure 13 are lines of constant $\mathrm{N}_{2} \mathrm{H}^{+}$abundance. The cores lie between approximately $\mathrm{N}_{\mathrm{N}_{2} \mathrm{H}^{+}} / \mathrm{N}_{\mathrm{H}_{2}}=10^{-9}$ and $10^{-10}$, consistent with what has been more accurately derived from detailed mapping and analysis of single cores (e.g., Shirley et al. 2005; Tafalla et al. 2004).

\section{CONCLUSIONS}

We present results from a survey of $\mathrm{N}_{2} \mathrm{H}^{+}(1-$ $0)$ and $\mathrm{C}^{18} \mathrm{O}(2-1)$ of 157 dense core candidates in the Perseus molecular cloud. We detect $\mathrm{N}_{2} \mathrm{H}^{+}$ in $62 \%$ of our targets, and $84 \%$ of our SCUBAselected targets. $\mathrm{N}_{2} \mathrm{H}^{+}$is a 'late-time' molecular ion which does not become abundant until $\sim 10^{5}$ years (Aikawa et al. 2003). Since we detect $\mathrm{N}_{2} \mathrm{H}^{+}$in the vast majority of SCUBA cores, this argues that objects which attain sufficient density to be detectable with SCUBA are not short-lived, transient objects. This is in agreement with the findings of Jørgensen et al. (2007) who argue that starless SCUBA cores have roughly equal lifetimes to that of deeply embedded protostars, which is on the order of $10^{5}$ years (Ward-Thompson et al. 2007).

We differentiated between starless cores and protostars on the basis of Spitzer data (Jørgensen et al. 2007). In $\mathrm{N}_{2} \mathrm{H}^{+}$, the starless cores have linewidths which are dominated by thermal broadening, while the protostars have slightly larger linewidths, consistent with many previous surveys including Benson \& Myers (1989) and Jijina et al. (1999). We find fewer $\mathrm{N}_{2} \mathrm{H}^{+}$cores dominated by nonthermal motions than predicted by the turbulent simulations of Klessen et al. (2005). For the starless cores, the mean ratio of non-thermal to thermal motions $\left(f_{\text {turb }} \sim 0.6\right)$ implies the ratio of non-thermal to thermal pressure, $f_{\text {turb }}^{2}$, is less 
than $40 \%$. Naively, this runs counter to turbulent models where cores as well as transient density peaks form at the convergence of supersonic flows. Simulations must therefore demonstrate that turbulent pressure does not dominate in the high density regime probed by $\mathrm{N}_{2} \mathrm{H}^{+}$.

The $\mathrm{C}^{18} \mathrm{O}$ observations, sensitive to lower density material, reveal much more non-thermal motions as previous surveys have also shown. There is less difference in non-thermal motions between those targets associated with protostars and those which are not associated with protostars which may imply that protostars have little effect on the dynamics of bulk of their envelopes at the earlier stages of evolution.

We find the relative motions of the dense $\mathrm{N}_{2} \mathrm{H}^{+}$ cores and their envelopes (measured in $\mathrm{C}^{18} \mathrm{O}$ ) tends to be less than thermal in the majority of cases, confirming and strengthening the results of Walsh et al. (2004, 2007) for clustered star forming environments.

Within large scale structure, defined through 2MASS extinction observations, the core-to-core motions of starless cores are not sufficient to provide support against gravity, however, the sparse sampling of each extinction region leads to large errors associated with the core-to-core velocity dispersions we measure. The total velocity dispersion tends to be smaller when measured in $\mathrm{N}_{2} \mathrm{H}^{+}$than $\mathrm{C}^{18} \mathrm{O}$ due to the smaller linewidths seen in $\mathrm{N}_{2} \mathrm{H}^{+}$.

The $\mathrm{N}_{2} \mathrm{H}^{+}$cores which have an associated submillimetre source detected with SCUBA have internal motions several times larger than is required to provide support against gravity. Inclusion of external pressure shows the cores to be in approximate virial equilibrium. The protostars tended to have higher SCUBA concentrations, and total fluxes. High ratios of $\mathrm{C}^{18} \mathrm{O}$ to $\mathrm{N}_{2} \mathrm{H}^{+}$integrated intensity, possibly indicating chemically young gas, were found for some cores which had a low flux measured with SCUBA. At higher SCUBA fluxes, only low ratios of $\mathrm{C}^{18} \mathrm{O}$ to $\mathrm{N}_{2} \mathrm{H}^{+}$integrated intensity were observed. Column densities derived for $\mathrm{N}_{2} \mathrm{H}^{+}$were consistent with abundance ratios between $10^{-9}$ and $10^{-10}$, in agreement with what has been previously derived for cores with more accurate observations.

Our survey utilized single pointings on most of our dense core candidates, rather than using the traditional route of mapping. We show that the lack of a full map around each source has a minimal effect on our dynamical analysis. High resolution maps are, however, quite helpful in disentagling the motions in complex regions such as NGC1333 where multiple objects along the line of sight could otherwise lead to confusion in interpretation of results. Our method is an efficient and effective way to survey the dynamics of dense cores over the full extent of a molecular cloud. In the future, this method can be applied to other molecular clouds in order to determine whether the dynamical properties of the cores observed in the Perseus molecular cloud are universal or are dependent on the cloud environment.

We thank the IRAM $30 \mathrm{~m}$ staff for their hospitality and support during our observations.

The Second Palomar Observatory Sky Survey (POSS-II) was made by the California Institute of Technology with funds from the National Science Foundation, the National Geographic Society, the Sloan Foundation, the Samuel Oschin Foundation, and the Eastman Kodak Corporation.

$\mathrm{HK}^{3}$ is supported by a Natural Sciences and Engineering Research Council of Canada CGS Award and a National Research Council of Canada GSSSP Award. DJ is supported by a Natural Sciences and Engineering Research Council of Canada grant.

HK would like to acknowledge valuable discussions with people at the CfA - other members of the COMPLETE collaboration, in particular Alyssa Goodman, Jens Kauffman, and Erik Rosolowsky, as well as Phil Myers and Charles Lada. Additionally, HK thanks Matthew Bate for a sending a preprint of his work.

\footnotetext{
${ }^{3}$ Guest User, Canadian Astronomy Data Centre, which is operated by the Herzberg Institute of Astrophysics, National Research Council of Canada
} 


\section{A. SCUBA OBSERVATIONS}

In this paper, we utilize newly created $850 \mu \mathrm{m}$ SCUBA maps with a finer sampling size of $3^{\prime \prime}$ to better determine SCUBA source properties. We used our full $6^{\prime \prime}$ sampled map of Paper I to define regions in which to create $3^{\prime \prime}$ sampled maps. As in Paper I, we combined all of the scan- and jiggle- map data in the JCMT archive 4 and used the same reduction procedure as in Paper I, making modifications only for the smaller sampling size. We first use the normal SCUBA software (Holland et al. 1999) to flat-field and atmospheric-extinction correct the raw data. We then used the matrix inversion technique of Johnstone et al. (2000) to produce the images. The matrix inversion techniqe has been shown to produce better images than the standard procedure used at the JCMT, particularly when combining data of different qualities (Johnstone et al. 2000), as is the case for the archival data used here. In order to correct for atmospheric fluctuations and other effects, SCUBA data is in the form of a series of difference measures (chops). Any image-reconstruction technique is thus insensitive to real structures which have sizes several times larger than the chop throw (Johnstone et al. 2000). We remove this structure by subtracting a large-scale smoothed version of the map from the original (we smooth with a Gaussian of $\sigma=90^{\prime \prime}$ ). In order to prevent the introduction of negative 'bowls' around bright sources (and similarly diffuse positive regions around deep compact 'holes'), we first create a map where all values outside of $\pm 0.1 \mathrm{Jy}^{\text {beam }}{ }^{-1}$ per pixel were replaced with those values before smoothing to create the large-scale smoothed map $\left(0.1 \mathrm{Jy} \mathrm{beam}^{-1}\right.$ corresponds to roughly five times the rms value). We also smoothed pixel-to-pixel noise using a Gaussian with $\sigma=3^{\prime \prime}$. Figure 14 shows our map of B1 as an example of the 3" SCUBA maps.

To identify SCUBA cores in the maps, we utilized the object-identifying algorithm of Williams, de Geus, \& Blitz (1994), 'Clumpfind 2D'. In this algorithm, objects are identified as peaks at 2 ' $\sigma_{C}$ ' intervals and extended until they either encounter another object or the lowest allowed ' $\sigma_{C}$ ' level. Normally, $\sigma_{C}$ is the noise level in the map, however, in order to have a consistent core-identification threshold in all of the $3^{\prime \prime}$ mapped regions, we used $\sigma_{C}=0.03 \mathrm{Jy}_{\text {beam }}{ }^{-1}$ per pixel, which corresponds to approximately the same level in which we identified SCUBA cores in our previous work Paper I. Accurate noise levels for each $3^{\prime \prime}$ sampled map were difficult to determine in some cases due to the small map sizes.

In addition, several regions had no cores identified but displayed hints of structures with peaks below the object-identification theshold of $5 \sigma_{C}$. In order to put some constraints / upper limits on the submillimetre properties of potential cores in these regions, we ran clumpfind to a lower identification threshold $\left(\sigma_{C}=\right.$ $0.01 \mathrm{Jy}$ beam $^{-1}$ per pixel) in these regions only. It should be noted that properties derived for these objects are not as reliable as the originally identified cores. We term these objects as having 'less secure fits' throughout the paper and do not include these in our quantitative analysis. Table 6 below denotes the properties of the SCUBA cores identified.

Finally, as discussed in Appendix C, SCUBA observations in the region of NGC1333 appear to have a shift of $6^{\prime \prime}$ in RA relative to data at other wavelengths, apparently due to an unusually large pointing error at the JCMT. Here, we apply a global shift of $6^{\prime \prime}$ to the NGC1333 observations to compensate for this.

\section{A.1. Comparison to Previous Results}

While Clumpfind does a reasonable job of identifying structures in two dimensional maps where the filling factor is low, the cores identified in the $3^{\prime \prime}$ sampled maps used here are different from the set we identified previously in the $6^{\prime \prime}$ sampled map of Paper I, even though the same data are used and the reduction procedure is almost identical, albeit with a different smoothing scale. This is because Clumpfind relies on contours for determining object edges, so that slight variations in flux per pixel can change the size of core boundaries, which then affects the measured size and total flux, although the peak flux would be unchanged. In clustered regions, the slight variation in flux per pixel can also change where or when cores are either separated from or

\footnotetext{
${ }^{4}$ Based on observations obtained with the James Clerk Maxwell Telescope, which is operated by the Joint Astronomy Centre in Hilo, Hawaii on behalf of the parent organizations PPARC in the United Kingdom, the National Research Council of Canada and The Netherlands Organization for Scientific Research.
} 
merged with close neighbours. Clumpfind identifies distinct clumps where two regions are isolated at a given search contour (every $2 \sigma_{C}$ ). For example, a peak at $6.9 \sigma_{C}$ surrounded by pixels at $6.1 \sigma_{C}$ and near a peak at $11 \sigma_{C}$ would be identified as a single object (at the 7 and $5 \sigma_{C}$ contours, all of the flux is connected). If the $6.9 \sigma_{C}$ peak were instead a peak at $7.1 \sigma_{C}$, it would be identified as a separate object from the $11 \sigma_{C}$ peak (the flux is in two unconnected regions at the $7 \sigma_{C}$ contour). Thus individual core properties are difficult to compare between maps reduced under even slightly different schemes or resolutions. We do not show a comparison of the cores identified here with those identified in the $6^{\prime \prime}$ sampled map of Paper I, but note that given variations in core boundaries and potential merging of cores, the list of cores we identify in the $3^{\prime \prime}$ sampled map spans the cores identified in the 6 " sampled map and also includes an additional four cores $(\# 4,28,72,73)$.

\section{A.2. Core Properties}

The properties of the cores identified in the $3^{\prime \prime}$ sampled map are shown in Table 6 . The core radius, peak flux, and total flux are found with Clumpfind. We also calculate the concentration of each core - previous work has shown this to be an indicator of the evolutionary state of the core, with higher concentrations corresponding to later stages of evolution (Walawender et al. 2005, 2006; Johnstone \& Bally 2006). Following Johnstone et al. (2001), the concentration can be calculated from observational quantities as:

$$
C=1-\frac{1.13 B^{2} S_{850}}{\left(\pi R_{o b s}^{2}\right) f_{0}}
$$

where B is the beamsize, $S_{850}$ the total flux, $R_{o b s}$ the radius, and $f_{0}$ the peak flux. As in Paper I, we can also model the cores as Bonnor Ebert (BE) spheres - spherically symmetric isothermal objects where thermal pressure balances gravity and an external pressure. The best fit BE sphere model properties are also included in Table 6

\section{B. TWO-COMPONENT $\mathrm{N}_{2} \mathrm{H}^{+}$CORES}

In this section we discuss the $\mathrm{N}_{2} \mathrm{H}^{+}$spectra which we found required two velocity components for a good model fit. We treated these two velocity components as originating from independent objects along the line of sight, rather that a single core whose spectrum shows self-absorption. The optimal method for distinguishing between self-absorption and two distinct cores would be to observe the region with an optically thinner tracer. Since this is not available to us, we instead examine the data we do have for these cores (e.g. spectra at cross positions, SCUBA observations, and other $\mathrm{N}_{2} \mathrm{H}^{+}$survey data) and discuss how well they support our interpretation.

Most of the cores for which we fit to two components lie in regions where complex motions are seen on smaller scales, such as NGC1333, where it is not unsurprising to find two cores along the line of sight. In instances where we found a common velocity component between two close pointings, we excluded this common velocity component from the second source in our subsequent analysis in order to avoid counting the same core twice.

In NGC1333, we found six cores with two velocity components - \#99, 103, 106, 107, 111, and 118. All of these except \#99 fall within the survey region of Walsh et al. (2007) which in every instance identifies a distinct object at each velocity which we fit to our data. Source \#99, which falls outside of the Walsh et al. (2007) survey region, was observed at cross positions (see Figure 15). The two components show varying relative intensities across the five positions mapped, supporting the hypothesis of two distinct cores.

In IC348, we fit two cores with two velocity components, \#22 and 27. While there is no high resolution $\mathrm{N}_{2} \mathrm{H}^{+}$map of IC348, Tafalla et al. (2006) provide a 50" resolution map. Our core \#22 corresponds to Tafalla et al. (2006)'s source C in IC348-SW1 which they show appears to be related to outflow structure seen in CO. Tafalla et al. (2006) identify two velocity components in $\mathrm{N}_{2} \mathrm{H}^{+}$which correspond to the velocities we found. Our core \#27 corresponds to source A in IC348-SW1 which Tafalla et al. (2006) associate with 
a single broad $(\sim 1.6 \mathrm{~km} / \mathrm{s})$ velocity component. Our observations (Figure 16) clearly show two distinct velocity components, perhaps resolvable due to the smaller beamsize of our observations.

In L1544, one core (\#136) was fit with two velocity components. Cross positions were also observed, and where the $\mathrm{S} / \mathrm{N}$ is high enough, the two components are clearly quite separate (see Figure 17).

North of B1, one core (\#76) was fit with two velocity components at one cross position only. This observation has low $\mathrm{S} / \mathrm{N}$ and is designated as being of poor quality, and therefore was not used in any of the analysis.

The core with the poorest two velocity component fit is \#148 in L1448. In this instance, the model does not well fit the data in several places (see Figure 18), making the interpretation of two distinct cores uncertain. The SCUBA map suggests the core is isolated - the nearest SCUBA core is roughly an arcminute away. Without additional observations, no firm interpretation can be made.

\section{EFFECT OF UTILIZING SINGLE POINTINGS}

For the analysis in the paper, we utilized only the data from the central pointing on each target in order to have a consistent dataset. Since we have four-point cross data around some of our targets, we can ask two additional questions - how accurate were the target centre positions that we used and does our utilization of only the central point bias or change any of our results. Here we address these questions in turn.

\section{C.1. Accuracy of Dense Core Pointings}

We first note one occurence that led to small offsets between some positions in the SCUBA catalog we used for determining our target positions and the catalog of Appendix A. After the publication of Paper I, we discovered an offset of $\sim 6^{\prime \prime}$ in RA in the region of NGC1333 in the SCUBA data compared with data at other wavelengths. This is intrinsic to the data (not caused by an analysis error) and is apparently caused by an unusually large pointing error with SCUBA. This offset is further discussed in Di Francesco et al. (2007). This offset was not known at the time of our IRAM observations, hence was not accounted for when the SCUBA target list was created. This $6^{\prime \prime}$ offset is much smaller than the IRAM beamsize $\left(25^{\prime \prime}\right)$ and hence should not have a large effect on the results, but is noted here for completeness.

We expect the $\mathrm{N}_{2} \mathrm{H}^{+}$cores to have extents of order one or two IRAM beams $\left(25^{\prime \prime}\right)$ in $\mathrm{N}_{2} \mathrm{H}^{+}$, the typical size of the SCUBA cores. SCUBA is sensitive to a similar range of densities, $\sim 10^{4}-10^{6} \mathrm{~cm}^{-3}$ using the approximation in $\S 7$. If we chose our target positions well, we expect the central position to show more signal than offset positions, although the cores should extend past the central pointing.

Figure 19 shows the fractional difference between the integrated intensity at the central position and largest value at an offset position (pluses) as well as the difference with the average value of all offset positions (squares). The vertical lines indicate the error in the difference measure for the maximum difference. Nearly half of the cores plotted have highest integrated intensities at the central pointing, while another third have integrated intensities which are slightly larger at a single cross position. Only about one fifth of the cores show significantly larger integrated intensities at a single offset position. An additional thirteen positions where offset observations were made are not plotted due to a lack of a good central detection. Of these, ten also had no detections at any offset positions.

It should be noted that we utilized two different set of criteria to determine which targets to map crosses around. Approximately half (thirty of sixty-two) of the cross targets had strong central detections - we observed at offsets to search for extended structure. The remaining half of the targets were chosen based on a very weak or non-existent central detection in order to search for a stronger signal nearby (2MASS or Palomar plate - selected targets). The first of these cross-map criteria biases towards targets where the centre was well chosen, while the second biases towards poorly chosen centres. The former set of cross maps were mostly based on SCUBA cores where we had a high detection probability and it was easiest to determine precise core centres. Nearly all of the SCUBA-selected cores with crosses are consistent with 
having their strongest integrated intensity at the central position. The latter-chosen cross targets account for the largest integrated intensity differences at cross positions as well as the targets with insufficient signal to noise to obtain a fit and thus be included in the plot. Not surprisingly, our position selection was less accurate for these latter targets - many of the detections are not consistent with the central position having the highest integrated intensity. Since these latter crossed observations are biased to the worst-determined centre positions, we expect that our overall determination of centres was more successful.

We can therefore conclude that the pointings were quite accurate for the SCUBA-selected targets and reasonably accurate for the targets selected using the other methods, especially given the difficulties in determining precise centres in the latter case. As we shall see in the following section, the question of accuracy of the centre positions does not play an important role in the kinematical results presented earlier - these change very little between centre and cross positions.

\section{C.2. Impact on Results}

Now we examine whether our utilization of a single pointing of each dense $\mathrm{N}_{2} \mathrm{H}^{+}$core introduces significant bias or error in the core properties measured.

\section{C.2.1. Line Widths}

We calculated the difference in $\mathrm{N}_{2} \mathrm{H}^{+}$linewidth between each centre position and the surrounding cross and found this difference to be very small. Most $(93 \%)$ of the $\mathrm{N}_{2} \mathrm{H}^{+}$cores have mean differences less than one or two spectral channels $(0.05 \mathrm{~km} / \mathrm{s}$ in FWHM units), i.e., consistent with measuring the same value. The mean absolute difference of the entire sample was $0.018 \mathrm{~km} / \mathrm{s}$ and none had differences close to the sound speed (FWHM of $0.15 \mathrm{~km} / \mathrm{s}$ for $\mathrm{N}_{2} \mathrm{H}^{+}$) and the mean difference was approximately zero. Therefore, we expect that our analysis utilizing only central pointings does not introduce significant error or bias to our measurement of core linewidth.

\section{C.2.2. Centroid Velocities}

The difference in centroid velocity for the $\mathrm{N}_{2} \mathrm{H}^{+}$cores at centre and cross positions is also small, as shown in Figure 20. In Figure 20, the vertical lines indicate the range in differences over the four cross positions. Note that the six sources with two velocity components fit at either centre or cross position have not been included in this plot. All but one of the $\mathrm{N}_{2} \mathrm{H}^{+}$cores have a difference between the central and average cross velocity of less than the thermal velocity dispersion; the mean difference is approximately zero and the standard deviation is $0.04 \mathrm{~km} \mathrm{~s}^{-1}$. The $\mathrm{N}_{2} \mathrm{H}^{+}$cores which have the largest centroid velocity differences have less secure fits where there is greater uncertainty in the centroid velocity determined. On the other hand, in the majority of cases the difference in velocities between cross and central positions are larger than the the fitting errors of those velocities, indicating that there is real variation in the centroid velocity between locations. This variation is much smaller than the core-to-core variations analyzed in the $\S 6$, however, where extinction regions require support against gravity with core-to-core motions many times larger than the sound speed. We thus find that little error or bias is introduced into our results by using data from a central pointing only. 


\section{REFERENCES}

Aikawa, Y., Ohashi, N. \& Herbst, E. 2003, ApJ, 593, 906

Alves, J.\& Lombardi, M. 2007, in preparation

Ayliffe, B. A., Langdon, J. C., Cohl, H. S., \& Bate, M.R. 2007, MNRAS, 374, 1198

Bally, J., Walawender, J., Johnstone, D., Kirk, H., Goodman, A., Porras, A. \& Ridge, N. Handbook of Star Forming Regions Vol. I. The Northern Sky (ed. Reipurth), in prep.

Barranco, J. A. \& Goodman, A. A. 1998, ApJ, 504, 207

Bate, M. R., Lubow, S. H., Ogilvie, G. I. \& Miller, K. A. 2003, MNRAS, 341, 213

Benson, P. J. \& Myers, P. C. 1989, ApJS, 71, 89

Bertoldi, F. \& McKee, C. F. 1992, ApJ, 395, 140

Caselli, P., Myers, P. C., Thaddeus, P. 1995, ApJ, 455L, 77

Caselli, P. \& Myers, P. C. 1995, ApJ, 446, 665

Caselli, P., Benson, P. J., Myers, P. C., \&Tafalla, M. 2002, ApJ, 572, 238

Cernis, K. 1993, BaltA, 2, 214

Cohen, M. \&Kuhi, L. V. 1979, ApJS, 41, 743

Crapsi, A., Caselli, P., Walmsley, C. M., Myers, P. C., Tafalla, M., Lee, C. W., \& Bourke, T. L. 2005, ApJ, 619, 379

de Gregorio-Monsalvo, I., Gómez, J. F., Suárez, O., Kuiper, T. B. H., Rodríguez, L. F., Jiménez-Bailón, E. 2006, ApJ, 642, 319

Di Francesco, J., Johnstone, D., Kirk, H., Ledwosinksa, E. \& MacKenzie, T., ApJS submitted

Dib, S., Vazquez-Semadeni, E., Kim, J., Burkert, A. \& Shadmehri, M. 2007, ApJ, 661, 262

Evans, N. J. et al. 2003, PASP, 115, 965

Goodman, A. A., Barranco, J. A., Wilner, D. J. \& Heyer, M. H. 1998, ApJ, 504, 223
Hartmann, L. 1998, Accretion Processes in Star Formation (Cambridge: Cambridge University Press)

Hatchell, J., Richer, J. S., Fuller, G. A., Qualtrough, C. J., Ladd, E. F., \& Chandler, C. J. 2005, A\&A, 440, 151

Hatchell, J., Fuller, G. A., Richer, J. S., Harries, T. J., \& Ladd, E. F. 2007, A\&A, accepted

Holland, W. S., et al. 1999, MNRAS, 303, 659

Jijina, J., Myers, P. C., Adams, F. C. 1999, ApJS, 125,161

Johnstone, D., Wilson, C.D., MoriartySchieven, G., Giannakopoulou-Creighton, J., \& Gregersen, E. 2000, ApJ, 131, 505

Johnstone, D., Fich, M., Mitchell, G.F. \& Moriarty-Schieven, G. 2001, ApJ, 559, 307

Johnstone, D. \& Bally, J. 2006, ApJ, 653, 383

Jørgensen, J. K., Harvey, P. M., Evans, N. J II, Huard, T. L., Allen, L. E., Porras, A., et al 2006, ApJ, 645, 1246

Jørgensen, J. K., Johstone, D., Kirk, H., \& Myers, P. C. 2007, ApJ, 656, 293

Kirk, H., Johnstone, D., \& Di Francesco, J. 2006, ApJ, 646, 1009

Klessen, R. S., Ballesteros-Paredes, J., VázquezSemadeni, E. \& Durán-Rojas, C. 2005, ApJ, 620,786

Larson, R. B. 1981, MNRAS, 194, 809

Lee, C. W., Myers, P. C., \& Tafalla, M. 2001, ApJS, 136, 703

Lombardi, M. \& Alves, J. 2001, A\&A, 377, 1023

Morata, O., Girart, J. M., Estalella, R. 2005, A\&A, 435, 113

Müller, H. S. P., Thorwirth, S., Roth, D. A. \& Winnewisser, G. 2001, A\&A, 370, L49

Rebull, L. et al., 2007, ApJ in press

Ridge, N. A., Di Francesco, J., Kirk, H., Li, D., Goodman, A. A., et al. 2006, AJ, 131, 2921 
Shirley, Y. L., Nordhaus, M. K., Grcevich, J. M., Evans, N. J. II, Rawlings, J. M. C. \& Tatematsu, K. 2005, ApJ, 632, 982

Tafalla, M., Myers, P. C., Caselli, P., Walmsley, C. M., Comito, C. 2002, ApJ, 569, 815

Tafalla, M., Myers, P. C., Caselli, P., \& Walmsley, C. M. 2004, A\&A, 416, 191

Tafalla, M., Kumar, M. S. N., \& Bachiller, R. 2006, A\&A, 456, 179

Ungerechts, H., Bergin, E. A., Goldsmith, P. F., Irvine, W. M., Schloerb, F. P. \& Snell, R. L. 1997, ApJ, 482, 245

Walawender, J., Bally, J., Kirk, H., Johnstone, D. 2005, AJ, 130, 1795

Walawender, J., Bally, J., Kirk, H., Johnstone, D., Reipurth, B., \& Aspin, C. 2006, AJ, 132, 467

Walsh, A. J., Myers, P. C. \& Burton, M. G. 2004, ApJ, 614, 194

Walsh, A. J., Myers, P. C., Di Francesco, J., Mohanty, S., Bourke, T. L., Gutermuth, R., \& Wilner, D. 2007, ApJ, 655, 958

Ward-Thompson, D., Nutter, D, Bontemps, S, Whitworth, A, \& Attwood, R. 2006, MNRAS, 369,1201

Ward-Thompson, D., André, P., Crutcher, R., Johnstone, D., Onishi, T. \& Wilson, C. 2007, in Protostars and Planets V, ed. B. Reipurth, D. Jewitt, \& K. Keil (Tucson: Univ. Arizona Press), 33

Williams, J.P., de Geus, E.J., \& Blitz, L. 1994, ApJ, 428, 693

This 2-column preprint was prepared with the AAS LATEX macros v5.2. 
TABLE 1

TARget Properties

\begin{tabular}{|c|c|c|c|c|c|c|c|c|c|}
\hline Number & $\begin{array}{c}\mathrm{RA} \\
(\mathrm{J} 2000.0)\end{array}$ & $\begin{array}{c}\text { Dec } \\
(\mathrm{J} 2000.0)\end{array}$ & $\begin{array}{c}\text { Sel. }^{\text {a }} \\
\text { Method }\end{array}$ & Cross? & $\begin{array}{c}\text { SCUBA }^{c} \\
\text { core }\end{array}$ & $\begin{array}{l}\text { SCUBA d } \\
\text { flux (Jy) }\end{array}$ & $\begin{array}{l}\text { Spitzer }^{\mathrm{e}} \\
\text { protostar }\end{array}$ & $\begin{array}{l}\text { Ext. }{ }^{\mathrm{f}} \\
\text { Region }\end{array}$ & $\begin{array}{c}\text { Mean Ext. }{ }^{\mathrm{g}} \\
\left(\mathrm{A}_{V}\right)\end{array}$ \\
\hline 1 & $3: 48: 31.1$ & $32: 38: 21.0$ & $\mathrm{P}$ & no & .. & 0 & .. & $\ldots$ & 1.9 \\
\hline 2 & $3: 48: 29.1$ & $32: 54: 33.0$ & $\mathrm{P}$ & no & .. & 0 & .. & 1 & 4.2 \\
\hline 3 & $3: 47: 42.3$ & $32: 52: 28.1$ & $\mathrm{E}$ & yes & .. & 0.88 & .. & 1 & 8.1 \\
\hline 4 & $3: 47: 41.8$ & $32: 51: 40.3$ & $\mathrm{~S}$ & no & 1 & 1.74 & 49 & 1 & 8.0 \\
\hline 5 & $3: 47: 40.4$ & $32: 54: 39.0$ & $\mathrm{P}$ & yes & .. & 0.28 & .. & 1 & 8.2 \\
\hline 6 & $3: 47: 39.0$ & $32: 52: 11.2$ & $\mathrm{~S}$ & no & 3 & 1.46 & .. & 1 & 8.1 \\
\hline 7 & $3: 47: 37.0$ & $32: 52: 03.0$ & $\mathrm{P}$ & yes & .. & 0.28 & .. & 1 & 7.8 \\
\hline 8 & $3: 47: 36.1$ & $32: 50: 11.0$ & $\mathrm{P}$ & yes & ... & 0 & ... & 1 & 7.1 \\
\hline 9 & $3: 47: 28.1$ & $32: 50: 13.0$ & $\mathrm{P}$ & no & $\begin{array}{l}. . \\
. .\end{array}$ & 0.32 & $\begin{array}{l}. . \\
. .\end{array}$ & 1 & 6.0 \\
\hline 10 & $3: 47: 27.2$ & $32: 57: 56.0$ & $\mathrm{P}$ & no &.. & 1.18 & .. & 1 & 5.1 \\
\hline 11 & $3: 47: 27.1$ & $32: 38: 08.0$ & $\mathrm{P}$ & no &.. & 0 &.. & 1 & 3.3 \\
\hline 12 & $3: 47: 17.7$ & $32: 45: 26.0$ & $\mathrm{P}$ & yes &.. & 0 & .. & 1 & 5.3 \\
\hline 13 & $3: 47: 05.6$ & $32: 43: 12.0$ & $\mathrm{P}$ & yes &.. & 0 & .. & 1 & 6.0 \\
\hline 14 & $3: 44: 49.0$ & $31: 41: 20.2$ & $\mathrm{E}$ & no & .. & 0.08 & .. & 2 & 7.2 \\
\hline 15 & $3: 44: 48.9$ & $32: 00: 31.8$ & $\mathrm{~S}$ & no & $\ddot{4}$ & 1.32 &.. & 2 & 6.5 \\
\hline 16 & $3: 44: 44.2$ & $32: 01: 26.9$ & $\mathrm{~S}$ & yes & 5 & 2.50 & 48 & 2 & 6.6 \\
\hline 17 & $3: 44: 37.3$ & $32: 14: 04.3$ & $\mathrm{E}$ & no & .. & 0 &.. & 2 & 6.0 \\
\hline 18 & $3: 44: 36.9$ & $31: 58: 40.7$ & $\bar{S}$ & yes & 6 & 1.42 & ... & 2 & 7.2 \\
\hline 19 & 3:44:06.6 & $32: 02: 05.6$ & $\mathrm{~S}$ & no & 8 & 1.76 & .. & 2 & 9.5 \\
\hline 20 & $3: 44: 03.3$ & $32: 02: 24.3$ & $\mathrm{~S}$ & no & 9 & 2.62 & 47 & 2 & 9.5 \\
\hline 21 & $3: 44: 01.8$ & $32: 01: 54.6$ & $\mathrm{~S}$ & no & 10 & 2.44 & 47 & 2 & 9.9 \\
\hline 22 & $3: 43: 58.9$ & $32: 00: 37.3$ & $\mathrm{E}$ & yes & .. & 1.58 & 46 & 2 & 10.4 \\
\hline 23 & $3: 43: 58.2$ & $32: 04: 01.4$ & $\overline{\mathrm{S}}$ & no & 11 & 2.08 & .. & 2 & 8.0 \\
\hline 24 & $3: 43: 57.2$ & 32:03:01.6 & $\mathrm{S}$ & no & 12 & 4.90 & $\ddot{43}$ & 2 & 9.3 \\
\hline 25 & $3: 43: 57.0$ & $32: 00: 49.7$ & $\mathrm{~S}$ & no & 13 & 6.40 & 44 & 2 & 10.5 \\
\hline 26 & $3: 43: 51.1$ & $32: 03: 20.9$ & $\mathrm{~S}$ & no & 15 & 3.08 & 41 & 2 & 9.1 \\
\hline 27 & $3: 43: 44.0$ & $32: 02: 46.4$ & $\mathrm{~S}$ & no &.. & 1.50 &.. & 2 & 9.3 \\
\hline 28 & $3: 43: 38.3$ & $32: 03: 05.6$ & $\mathrm{~S}$ & no & 16 & 1.50 & .. & 2 & 8.3 \\
\hline 29 & $3: 43: 26.5$ & $31: 43: 14.3$ & $\mathrm{E}$ & no & .. & 0 & .. & 2 & 8.5 \\
\hline 30 & $3: 42: 48.1$ & $31: 58: 51.0$ & $\mathrm{~S}$ & yes &.. & 1.04 &.. & 2 & 5.7 \\
\hline 31 & $3: 42: 06.4$ & $31: 47: 41.0$ & $\mathrm{~S}$ & no &.. & 1.08 &.. & 2 & 9.5 \\
\hline 32 & $3: 41: 57.9$ & $31: 47: 48.1$ & $\mathrm{E}$ & no &.. & 0 &.. & 2 & 9.6 \\
\hline 33 & $3: 41: 57.1$ & $31: 58: 27.0$ & $\mathrm{P}$ & yes &.. & 0.38 &.. & 2 & 8.1 \\
\hline 34 & $3: 41: 46.2$ & $31: 48: 14.0$ & $\mathrm{~S}$ & yes & 18 & 0.56 & .. & 2 & 9.1 \\
\hline 35 & $3: 41: 44.3$ & $31: 56: 08.1$ & $\mathrm{E}$ & no &.. & 0.04 &.. & 2 & 8.8 \\
\hline 36 & $3: 41: 43.8$ & $31: 57: 22.0$ & $\mathrm{P}$ & yes &.. & 0.36 & .. & 2 & 8.9 \\
\hline 37 & $3: 41: 36.2$ & $31: 53: 48.0$ & $\mathrm{P}$ & no &.. & 0 &.. & 2 & 7.4 \\
\hline 38 & $3: 41: 32.0$ & $31: 59: 46.0$ & $\mathrm{P}$ & no &.. & 0.20 & .. & 2 & 6.5 \\
\hline 39 & $3: 41: 24.5$ & $31: 56: 04.0$ & $\mathrm{P}$ & no & .. & 0 & .. & 2 & 8.1 \\
\hline 40 & $3: 41: 17.2$ & $31: 53: 07.0$ & $\mathrm{P}$ & no & ... & 0.18 & ... & 2 & 6.4 \\
\hline 41 & $3: 40: 49.7$ & $31: 48: 34.0$ & $\mathrm{~S}$ & yes & $\ddot{22}$ & 0.78 & ... & 2 & 8.3 \\
\hline 42 & $3: 40: 49.6$ & $31: 36: 35.0$ & $\mathrm{P}$ & yes & .. & 0.38 &.. & 3 & 3.4 \\
\hline 43 & $3: 40: 42.7$ & $31: 54: 05.0$ & $\mathrm{P}$ & no & ... & 0.36 & ... & 2 & 7.7 \\
\hline 44 & $3: 40: 36.4$ & $31: 31: 08.0$ & $\mathrm{P}$ & yes & .. & 0.34 & .. & 3 & 4.5 \\
\hline 45 & $3: 40: 28.6$ & $31: 14: 42.3$ & $\mathrm{E}$ & no &.. & 0 &.. & 3 & 5.6 \\
\hline 46 & $3: 40: 22.0$ & $31: 59: 29.0$ & $\mathrm{P}$ & yes &.. & 0.16 & .. & 2 & 7.9 \\
\hline 47 & $3: 40: 20.9$ & $31: 35: 50.0$ & $\mathrm{P}$ & no & .. & 0.38 & .. & 3 & 5.1 \\
\hline 48 & $3: 40: 08.7$ & $31: 24: 57.0$ & $\mathrm{P}$ & no & .. & 0.14 & .. & 3 & 4.1 \\
\hline 49 & 3:40:06.3 & $32: 01: 33.0$ & $\mathrm{P}$ & yes &.. & 0.42 &.. & 2 & 5.7 \\
\hline 50 & 3:40:02.0 & $31: 32: 24.0$ & $\mathrm{P}$ & no &.. & 0 & .. & 3 & 5.9 \\
\hline 51 & $3: 39: 58.3$ & $31: 27: 34.0$ & $\mathrm{P}$ & yes &.. & 0.44 & .. & 3 & 4.7 \\
\hline 52 & $3: 39: 52.6$ & $32: 03: 52.0$ & $\mathrm{P}$ & yes & .. & 0 & .. & 2 & 5.7 \\
\hline 53 & $3: 39: 47.7$ & $31: 35: 16.0$ & $\mathrm{P}$ & no & 23 & 0.40 & .. & 3 & 3.6 \\
\hline 54 & $3: 39: 42.6$ & $31: 43: 11.0$ & $\mathrm{P}$ & no & .. & 0.12 & .. & 3 & 3.4 \\
\hline 55 & $3: 39: 38.0$ & $31: 31: 42.0$ & $\mathrm{P}$ & yes & $\ddot{25}$ & 0.42 & ... & 3 & 5.7 \\
\hline 56 & $3: 39: 28.5$ & $31: 22: 36.2$ & $\mathrm{E}$ & no & .. & 0 & $\begin{array}{l}. . \\
. .\end{array}$ & 3 & 6.4 \\
\hline 57 & $3: 38: 49.0$ & $31: 17: 31.0$ & $\mathrm{~S}$ & no & $\begin{array}{l}. . \\
. .\end{array}$ & 0 & $\begin{array}{l}. . \\
. .\end{array}$ & 3 & 4.0 \\
\hline 58 & $3: 37: 53.4$ & $31: 23: 29.9$ & $\mathrm{E}$ & no & .. & 0.38 & .. & 3 & 6.0 \\
\hline
\end{tabular}


TABLE 1-Continued

\begin{tabular}{|c|c|c|c|c|c|c|c|c|c|}
\hline Number & $\begin{array}{c}\text { RA } \\
(\mathrm{J} 2000.0)\end{array}$ & $\begin{array}{c}\text { Dec } \\
(\mathrm{J} 2000.0)\end{array}$ & $\begin{array}{c}\text { Sel. }{ }^{\text {a }} \\
\text { Method }\end{array}$ & Cross? & $\begin{array}{c}\text { SCUBA }^{\mathrm{c}} \\
\text { core }\end{array}$ & $\begin{array}{l}\text { SCUBA d } \\
\text { flux }(J y)\end{array}$ & $\begin{array}{l}\text { Spitzer }^{\mathrm{e}} \\
\text { protostar }\end{array}$ & $\begin{array}{l}\text { Ext. }{ }^{f} \\
\text { Region }\end{array}$ & $\begin{array}{c}\text { Mean Ext. } \\
\left(\mathrm{A}_{V}\right)\end{array}$ \\
\hline 59 & $3: 36: 39.3$ & $31: 11: 49.0$ & $\mathrm{~S}$ & no & .. & 0.52 & .. & 4 & 8.5 \\
\hline 60 & $3: 36: 23.9$ & $31: 11: 13.2$ & $\mathrm{E}$ & no & .. & 0.02 & ... & 4 & 9.5 \\
\hline 61 & $3: 35: 55.7$ & $31: 10: 28.0$ & $\mathrm{P}$ & yes & .. & 0 & .. & 4 & 7.1 \\
\hline 62 & $3: 35: 51.2$ & $31: 13: 21.0$ & $\mathrm{P}$ & yes &.. & 0 & .. & 4 & 5.9 \\
\hline 63 & $3: 35: 20.8$ & $31: 07: 05.0$ & $\mathrm{P}$ & yes & .. & 0.54 & .. & 4 & 4.4 \\
\hline 64 & $3: 34: 47.8$ & $31: 21: 25.0$ & $\mathrm{P}$ & yes & .. & 0.36 & .. & 5 & 4.6 \\
\hline 65 & $3: 34: 02.4$ & $31: 21: 08.0$ & $\mathrm{~S}$ & yes & $\begin{array}{l}. . \\
. .\end{array}$ & 0.76 & $\begin{array}{l}. . \\
. .\end{array}$ & 5 & 7.3 \\
\hline 66 & $3: 33: 55.0$ & $31: 19: 25.0$ & $\mathrm{~S}$ & no & .. & 0.64 & .. & 5 & 7.3 \\
\hline 67 & $3: 33: 29.2$ & $31: 20: 11.0$ & $\mathrm{~S}$ & yes &.. & 0.82 &.. & 5 & 9.2 \\
\hline 68 & $3: 33: 27.3$ & $31: 06: 58.7$ & $\mathrm{~S}$ & no & 28 & 1.02 & 40 & 5 & 7.5 \\
\hline 69 & $3: 33: 24.1$ & $31: 04: 10.4$ & $\mathrm{E}$ & no & .. & 0 & .. & 5 & 9.4 \\
\hline 70 & $3: 33: 22.7$ & $31: 18: 34.2$ & $\mathrm{E}$ & no & ... & 0 & .. & 5 & 9.2 \\
\hline 71 & $3: 33: 21.7$ & $31: 07: 22.2$ & $\mathrm{~S}$ & no & $\ddot{29}$ & 7.16 & 39 & 5 & 7.8 \\
\hline 72 & $3: 33: 17.9$ & $31: 09: 27.8$ & $\mathrm{~S}$ & yes & 30 & 7.26 & 38 & 5 & 7.6 \\
\hline 73 & $3: 33: 16.1$ & $31: 06: 51.6$ & $\mathrm{~S}$ & no & 32 & 4.74 & 36 & 5 & 8.4 \\
\hline 74 & $3: 33: 13.8$ & $31: 19: 51.3$ & $\mathrm{~S}$ & yes & 33 & 1.54 & 34 & 5 & 8.9 \\
\hline 75 & $3: 33: 05.9$ & $31: 04: 56.6$ & $\mathrm{~S}$ & yes & 34 & 1.84 & .. & 5 & 7.6 \\
\hline 76 & $3: 33: 00.6$ & $31: 20: 50.0$ & $\mathrm{~S}$ & yes & .. & 1.00 & .. & 5 & 6.4 \\
\hline 77 & $3: 32: 58.0$ & $31: 03: 44.0$ & $\mathrm{~S}$ & yes & .. & 1.64 & .. & 5 & 7.0 \\
\hline 78 & $3: 32: 52.5$ & $31: 01: 49.0$ & $\mathrm{~S}$ & yes & ... & 0.96 & $\begin{array}{l}. . \\
. .\end{array}$ & 5 & 9.0 \\
\hline 79 & $3: 32: 43.2$ & $30: 59: 60.0$ & $\mathrm{~S}$ & yes & .. & 1.50 & .. & 5 & 10.8 \\
\hline 80 & $3: 32: 38.2$ & $30: 57: 53.0$ & $\mathrm{~S}$ & yes & .. & 0.60 & .. & 5 & 8.8 \\
\hline 81 & $3: 32: 33.6$ & $30: 52: 59.0$ & $\mathrm{~S}$ & no & .. & 0.28 & .. & 5 & 5.8 \\
\hline 82 & $3: 32: 31.2$ & $30: 57: 52.9$ & $\mathrm{E}$ & no & $\begin{array}{l}. . \\
. .\end{array}$ & 0 & $\begin{array}{l}. . \\
. .\end{array}$ & 5 & 10.7 \\
\hline 83 & $3: 32: 31.0$ & $30: 50: 29.0$ & $\mathrm{~S}$ & yes & ... & 0.50 & ... & 5 & 5.0 \\
\hline 84 & $3: 32: 28.6$ & $31: 02: 35.0$ & $\mathrm{~S}$ & yes & .. & 0.74 & .. & 5 & 7.2 \\
\hline 85 & $3: 32: 27.4$ & $30: 59: 22.0$ & $\mathrm{~S}$ & yes & .. & 1.44 & .. & 5 & 11.0 \\
\hline 86 & $3: 32: 18.0$ & $30: 49: 45.4$ & $\mathrm{~S}$ & yes & 37 & 5.94 & 33 & 5 & 7.2 \\
\hline 87 & $3: 32: 14.5$ & $30: 54: 45.0$ & $\mathrm{~S}$ & yes & .. & 0.92 & .. & 5 & 6.9 \\
\hline 88 & $3: 31: 57.7$ & $30: 47: 01.0$ & $\mathrm{~S}$ & no & $\begin{array}{l}. . \\
. .\end{array}$ & 0.90 & $\begin{array}{l}. . \\
. .\end{array}$ & 5 & 4.0 \\
\hline 89 & $3: 31: 31.3$ & $30: 43: 27.2$ & $\mathrm{~S}$ & no & .. & 0.92 & .. & 6 & 4.9 \\
\hline 90 & $3: 31: 21.0$ & $30: 45: 25.6$ & $\mathrm{~S}$ & yes & 38 & 2.72 & 32 & 6 & 4.0 \\
\hline 91 & $3: 30: 46.1$ & $30: 52: 44.0$ & $\mathrm{~S}$ & yes & .. & 0.88 & .. & $\ldots$ & 3.5 \\
\hline 92 & $3: 30: 32.0$ & $30: 26: 24.0$ & $\mathrm{~S}$ & yes & .. & 0.66 & .. & 6 & 6.6 \\
\hline 93 & $3: 30: 26.9$ & $30: 26: 25.2$ & $\mathrm{E}$ & no &.. & 0 &.. & 6 & 7.1 \\
\hline 94 & $3: 30: 15.0$ & $30: 23: 45.0$ & $\mathrm{~S}$ & yes & 39 & 0.90 &.. & 6 & 6.0 \\
\hline 95 & $3: 29: 52.0$ & $31: 39: 03.4$ & $\mathrm{~S}$ & yes & 40 & 1.60 & $\ddot{31}$ & 7 & 5.9 \\
\hline 96 & $3: 29: 25.1$ & $31: 28: 16.1$ & $\mathrm{~S}$ & no & 41 & 1.00 & .. & 7 & 5.1 \\
\hline 97 & $3: 29: 23.4$ & $31: 33: 15.7$ & $\mathrm{~S}$ & yes & 42 & 1.22 & 30 & 7 & 6.1 \\
\hline 98 & $3: 29: 18.5$ & $31: 23: 08.8$ & $\mathrm{~S}$ & no & 44 & 1.36 & 28 & 7 & 7.9 \\
\hline 99 & $3: 29: 18.4$ & $31: 25: 02.7$ & $\mathrm{~S}$ & yes & 45 & 2.02 & .. & 7 & 7.0 \\
\hline 100 & $3: 29: 17.2$ & $31: 27: 44.4$ & $\mathrm{~S}$ & $\begin{array}{c}\text { yes } \\
\text { no }\end{array}$ & 46 & 1.30 & $\ddot{27}$ & 7 & 5.8 \\
\hline 101 & $3: 29: 15.0$ & $31: 20: 32.1$ & $\mathrm{~S}$ & no & 47 & 1.56 &.. & 7 & 9.0 \\
\hline 102 & $3: 29: 13.2$ & $31: 13: 55.8$ & $\mathrm{~S}$ & no & 48 & 5.62 & $\ddot{26}$ & 7 & 6.7 \\
\hline 103 & $3: 29: 11.3$ & $31: 13: 07.4$ & $\mathrm{~S}$ & no & 49 & 15.88 & 25 & 7 & 6.6 \\
\hline 104 & $3: 29: 10.5$ & $31: 18: 25.1$ & $\mathrm{~S}$ & no & 50 & 6.40 & 23 & 7 & 9.4 \\
\hline 105 & $3: 29: 10.2$ & $31: 21: 43.0$ & $\mathrm{~S}$ & no & 51 & 4.14 & .. & 7 & 10.0 \\
\hline 106 & $3: 29: 09.9$ & $31: 13: 31.1$ & $\mathrm{~S}$ & yes & 52 & 27.86 & 22 & 7 & 7.0 \\
\hline 107 & $3: 29: 08.8$ & $31: 15: 12.8$ & $\mathrm{~S}$ & no & 53 & 5.08 & .. & 7 & 8.1 \\
\hline 108 & $3: 29: 07.4$ & $31: 21: 48.4$ & $\mathrm{~S}$ & no & 55 & 3.90 & .. & 7 & 10.5 \\
\hline 109 & $3: 29: 06.8$ & $31: 17: 18.3$ & $\mathrm{~S}$ & no & 56 & 1.98 & .. & 7 & 9.2 \\
\hline 110 & $3: 29: 06.5$ & $31: 15: 36.3$ & $\mathrm{~S}$ & no & 57 & 6.24 & ... & 7 & 8.6 \\
\hline 111 & $3: 29: 03.7$ & $31: 14: 47.7$ & $\mathrm{~S}$ & no & 60 & 2.96 & $\ddot{21}$ & 7 & 8.5 \\
\hline 112 & $3: 29: 03.2$ & $31: 15: 53.6$ & $\mathrm{~S}$ & no & 61 & 14.68 & 20 & 7 & 9.0 \\
\hline 113 & $3: 29: 01.4$ & $31: 20: 23.1$ & $\mathrm{~S}$ & no & 62 & 6.32 & 19 & 7 & 10.3 \\
\hline 114 & $3: 29: 00.8$ & $31: 22: 34.9$ & $\mathrm{E}$ & no & .. & 0 &.. & 7 & 11.5 \\
\hline 115 & $3: 29: 00.2$ & $31: 11: 53.0$ & $\mathrm{~S}$ & no & $\ddot{64}$ & 0.36 & $\ddot{18}$ & 7 & 8.2 \\
\hline 116 & $3: 28: 59.5$ & $31: 21: 28.7$ & $\mathrm{~S}$ & no & 65 & 4.58 & 17 & 7 & 10.7 \\
\hline
\end{tabular}


TABLE 1-Continued

\begin{tabular}{|c|c|c|c|c|c|c|c|c|c|}
\hline Number & $\begin{array}{c}\text { RA } \\
(\mathrm{J} 2000.0)\end{array}$ & $\begin{array}{c}\text { Dec } \\
(\mathrm{J} 2000.0)\end{array}$ & $\begin{array}{c}\text { Sel. a } \\
\text { Method }\end{array}$ & Cross? & $\begin{array}{l}\text { SCUBA }^{c} \\
\text { core }\end{array}$ & $\begin{array}{l}\text { SCUBA d } \\
\text { flux }(J y)\end{array}$ & $\begin{array}{l}\text { Spitzer }^{\mathrm{e}} \\
\text { protostar }\end{array}$ & $\begin{array}{l}\text { Ext. }{ }^{f} \\
\text { Region }\end{array}$ & $\begin{array}{c}\text { Mean Ext. } \\
\left(\mathrm{A}_{V}\right)\end{array}$ \\
\hline 117 & $3: 28: 57.3$ & $30: 44: 28.9$ & $\mathrm{E}$ & no & .. & 0.48 & .. & 8 & 5.9 \\
\hline 118 & $3: 28: 55.3$ & $31: 14: 27.9$ & $\mathrm{~S}$ & yes & 66 & 7.78 & 15 & 7 & 8.8 \\
\hline 119 & $3: 28: 51.4$ & $31: 10: 57.0$ & $\mathrm{E}$ & no &.. & 0 & .. & 7 & 10.1 \\
\hline 120 & $3: 28: 47.6$ & $30: 33: 21.1$ & $\mathrm{E}$ & no &.. & 0 & .. & 8 & 5.6 \\
\hline 121 & $3: 28: 42.5$ & $31: 06: 13.1$ & $\mathrm{~S}$ & no & 67 & 1.62 & .. & 7 & 5.8 \\
\hline 122 & $3: 28: 40.1$ & $31: 17: 48.4$ & $\mathrm{~S}$ & no & 68 & 2.86 & 13 & 7 & 8.1 \\
\hline 123 & $3: 28: 39.1$ & $31: 18: 24.1$ & $\mathrm{~S}$ & no & 69 & 3.22 & .. & 7 & 8.1 \\
\hline 124 & $3: 28: 38.8$ & $31: 05: 54.3$ & $\mathrm{~S}$ & no & 70 & 1.56 & $\ddot{12}$ & 7 & 5.4 \\
\hline 125 & $3: 28: 36.7$ & $31: 13: 23.6$ & $\mathrm{~S}$ & yes & 71 & 2.28 & 11 & 7 & 8.0 \\
\hline 126 & $3: 28: 34.5$ & $31: 06: 59.3$ & $\mathrm{~S}$ & no & 72 & 0.42 & 10 & 7 & 5.2 \\
\hline 127 & $3: 28: 34.4$ & $30: 18: 59.9$ & $\mathrm{E}$ & yes & .. & 0.18 & .. & 9 & 6.3 \\
\hline 128 & $3: 28: 32.3$ & $31: 10: 58.7$ & $\mathrm{~S}$ & yes & 73 & 1.16 & 9 & 7 & 6.3 \\
\hline 129 & $3: 28: 08.4$ & $30: 05: 37.0$ & $\mathrm{P}$ & yes & .. & 0 & .. & 9 & 4.5 \\
\hline 130 & $3: 27: 57.1$ & $30: 07: 57.0$ & $\mathrm{P}$ & yes & .. & 0.36 & .. & 9 & 6.6 \\
\hline 131 & $3: 27: 55.6$ & $30: 05: 40.0$ & $\mathrm{P}$ & yes & ... & 0 & ... & 9 & 4.9 \\
\hline 132 & $3: 27: 51.7$ & $30: 11: 06.0$ & $\mathrm{P}$ & yes &.. & 0.18 & .. & 9 & 7.0 \\
\hline 133 & $3: 27: 48.3$ & $30: 12: 08.0$ & $\mathrm{~S}$ & yes & 75 & 2.30 & 8 & 9 & 7.7 \\
\hline 134 & $3: 27: 42.7$ & $30: 12: 24.5$ & $\mathrm{~S}$ & no & 76 & 2.82 & 7 & 9 & 9.3 \\
\hline 135 & $3: 27: 39.0$ & $30: 12: 53.6$ & $\mathrm{~S}$ & no & 78 & 2.80 & 6 & 9 & 10.1 \\
\hline 136 & $3: 27: 37.9$ & $30: 13: 53.2$ & $\mathrm{~S}$ & yes & 79 & 1.20 & 5 & 9 & 9.5 \\
\hline 137 & $3: 27: 36.8$ & $30: 11: 17.1$ & $\mathrm{E}$ & no & .. & 0 & .. & 9 & 9.9 \\
\hline 138 & $3: 27: 35.6$ & $30: 10: 12.0$ & $\mathrm{P}$ & yes & .. & 0 & .. & 9 & 8.5 \\
\hline 139 & $3: 27: 29.5$ & $30: 15: 09.0$ & $\mathrm{~S}$ & no & .. & 0.84 & .. & 9 & 7.9 \\
\hline 140 & $3: 27: 27.6$ & $29: 58: 54.0$ & $\mathrm{P}$ & yes & ... & 0 & .. & 9 & 3.3 \\
\hline 141 & $3: 27: 18.7$ & $30: 17: 12.0$ & $\mathrm{~S}$ & no & $\begin{array}{l}. . \\
. .\end{array}$ & 0.86 & ... & 9 & 4.1 \\
\hline 142 & $3: 27: 00.4$ & $30: 24: 01.0$ & $\mathrm{~S}$ & no & $\begin{array}{l}. . \\
. .\end{array}$ & 0.82 & $\begin{array}{l}. . \\
. .\end{array}$ & $\ldots$ & 2.0 \\
\hline 143 & $3: 26: 37.2$ & $30: 15: 18.7$ & $\mathrm{~S}$ & yes & 80 & 1.08 & $\ddot{4}$ & 9 & 3.0 \\
\hline 144 & $3: 26: 12.9$ & $30: 30: 34.8$ & $\mathrm{E}$ & no & .. & 0.16 & .. & 10 & 5.2 \\
\hline 145 & $3: 26: 02.5$ & $30: 37: 58.0$ & $\mathrm{P}$ & no & .. & 0.20 & .. & 10 & 3.7 \\
\hline 146 & $3: 25: 49.3$ & $30: 42: 15.1$ & $\mathrm{~S}$ & no & 82 & 2.58 & .. & 10 & 5.4 \\
\hline 147 & $3: 25: 46.3$ & $30: 44: 14.1$ & $\mathrm{~S}$ & no & .. & 0.66 & .. & 10 & 5.0 \\
\hline 148 & $3: 25: 38.9$ & $30: 43: 59.8$ & $\mathrm{~S}$ & no & 83 & 5.12 & 3 & 10 & 5.4 \\
\hline 149 & $3: 25: 36.0$ & $30: 45: 10.8$ & $\mathrm{~S}$ & no & 84 & 11.16 & 2 & 10 & 5.4 \\
\hline 150 & $3: 25: 25.7$ & $30: 45: 01.6$ & $\mathrm{~S}$ & no & 85 & 3.34 & .. & 10 & 5.8 \\
\hline 151 & $3: 25: 23.7$ & $30: 21: 07.0$ & $\mathrm{P}$ & no & .. & 0 & .. & 11 & 6.1 \\
\hline 152 & $3: 25: 22.5$ & $30: 45: 06.5$ & $\mathrm{~S}$ & no & 86 & 4.88 & 1 & 10 & 5.9 \\
\hline 153 & $3: 25: 20.2$ & $30: 32: 31.0$ & $\mathrm{P}$ & yes & .. & 0 & .. & $\ldots$ & 2.2 \\
\hline 154 & $3: 25: 17.1$ & $30: 43: 20.7$ & $\mathrm{E}$ & no & ... & 0 & ... & 10 & 5.9 \\
\hline 155 & $3: 25: 05.4$ & $30: 24: 13.0$ & $\mathrm{P}$ & no & ... & 0 & .. & 11 & 4.2 \\
\hline 156 & $3: 24: 51.0$ & $30: 21: 57.3$ & $\mathrm{E}$ & no & ... & 0 & ... & 11 & 6.2 \\
\hline 157 & $3: 24: 33.7$ & $30: 22: 07.0$ & $\mathrm{P}$ & no & ... & 0.10 & ... & 11 & 5.1 \\
\hline
\end{tabular}

a Target selection was based on SCUBA cores (S), potential SCUBA cores (SA), Palomar plate candidates (P), and 2MASS extinction structures (E).

${ }^{\mathrm{b}}$ Were offset positions observed?

${ }^{\mathrm{c}} \mathrm{SCUBA}$ core reference number (see Appendix)

${ }^{\mathrm{d}}$ Total SCUBA flux within the IRAM beam (derived from the $6^{\prime \prime}$ map of Kirk, Johnstone, \& Di Francesco 2006).

${ }^{\mathrm{e}}$ Spitzer reference number (from Jørgensen et al. 2007)

${ }^{\mathrm{f}}$ Extinction region number (from Kirk, Johnstone, \& Di Francesco 2006)

${ }^{\mathrm{g}}$ Mean extinction within the IRAM beam. 
TABLE 2

DETECTION RATES FOR THE TARGET SELECTION METHODS.

\begin{tabular}{ccccc}
\hline \hline Tracer & SCUBA & Palomar & 2MASS & Total $^{\mathrm{a}}$ \\
\hline $\mathrm{N}_{2} \mathrm{H}^{+}(1-0)$ & $84 \%(75 / 89)$ & $42 \%(18 / 43)$ & $14 \%(3 / 22)$ & $62 \%(96 / 154)$ \\
$\mathrm{C}^{18} \mathrm{O}(2-1)$ & $98 \%(87 / 89)$ & $93 \%(40 / 43)$ & $95 \%(21 / 22)$ & $96 \%(148 / 154)$ \\
\hline
\end{tabular}

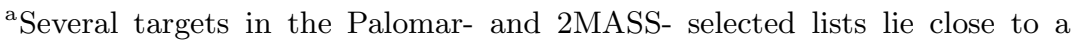
SCUBA-selected target and appear to sample the same object (one and two targets respectively). We only count these targets once for both these statistics and the subsequent analysis. 
TABle 3

Parameters of Spectral Fitting for $\mathrm{N}_{2} \mathrm{H}^{+}$

\begin{tabular}{|c|c|c|c|c|c|c|c|c|c|c|c|}
\hline$\#^{\mathrm{a}}$ & $\begin{array}{l}\mathrm{RA}^{\mathrm{b}} \\
\text { offset }\end{array}$ & $\begin{array}{l}\operatorname{dec}^{b} \\
\text { offset }\end{array}$ & $\begin{array}{c}V_{C}^{\mathrm{c}, d} \\
\left(\mathrm{~km} \mathrm{~s}^{-1}\right)\end{array}$ & $\begin{array}{c}\Delta V^{\mathrm{c}} \\
\left(\mathrm{km} \mathrm{s}^{-1}\right)\end{array}$ & $\begin{array}{c}\text { error }^{\mathrm{c}} \\
\left(\mathrm{m} \mathrm{s}^{-1}\right)\end{array}$ & $\begin{array}{l}\text { optical }^{\mathrm{c}} \\
\text { depth }\end{array}$ & error $^{\mathrm{c}}$ & $\begin{array}{c}\mathrm{rms}^{\mathrm{c}} \\
\operatorname{base}(\mathrm{K})\end{array}$ & $\begin{array}{r}\mathrm{rms}^{\mathrm{c}} \\
\mathrm{fit}(\mathrm{K})\end{array}$ & $\int_{\left(\mathrm{K} \mathrm{km} \mathrm{s}^{-1}\right)}$ & $\begin{array}{c}\text { secure }^{f} \\
\text { fit? }\end{array}$ \\
\hline 1 & 0 & 0 & $\ldots$ & $\ldots$ & $\ldots$ & $\ldots$ & $\ldots$ & 0.15 & $\ldots$ & $\ldots$ & $\ldots$ \\
\hline 2 & 0 & 0 & $\ldots$ & $\ldots$ & $\ldots$ & $\ldots$ & $\ldots$ & 0.15 & $\ldots$ & $\ldots$ & $\ldots$ \\
\hline 3 & 0 & 0 & 10.22 & 0.25 & 5 & 6.53 & 0.64 & 0.08 & 0.10 & 2.38 & yes \\
\hline 3 & 0 & -1 & 10.26 & 0.40 & 6 & 5.41 & 0.48 & 0.12 & 0.15 & 5.54 & yes \\
\hline 3 & 0 & 1 & 10.21 & 0.28 & 12 & 1.75 & 1.19 & 0.12 & 0.11 & 1.40 & yes \\
\hline 3 & -1 & 0 & 10.23 & 0.36 & 7 & 5.29 & 0.60 & 0.12 & 0.17 & 3.71 & yes \\
\hline 3 & 1 & 0 & 10.22 & 0.28 & 8 & 0.88 & 0.50 & 0.12 & 0.11 & 0.98 & yes \\
\hline 4 & 0 & 0 & 10.24 & 0.45 & 5 & 6.30 & 0.33 & 0.10 & 0.18 & 7.39 & yes \\
\hline 5 & 0 & 0 & 10.20 & 0.26 & 11 & 4.28 & 1.24 & 0.15 & 0.17 & 1.94 & yes \\
\hline 5 & 0 & -1 & 10.10 & 0.31 & 12 & 2.86 & 1.20 & 0.14 & 0.13 & 1.64 & yes \\
\hline 5 & 0 & 1 & 10.22 & 0.23 & 5 & 6.27 & 0.75 & 0.13 & 0.16 & 2.11 & yes \\
\hline 5 & -1 & 0 & 10.10 & 0.27 & 23 & 7.97 & 3.62 & 0.13 & 0.14 & 0.64 & yes \\
\hline 5 & 1 & 0 & 10.25 & 0.25 & 7 & 4.34 & 0.98 & 0.14 & 0.14 & 2.11 & yes \\
\hline 6 & 0 & 0 & 10.37 & 0.41 & 7 & 6.19 & 0.55 & 0.10 & 0.11 & 4.38 & yes \\
\hline 7 & 0 & 0 & 10.43 & 0.38 & 30 & 3.69 & 2.20 & 0.14 & 0.15 & 1.08 & no \\
\hline 7 & 0 & -1 & $\ldots$ & $\ldots$ & $\ldots$ & $\ldots$ & $\ldots$ & 0.14 & $\ldots$ & $\ldots$ & $\ldots$ \\
\hline 7 & 0 & 1 & 10.34 & 0.42 & 48 & 7.78 & 3.81 & 0.13 & 0.12 & 0.68 & no \\
\hline 7 & -1 & 0 & $\ldots$ & $\ldots$ & $\ldots$ & $\ldots$ & $\ldots$ & 0.13 & $\ldots$ & $\ldots$ & $\ldots$ \\
\hline 7 & 1 & 0 & 10.35 & 0.42 & 11 & 6.21 & 0.93 & 0.14 & 0.14 & 3.35 & yes \\
\hline 8 & 0 & 0 & 10.07 & 0.27 & 14 & 0.38 & 0.04 & 0.14 & 0.14 & 1.07 & yes \\
\hline 8 & 0 & -1 & $\ldots$ & $\ldots$ & $\ldots$ & $\ldots$ & $\ldots$ & 0.14 & $\ldots$ & $\ldots$ & $\ldots$ \\
\hline 8 & 0 & 1 & 10.07 & 0.23 & $\dddot{8}$ & 3.96 & 1.07 & 0.13 & 0.14 & 1.66 & yes \\
\hline 8 & -1 & 0 & $\ldots$ & $\ldots$ & $\ldots$ & $\ldots$ & $\ldots$ & 0.14 & $\ldots$ & $\ldots$ & $\ldots$ \\
\hline 8 & 1 & 0 & 10.01 & 0.18 & 5 & 2.29 & 0.86 & 0.14 & 0.15 & 1.39 & yes \\
\hline 9 & 0 & 0 & $\ldots$ & $\ldots$ & $\ldots$ & $\ldots$ & $\ldots$ & 0.23 & $\ldots$ & $\ldots$ & $\ldots$ \\
\hline 10 & 0 & 0 & $\ldots$ & $\ldots$ & $\ldots$ & $\ldots$ & $\ldots$ & 0.14 & $\ldots$ & $\ldots$ & $\ldots$ \\
\hline 11 & 0 & 0 & $\ldots$ & $\ldots$ & $\ldots$ & $\ldots$ & $\ldots$ & 0.15 & $\ldots$ & $\ldots$ & $\ldots$ \\
\hline 12 & 0 & 0 & 10.76 & 0.21 & 10 & 0.58 & 1.08 & 0.14 & 0.14 & 1.10 & yes \\
\hline 12 & 0 & -1 & 10.81 & 0.18 & 8 & 1.80 & 1.30 & 0.11 & 0.11 & 0.89 & yes \\
\hline 12 & 0 & 1 & 10.72 & 0.20 & 9 & 0.16 & 2.77 & 0.11 & 0.12 & 0.81 & yes \\
\hline 12 & -1 & 0 & $\ldots$ & $\ldots$ & $\ldots$ & $\ldots$ & $\ldots$ & 0.11 & $\ldots$ & $\ldots$ & $\ldots$ \\
\hline 12 & 1 & 0 & 10.72 & 0.19 & 8 & 3.63 & 1.27 & 0.12 & 0.10 & 1.05 & yes \\
\hline 13 & 0 & 0 & 10.99 & 0.29 & 9 & 4.08 & 0.93 & 0.14 & 0.16 & 2.43 & yes \\
\hline 13 & 0 & -1 & 10.83 & 0.26 & 5 & 3.67 & 0.54 & 0.11 & 0.16 & 3.14 & yes \\
\hline 13 & 0 & 1 & 11.05 & 0.20 & 13 & 4.82 & 2.16 & 0.11 & 0.11 & 0.67 & yes \\
\hline 13 & -1 & 0 & 10.84 & 0.25 & 19 & 1.25 & 0.77 & 0.11 & 0.10 & 0.54 & yes \\
\hline 13 & 1 & 0 & 11.00 & 0.31 & 9 & 0.10 & 0.61 & 0.11 & 0.13 & 1.60 & yes \\
\hline 14 & 0 & 0 & $\ldots$ & $\ldots$ & $\ldots$ & $\ldots$ & $\ldots$ & 0.12 & $\ldots$ & $\ldots$ & $\ldots$ \\
\hline 15 & 0 & 0 & 8.94 & 0.29 & $\dddot{6}$ & 4.87 & 0.67 & 0.11 & 0.12 & 2.96 & $\begin{array}{c}\cdots \\
\text { yes }\end{array}$ \\
\hline 16 & 0 & 0 & 9.87 & 0.74 & 32 & 1.56 & 0.65 & 0.11 & 0.13 & 3.15 & yes \\
\hline 16 & 0 & -1 & 9.57 & 0.39 & 22 & 0.32 & 1.64 & 0.12 & 0.13 & 1.62 & yes \\
\hline 16 & 0 & 1 & $\ldots$ & $\ldots$ & $\ldots$ & $\ldots$ & $\ldots$ & 0.13 & $\ldots$ & $\ldots$ & $\ldots$ \\
\hline 16 & -1 & 0 & $\cdots$ & $\ldots$ & $\ldots$ & $\cdots$ & $\cdots$ & 0.13 & $\ldots$ & $\cdots$ & $\ldots$ \\
\hline 16 & 1 & 0 & 9.67 & 0.49 & 53 & 3.47 & 2.07 & 0.12 & 0.13 & 1.18 & no \\
\hline 17 & 0 & 0 & $\ldots$ & $\ldots$ & $\ldots$ & $\ldots$ & $\ldots$ & 0.11 & $\ldots$ & $\ldots$ & $\ldots$ \\
\hline 18 & 0 & 0 & 9.92 & 0.52 & 13 & 3.96 & 0.63 & 0.10 & 0.15 & 3.01 & yes \\
\hline 18 & 0 & -1 & 9.99 & 0.37 & 17 & 2.03 & 1.12 & 0.13 & 0.14 & 1.89 & yes \\
\hline 18 & 0 & 1 & 9.87 & 0.46 & 23 & 3.05 & 1.36 & 0.13 & 0.13 & 1.83 & yes \\
\hline 18 & -1 & 0 & 9.61 & 0.66 & 48 & 0.10 & 1.56 & 0.13 & 0.12 & 1.22 & yes \\
\hline 18 & 1 & 0 & 9.74 & 0.59 & 105 & 0.25 & 0.10 & 0.12 & 0.13 & 0.93 & no \\
\hline 19 & 0 & 0 & 8.55 & 0.35 & 4 & 4.11 & 0.36 & 0.10 & 0.13 & 4.79 & yes \\
\hline 20 & 0 & 0 & 8.57 & 0.68 & 19 & 2.19 & 0.40 & 0.11 & 0.27 & 5.48 & yes \\
\hline 21 & 0 & 0 & 9.02 & 0.65 & 9 & 2.05 & 0.29 & 0.10 & 0.13 & 6.41 & yes \\
\hline 22 & 0 & 0 & 8.88 & 0.65 & 53 & 6.69 & 1.74 & 0.08 & 0.08 & 1.15 & no \\
\hline 22 & 0 & 0 & 8.11 & 0.24 & 23 & 3.45 & 1.13 & 0.08 & 0.08 & 1.15 & no \\
\hline 22 & 0 & -1 & 8.16 & 0.28 & 8 & 0.54 & 0.01 & 0.12 & 0.14 & 1.97 & yes \\
\hline 22 & 0 & 1 & 9.28 & 0.24 & 14 & 3.88 & 1.71 & 0.12 & 0.13 & 1.42 & yes \\
\hline 22 & -1 & 0 & 8.95 & 0.57 & 12 & 2.26 & 0.52 & 0.14 & 0.19 & 5.21 & yes \\
\hline
\end{tabular}


TABLE 3-Continued

\begin{tabular}{|c|c|c|c|c|c|c|c|c|c|c|c|}
\hline$\#^{\mathrm{a}}$ & $\begin{array}{l}\mathrm{RA}^{\mathrm{b}} \\
\text { offset }\end{array}$ & $\begin{array}{l}\operatorname{dec}^{b} \\
\text { offset }\end{array}$ & $\begin{array}{c}V_{C}^{\mathrm{c}, d} \\
\left(\mathrm{~km} \mathrm{~s}^{-1}\right)\end{array}$ & $\begin{array}{c}\Delta V^{\mathrm{c}} \\
\left(\mathrm{km} \mathrm{s}^{-1}\right)\end{array}$ & $\begin{array}{c}\text { error }^{\mathrm{c}} \\
\left(\mathrm{m} \mathrm{s}^{-1}\right)\end{array}$ & $\begin{array}{l}\text { optical }^{\mathrm{c}} \\
\text { depth }\end{array}$ & error $^{c}$ & $\begin{array}{c}\mathrm{rms}^{\mathrm{c}} \\
\mathrm{base}(\mathrm{K})\end{array}$ & $\begin{array}{r}\mathrm{rms}^{\mathrm{c}} \\
\mathrm{fit}(\mathrm{K})\end{array}$ & $\begin{array}{c}\int \mathrm{I}^{\mathrm{e}} \\
\left(\mathrm{K} \mathrm{km} \mathrm{s}^{-1}\right)\end{array}$ & $\begin{array}{c}\text { secure }^{\mathrm{f}} \\
\text { fit? }\end{array}$ \\
\hline 22 & 1 & 0 & $\ldots$ & $\ldots$ & $\ldots$ & $\ldots$ & $\ldots$ & 0.12 & $\ldots$ & $\ldots$ & $\ldots$ \\
\hline 23 & 0 & 0 & 8.27 & 0.41 & 0 & 0.23 & 0.00 & 0.10 & 0.15 & 3.99 & yes \\
\hline 24 & 0 & 0 & 8.74 & 0.46 & 8 & 3.02 & 0.48 & 0.10 & 0.11 & 4.06 & yes \\
\hline 25 & 0 & 0 & 9.06 & 0.48 & 6 & 5.13 & 0.38 & 0.11 & 0.13 & 6.90 & yes \\
\hline 26 & 0 & 0 & 8.56 & 0.42 & 4 & 4.24 & 0.26 & 0.10 & 0.14 & 7.29 & yes \\
\hline 27 & 0 & 0 & 8.24 & 0.34 & 12 & 1.27 & 0.01 & 0.10 & 0.11 & 3.23 & yes \\
\hline 27 & 0 & 0 & 8.70 & 0.27 & 6 & 2.97 & 0.36 & 0.10 & 0.11 & 3.23 & yes \\
\hline 28 & 0 & 0 & 8.46 & 0.58 & 15 & 6.07 & 0.91 & 0.11 & 0.16 & 3.33 & yes \\
\hline 29 & 0 & 0 & $\ldots$ & $\ldots$ & $\ldots$ & $\ldots$ & $\ldots$ & 0.12 & $\ldots$ & $\ldots$ & $\ldots$ \\
\hline 30 & 0 & 0 & 8.84 & 0.22 & 14 & 2.92 & 1.86 & 0.13 & 0.13 & 0.78 & yes \\
\hline 30 & 0 & -1 & $\ldots$ & $\ldots$ & $\ldots$ & $\ldots$ & $\ldots$ & 0.13 & $\ldots$ & $\ldots$ & $\ldots$ \\
\hline 30 & 0 & 1 & $\ldots$ & $\ldots$ & $\ldots$ & $\ldots$ & $\ldots$ & 0.13 & $\ldots$ & $\ldots$ & $\ldots$ \\
\hline 30 & -1 & 0 & 8.86 & 0.19 & 13 & 3.37 & 1.77 & 0.12 & 0.11 & 0.82 & yes \\
\hline 30 & 1 & 0 & $\ldots$ & $\ldots$ & $\ldots$ & $\ldots$ & $\ldots$ & 0.12 & $\ldots$ & $\ldots$ & $\ldots$ \\
\hline 31 & 0 & 0 & $\ldots$ & $\ldots$ & $\ldots$ & $\ldots$ & $\ldots$ & 0.12 & $\ldots$ & $\ldots$ & $\ldots$ \\
\hline 32 & 0 & 0 & $\ldots$ & $\ldots$ & $\ldots$ & $\ldots$ & $\ldots$ & 0.08 & $\ldots$ & $\ldots$ & $\ldots$ \\
\hline 33 & 0 & 0 & 9.45 & 0.35 & 105 & 0.79 & 0.10 & 0.14 & 0.15 & 0.60 & no \\
\hline 33 & 0 & -1 & $\ldots$ & $\ldots$ & $\ldots$ & $\ldots$ & $\ldots$ & 0.12 & $\ldots$ & $\ldots$ & $\ldots$ \\
\hline 33 & 0 & 1 & 9.40 & 0.21 & 11 & 12.04 & 2.87 & 0.11 & 0.10 & 0.79 & yes \\
\hline 33 & -1 & 0 & 9.41 & 0.23 & 25 & 0.24 & 19.08 & 0.11 & 0.10 & 0.28 & no \\
\hline 33 & 1 & 0 & 9.40 & 0.35 & 2 & 1.17 & 1.28 & 0.11 & 0.13 & 0.64 & yes \\
\hline 34 & 0 & 0 & 8.21 & 0.25 & 5 & 0.81 & 0.00 & 0.12 & 0.12 & 0.52 & no \\
\hline 34 & 0 & -1 & 8.19 & 0.22 & 21 & 0.10 & 1.10 & 0.12 & 0.12 & 0.36 & no \\
\hline 34 & 0 & 1 & $\ldots$ & $\ldots$ & $\ldots$ & $\ldots$ & $\ldots$ & 0.12 & $\ldots$ & $\ldots$ & $\ldots$ \\
\hline 34 & -1 & 0 & $\ldots$ & $\ldots$ & $\ldots$ & $\ldots$ & $\ldots$ & 0.12 & $\ldots$ & $\ldots$ & $\ldots$ \\
\hline 34 & 1 & 0 & 8.24 & 0.20 & 11 & 3.44 & 1.62 & 0.12 & 0.10 & 0.77 & no \\
\hline 35 & 0 & 0 & $\ldots$ & $\ldots$ & $\ldots$ & $\ldots$ & $\ldots$ & 0.11 & $\ldots$ & $\ldots$ & $\ldots$ \\
\hline 36 & 0 & 0 & 9.39 & 0.20 & 5 & 4.32 & 0.76 & 0.14 & 0.15 & 2.59 & yes \\
\hline 36 & 0 & -1 & 9.39 & 0.18 & 10 & 2.19 & 1.55 & 0.12 & 0.13 & 0.68 & yes \\
\hline 36 & 0 & 1 & 9.43 & 0.19 & 5 & 4.21 & 0.75 & 0.11 & 0.12 & 1.95 & yes \\
\hline 36 & -1 & 0 & 9.42 & 0.19 & 6 & 3.91 & 0.98 & 0.12 & 0.14 & 1.49 & yes \\
\hline 36 & 1 & 0 & 9.41 & 0.22 & 4 & 6.70 & 0.66 & 0.11 & 0.12 & 2.80 & yes \\
\hline 37 & 0 & 0 & $\ldots$ & $\ldots$ & $\ldots$ & $\ldots$ & $\ldots$ & 0.14 & $\ldots$ & $\ldots$ & $\ldots$ \\
\hline 38 & 0 & 0 & $\ldots$ & $\ldots$ & $\ldots$ & $\ldots$ & $\ldots$ & 0.15 & $\ldots$ & $\ldots$ & $\ldots$ \\
\hline 39 & 0 & 0 & $\ldots$ & $\ldots$ & $\ldots$ & $\ldots$ & $\ldots$ & 0.14 & $\ldots$ & $\ldots$ & $\ldots$ \\
\hline 40 & 0 & 0 & $\ldots$ & $\ldots$ & $\ldots$ & $\ldots$ & $\ldots$ & 0.14 & $\ldots$ & $\ldots$ & $\ldots$ \\
\hline 41 & 0 & 0 & 8.45 & 0.23 & 9 & 4.71 & 1.16 & 0.12 & 0.16 & 1.47 & yes \\
\hline 41 & 0 & -1 & $\ldots$ & $\ldots$ & $\ldots$ & $\ldots$ & $\ldots$ & 0.15 & $\ldots$ & $\ldots$ & $\ldots$ \\
\hline 41 & 0 & 1 & 8.40 & 0.28 & 18 & 4.62 & 2.09 & 0.14 & 0.14 & 1.18 & yes \\
\hline 41 & -1 & 0 & $\ldots$ & $\ldots$ & $\ldots$ & $\ldots$ & $\ldots$ & 0.14 & $\ldots$ & $\ldots$ & $\ldots$ \\
\hline 41 & 1 & 0 & 8.39 & 0.20 & 12 & 1.17 & 1.60 & 0.13 & 0.16 & 1.01 & yes \\
\hline 42 & 0 & 0 & $\ldots$ & $\ldots$ & $\ldots$ & $\ldots$ & $\ldots$ & 0.14 & $\ldots$ & $\ldots$ & $\ldots$ \\
\hline 42 & 0 & -1 & $\ldots$ & $\ldots$ & $\ldots$ & $\ldots$ & $\ldots$ & 0.11 & $\ldots$ & $\ldots$ & $\ldots$ \\
\hline 42 & 0 & 1 & $\ldots$ & $\ldots$ & $\ldots$ & $\ldots$ & $\ldots$ & 0.13 & $\ldots$ & $\ldots$ & $\ldots$ \\
\hline 42 & -1 & 0 & $\ldots$ & $\ldots$ & $\ldots$ & $\ldots$ & $\ldots$ & 0.12 & $\ldots$ & $\ldots$ & $\ldots$ \\
\hline 42 & 1 & 0 & $\ldots$ & $\ldots$ & $\ldots$ & $\ldots$ & $\ldots$ & 0.12 & $\ldots$ & $\ldots$ & $\ldots$ \\
\hline 43 & 0 & 0 & $\ldots$ & $\ldots$ & $\ldots$ & $\ldots$ & $\ldots$ & 0.14 & $\ldots$ & $\ldots$ & $\ldots$ \\
\hline 44 & 0 & 0 & $\ldots$ & $\ldots$ & $\ldots$ & $\ldots$ & $\ldots$ & 0.14 & $\ldots$ & $\ldots$ & $\ldots$ \\
\hline 44 & 0 & -1 & $\ldots$ & $\ldots$ & $\ldots$ & $\ldots$ & $\ldots$ & 0.12 & $\ldots$ & $\ldots$ & $\ldots$ \\
\hline 44 & 0 & 1 & $\ldots$ & $\ldots$ & $\ldots$ & $\ldots$ & $\ldots$ & 0.13 & $\ldots$ & $\ldots$ & $\ldots$ \\
\hline 44 & -1 & 0 & $\ldots$ & $\ldots$ & $\ldots$ & $\ldots$ & $\ldots$ & 0.12 & $\ldots$ & $\ldots$ & $\ldots$ \\
\hline 44 & 1 & 0 & $\cdots$ & $\cdots$ & $\ldots$ & $\ldots$ & $\ldots$ & 0.13 & $\ldots$ & $\cdots$ & $\cdots$ \\
\hline 45 & 0 & 0 & $\ldots$ & $\ldots$ & $\ldots$ & $\ldots$ & $\ldots$ & 0.12 & $\ldots$ & $\ldots$ & $\ldots$ \\
\hline 46 & 0 & 0 & $\ldots$ & $\ldots$ & $\ldots$ & $\ldots$ & $\ldots$ & 0.07 & $\ldots$ & $\ldots$ & $\ldots$ \\
\hline 46 & 0 & -1 & $\ldots$ & $\ldots$ & $\ldots$ & $\ldots$ & $\ldots$ & 0.07 & $\ldots$ & $\ldots$ & $\ldots$ \\
\hline 46 & 0 & 1 & $\ldots$ & $\ldots$ & $\ldots$ & $\ldots$ & $\ldots$ & 0.07 & $\ldots$ & $\ldots$ & $\ldots$ \\
\hline 46 & -1 & 0 & $\ldots$ & $\ldots$ & $\ldots$ & $\ldots$ & $\ldots$ & 0.08 & $\ldots$ & $\ldots$ & $\ldots$ \\
\hline 46 & 1 & 0 & $\ldots$ & $\ldots$ & $\ldots$ & $\ldots$ & $\ldots$ & 0.07 & $\ldots$ & $\ldots$ & $\ldots$ \\
\hline
\end{tabular}


TABLE 3-Continued

\begin{tabular}{|c|c|c|c|c|c|c|c|c|c|c|c|}
\hline$\#^{\mathrm{a}}$ & $\begin{array}{l}\mathrm{RA}^{\mathrm{b}} \\
\text { offset }\end{array}$ & $\begin{array}{l}\operatorname{dec}^{\mathrm{b}} \\
\text { offset }\end{array}$ & $\begin{array}{r}V_{C}^{\mathrm{c}, d} \\
\left(\mathrm{~km} \mathrm{~s}^{-1}\right)\end{array}$ & $\begin{array}{c}\Delta V^{\mathrm{c}} \\
\left(\mathrm{km} \mathrm{s}^{-1}\right)\end{array}$ & $\begin{array}{c}\text { error }^{c} \\
\left(\mathrm{~m} \mathrm{~s}^{-1}\right)\end{array}$ & $\begin{array}{c}\text { optical }^{\mathrm{c}} \\
\text { depth }\end{array}$ & error $^{\mathrm{c}}$ & $\begin{array}{c}\mathrm{rms}^{\mathrm{c}} \\
\mathrm{base}(\mathrm{K})\end{array}$ & $\begin{array}{r}\mathrm{rms}^{\mathrm{c}} \\
\mathrm{fit}(\mathrm{K})\end{array}$ & $\begin{array}{c}\int \mathrm{I}^{\mathrm{e}} \\
\left(\mathrm{K} \mathrm{km} \mathrm{s}^{-1}\right)\end{array}$ & $\begin{array}{c}\text { secure }^{f} \\
\text { fit? }\end{array}$ \\
\hline 47 & 0 & 0 & $\ldots$ & $\ldots$ & $\ldots$ & $\ldots$ & $\ldots$ & 0.13 & $\ldots$ & $\ldots$ & $\ldots$ \\
\hline 48 & 0 & 0 & $\ldots$ & $\ldots$ & $\ldots$ & $\ldots$ & $\ldots$ & 0.13 & $\ldots$ & $\ldots$ & $\ldots$ \\
\hline 49 & 0 & 0 & $\ldots$ & $\ldots$ & $\ldots$ & $\ldots$ & $\ldots$ & 0.14 & $\ldots$ & $\ldots$ & $\ldots$ \\
\hline 49 & 0 & -1 & $\ldots$ & $\ldots$ & $\ldots$ & $\ldots$ & $\ldots$ & 0.12 & $\ldots$ & $\ldots$ & $\ldots$ \\
\hline 49 & 0 & 1 & 7.90 & 0.22 & 10 & 5.13 & 1.47 & 0.11 & 0.11 & 1.14 & yes \\
\hline 49 & -1 & 0 & $\ldots$ & $\ldots$ & $\ldots$ & $\ldots$ & $\ldots$ & 0.12 & $\ldots$ & $\ldots$ & $\ldots$ \\
\hline 49 & 1 & 0 & 7.87 & 0.20 & 17 & 0.74 & 0.78 & 0.12 & 0.10 & 0.68 & no \\
\hline 50 & 0 & 0 & $\ldots$ & $\ldots$ & $\ldots$ & $\ldots$ & $\ldots$ & 0.13 & $\ldots$ & $\ldots$ & $\ldots$ \\
\hline 51 & 0 & 0 & $\ldots$ & $\ldots$ & $\ldots$ & $\ldots$ & $\ldots$ & 0.09 & $\ldots$ & $\ldots$ & $\ldots$ \\
\hline 51 & 0 & -1 & $\ldots$ & $\ldots$ & $\ldots$ & $\ldots$ & $\ldots$ & 0.08 & $\ldots$ & $\ldots$ & $\ldots$ \\
\hline 51 & 0 & 1 & $\ldots$ & $\cdots$ & $\ldots$ & $\ldots$ & $\ldots$ & 0.08 & $\ldots$ & $\cdots$ & $\ldots$ \\
\hline 51 & -1 & 0 & $\ldots$ & $\ldots$ & $\ldots$ & $\ldots$ & $\ldots$ & 0.08 & $\ldots$ & $\ldots$ & $\ldots$ \\
\hline 51 & 1 & 0 & $\ldots$ & $\ldots$ & $\ldots$ & $\ldots$ & $\ldots$ & 0.08 & $\ldots$ & $\ldots$ & $\ldots$ \\
\hline 52 & 0 & 0 & $\ldots$ & $\ldots$ & $\ldots$ & $\ldots$ & $\ldots$ & 0.14 & $\ldots$ & $\ldots$ & $\ldots$ \\
\hline 52 & 0 & -1 & $\ldots$ & $\ldots$ & $\ldots$ & $\ldots$ & $\ldots$ & 0.12 & $\cdots$ & $\cdots$ & $\ldots$ \\
\hline 52 & 0 & 1 & $\ldots$ & $\ldots$ & $\ldots$ & $\ldots$ & $\ldots$ & 0.12 & $\ldots$ & $\ldots$ & $\ldots$ \\
\hline 52 & -1 & 0 & $\ldots$ & $\ldots$ & $\ldots$ & $\ldots$ & $\ldots$ & 0.12 & $\ldots$ & $\ldots$ & $\ldots$ \\
\hline 52 & 1 & 0 & $\ldots$ & $\ldots$ & $\ldots$ & $\ldots$ & $\ldots$ & 0.12 & $\ldots$ & $\ldots$ & $\ldots$ \\
\hline 53 & 0 & 0 & 10.05 & 0.34 & 39 & 0.10 & 1.93 & 0.13 & 0.13 & 0.59 & no \\
\hline 54 & 0 & 0 & $\ldots$ & $\ldots$ & $\ldots$ & $\ldots$ & $\ldots$ & 0.12 & $\ldots$ & $\ldots$ & $\ldots$ \\
\hline 55 & 0 & 0 & 9.77 & 0.34 & 21 & 0.10 & 1.25 & 0.09 & 0.09 & 0.45 & yes \\
\hline 55 & 0 & -1 & 9.79 & 0.37 & 29 & 0.10 & 1.55 & 0.09 & 0.07 & 0.39 & no \\
\hline 55 & 0 & 1 & 9.82 & 0.28 & 16 & 0.41 & 1.43 & 0.08 & 0.08 & 0.66 & yes \\
\hline 55 & -1 & 0 & $\ldots$ & $\ldots$ & $\ldots$ & $\ldots$ & $\ldots$ & 0.09 & $\ldots$ & $\ldots$ & $\ldots$ \\
\hline 55 & 1 & 0 & 9.81 & 0.35 & 19 & 1.52 & 1.49 & 0.09 & 0.09 & 0.83 & yes \\
\hline 56 & 0 & 0 & $\ldots$ & $\ldots$ & $\ldots$ & $\ldots$ & $\ldots$ & 0.12 & $\ldots$ & $\ldots$ & $\ldots$ \\
\hline 57 & 0 & 0 & $\ldots$ & $\ldots$ & $\ldots$ & $\ldots$ & $\ldots$ & 0.13 & $\ldots$ & $\cdots$ & $\ldots$ \\
\hline 58 & 0 & 0 & $\ldots$ & $\ldots$ & $\ldots$ & $\ldots$ & $\ldots$ & 0.11 & $\ldots$ & $\ldots$ & $\ldots$ \\
\hline 59 & 0 & 0 & $\ldots$ & $\ldots$ & $\ldots$ & $\ldots$ & $\ldots$ & 0.13 & $\ldots$ & $\ldots$ & $\ldots$ \\
\hline 60 & 0 & 0 & $\ldots$ & $\ldots$ & $\ldots$ & $\ldots$ & $\ldots$ & 0.08 & $\ldots$ & $\ldots$ & $\ldots$ \\
\hline 61 & 0 & 0 & $\ldots$ & $\ldots$ & $\ldots$ & $\ldots$ & $\ldots$ & 0.14 & $\ldots$ & $\ldots$ & $\ldots$ \\
\hline 61 & 0 & -1 & $\ldots$ & $\ldots$ & $\ldots$ & $\ldots$ & $\ldots$ & 0.12 & $\ldots$ & $\ldots$ & $\ldots$ \\
\hline 61 & 0 & 1 & $\ldots$ & $\ldots$ & $\ldots$ & $\ldots$ & $\ldots$ & 0.12 & $\ldots$ & $\ldots$ & $\ldots$ \\
\hline 61 & -1 & 0 & $\ldots$ & $\ldots$ & $\ldots$ & $\ldots$ & $\ldots$ & 0.12 & $\ldots$ & $\ldots$ & $\ldots$ \\
\hline 61 & 1 & 0 & $\ldots$ & $\ldots$ & $\ldots$ & $\ldots$ & $\ldots$ & 0.13 & $\ldots$ & $\ldots$ & $\ldots$ \\
\hline 62 & 0 & 0 & $\ldots$ & $\ldots$ & $\ldots$ & $\ldots$ & $\ldots$ & 0.13 & $\ldots$ & $\ldots$ & $\ldots$ \\
\hline 62 & 0 & -1 & $\ldots$ & $\ldots$ & $\ldots$ & $\ldots$ & $\ldots$ & 0.12 & $\ldots$ & $\ldots$ & $\ldots$ \\
\hline 62 & 0 & 1 & $\ldots$ & $\ldots$ & $\ldots$ & $\ldots$ & $\ldots$ & 0.12 & $\ldots$ & $\ldots$ & $\ldots$ \\
\hline 62 & -1 & 0 & $\ldots$ & $\ldots$ & $\ldots$ & $\ldots$ & $\ldots$ & 0.12 & $\ldots$ & $\ldots$ & $\ldots$ \\
\hline 62 & 1 & 0 & $\ldots$ & $\ldots$ & $\ldots$ & $\ldots$ & $\ldots$ & 0.12 & $\ldots$ & $\ldots$ & $\ldots$ \\
\hline 63 & 0 & 0 & 7.01 & 0.33 & 29 & 0.10 & 20.01 & 0.06 & 0.06 & 0.29 & no \\
\hline 63 & 0 & -1 & 6.99 & 0.25 & 18 & 0.10 & 4.71 & 0.06 & 0.06 & 0.40 & yes \\
\hline 63 & 0 & 1 & 7.07 & 0.26 & 22 & 3.36 & 2.18 & 0.06 & 0.06 & 0.35 & no \\
\hline 63 & -1 & 0 & $\ldots$ & $\ldots$ & $\ldots$ & $\ldots$ & $\ldots$ & 0.06 & $\ldots$ & $\ldots$ & $\ldots$ \\
\hline 63 & 1 & 0 & $\ldots$ & $\ldots$ & $\ldots$ & $\ldots$ & $\ldots$ & 0.07 & $\ldots$ & $\ldots$ & $\ldots$ \\
\hline 64 & 0 & 0 & $\ldots$ & $\cdots$ & $\ldots$ & $\ldots$ & $\ldots$ & 0.13 & $\ldots$ & $\cdots$ & $\ldots$ \\
\hline 64 & 0 & -1 & $\ldots$ & $\ldots$ & $\ldots$ & $\ldots$ & $\ldots$ & 0.11 & $\ldots$ & $\ldots$ & $\ldots$ \\
\hline 64 & 0 & 1 & $\ldots$ & $\ldots$ & $\ldots$ & $\ldots$ & $\ldots$ & 0.12 & $\ldots$ & $\ldots$ & $\ldots$ \\
\hline 64 & -1 & 0 & $\ldots$ & $\ldots$ & $\ldots$ & $\ldots$ & $\ldots$ & 0.11 & $\ldots$ & $\ldots$ & $\ldots$ \\
\hline 64 & 1 & 0 & $\ldots$ & $\ldots$ & $\ldots$ & $\ldots$ & $\ldots$ & 0.06 & $\ldots$ & $\ldots$ & $\ldots$ \\
\hline 65 & 0 & 0 & $\ldots$ & $\ldots$ & $\ldots$ & $\ldots$ & $\ldots$ & 0.13 & $\ldots$ & $\ldots$ & $\ldots$ \\
\hline 65 & 0 & -1 & $\ldots$ & $\ldots$ & $\ldots$ & $\ldots$ & $\ldots$ & 0.12 & $\ldots$ & $\ldots$ & $\ldots$ \\
\hline 65 & 0 & 1 & $\ldots$ & $\ldots$ & $\ldots$ & $\ldots$ & $\ldots$ & 0.13 & $\ldots$ & $\ldots$ & $\ldots$ \\
\hline 65 & -1 & 0 & $\ldots$ & $\ldots$ & $\ldots$ & $\ldots$ & $\ldots$ & 0.13 & $\ldots$ & $\ldots$ & $\ldots$ \\
\hline 65 & 1 & 0 & $\ldots$ & $\ldots$ & $\ldots$ & $\ldots$ & $\ldots$ & 0.13 & $\ldots$ & $\ldots$ & $\ldots$ \\
\hline 66 & 0 & 0 & $\ldots$ & $\ldots$ & $\ldots$ & $\ldots$ & $\ldots$ & 0.13 & $\ldots$ & $\ldots$ & $\ldots$ \\
\hline 67 & 0 & 0 & 6.23 & 0.37 & 24 & 0.10 & 0.52 & 0.13 & 0.11 & 0.84 & yes \\
\hline 67 & 0 & -1 & $\ldots$ & $\ldots$ & $\ldots$ & $\ldots$ & $\ldots$ & 0.15 & $\ldots$ & $\ldots$ & $\ldots$ \\
\hline
\end{tabular}


TABLE 3-Continued

\begin{tabular}{|c|c|c|c|c|c|c|c|c|c|c|c|}
\hline$\#^{\mathrm{a}}$ & $\begin{array}{l}\mathrm{RA}^{\mathrm{b}} \\
\text { offset }\end{array}$ & $\begin{array}{l}\operatorname{dec}^{b} \\
\text { offset }\end{array}$ & $\begin{array}{r}V_{C}{ }^{\mathrm{c}, d} \\
\left(\mathrm{~km} \mathrm{~s}^{-1}\right)\end{array}$ & $\begin{array}{c}\Delta V^{\mathrm{c}} \\
\left(\mathrm{km} \mathrm{s}^{-1}\right)\end{array}$ & $\begin{array}{c}\text { error }^{\mathrm{c}} \\
\left(\mathrm{m} \mathrm{s}^{-1}\right)\end{array}$ & $\begin{array}{l}\text { optical }^{\mathrm{c}} \\
\text { depth }\end{array}$ & error $^{c}$ & $\begin{array}{c}\mathrm{rms}^{\mathrm{c}} \\
\operatorname{base}(\mathrm{K})\end{array}$ & $\begin{array}{r}\mathrm{rms}^{\mathrm{c}} \\
\mathrm{fit}(\mathrm{K})\end{array}$ & $\left(\mathrm{K} \mathrm{km} \mathrm{s}^{-1}\right)$ & $\begin{array}{c}\text { secure }^{\mathrm{f}} \\
\text { fit? }\end{array}$ \\
\hline 67 & 0 & 1 & 6.32 & 0.27 & 13 & 0.10 & 1.78 & 0.13 & 0.12 & 1.15 & yes \\
\hline 67 & -1 & 0 & 6.39 & 0.42 & 52 & 0.10 & 2.66 & 0.14 & 0.13 & 0.85 & no \\
\hline 67 & 1 & 0 & 6.22 & 0.34 & 17 & 1.22 & 1.26 & 0.14 & 0.13 & 1.82 & yes \\
\hline 68 & 0 & 0 & 6.92 & 0.55 & 8 & 0.19 & 0.01 & 0.11 & 0.15 & 4.25 & yes \\
\hline 69 & 0 & 0 & $\ldots$ & $\ldots$ & $\ldots$ & $\ldots$ & $\ldots$ & 0.12 & $\ldots$ & $\ldots$ & $\ldots$ \\
\hline 70 & 0 & 0 & $\ldots$ & $\ldots$ & $\ldots$ & $\ldots$ & $\ldots$ & 0.09 & $\ldots$ & $\ldots$ & $\ldots$ \\
\hline 71 & 0 & 0 & 6.66 & 0.87 & 8 & 8.07 & 0.23 & 0.11 & 0.19 & 14.06 & yes \\
\hline 72 & 0 & 0 & 6.27 & 0.76 & 6 & 5.93 & 0.20 & 0.11 & 0.21 & 13.39 & yes \\
\hline 72 & 0 & -1 & 6.55 & 0.56 & 8 & 8.79 & 0.50 & 0.12 & 0.16 & 7.32 & yes \\
\hline 72 & 0 & 1 & 6.05 & 0.63 & 9 & 5.34 & 0.35 & 0.13 & 0.16 & 8.00 & yes \\
\hline 72 & -1 & 0 & 6.29 & 0.77 & 15 & 1.75 & 0.39 & 0.12 & 0.14 & 5.79 & yes \\
\hline 72 & 1 & 0 & 6.21 & 0.72 & 14 & 4.70 & 0.44 & 0.12 & 0.19 & 6.51 & yes \\
\hline 73 & 0 & 0 & 6.43 & 0.56 & 3 & 13.04 & 0.09 & 0.11 & 0.19 & 10.68 & yes \\
\hline 74 & 0 & 0 & 6.84 & 0.32 & 4 & 9.10 & 0.46 & 0.10 & 0.17 & 4.53 & yes \\
\hline 74 & 0 & -1 & 6.77 & 0.34 & 7 & 0.26 & 0.01 & 0.12 & 0.17 & 2.92 & yes \\
\hline 74 & 0 & 1 & 6.88 & 0.38 & 8 & 4.99 & 0.73 & 0.12 & 0.16 & 3.47 & yes \\
\hline 74 & -1 & 0 & 6.79 & 0.35 & 7 & 4.71 & 0.64 & 0.12 & 0.15 & 3.74 & yes \\
\hline 74 & 1 & 0 & 6.76 & 0.33 & 30 & 4.14 & 3.06 & 0.13 & 0.13 & 1.01 & no \\
\hline 75 & 0 & 0 & 6.63 & 0.44 & 5 & 12.25 & 0.68 & 0.10 & 0.20 & 6.17 & yes \\
\hline 75 & 0 & -1 & 6.65 & 0.35 & 9 & 4.97 & 0.81 & 0.12 & 0.12 & 2.91 & yes \\
\hline 75 & 0 & 1 & 6.57 & 0.49 & 9 & 7.39 & 0.73 & 0.12 & 0.22 & 4.88 & yes \\
\hline 75 & -1 & 0 & 6.59 & 0.42 & 4 & 13.48 & 0.18 & 0.12 & 0.20 & 5.90 & yes \\
\hline 75 & 1 & 0 & 6.64 & 0.32 & 5 & 6.12 & 0.59 & 0.12 & 0.18 & 4.69 & yes \\
\hline 76 & 0 & 0 & 6.51 & 0.49 & 37 & 9.05 & 3.49 & 0.13 & 0.14 & 1.58 & yes \\
\hline 76 & 0 & -1 & 6.74 & 0.28 & 19 & 0.10 & 0.17 & 0.13 & 0.15 & 1.63 & no \\
\hline 76 & 0 & -1 & 6.22 & 0.34 & 35 & 1.89 & 0.82 & 0.13 & 0.15 & 1.63 & no \\
\hline 76 & 0 & 1 & $\ldots$ & $\ldots$ & $\ldots$ & $\ldots$ & $\ldots$ & 0.14 & $\ldots$ & $\ldots$ & $\ldots$ \\
\hline 76 & -1 & 0 & 6.50 & 0.67 & 65 & 0.10 & 1.08 & 0.13 & 0.12 & 0.80 & no \\
\hline 76 & 1 & 0 & 6.66 & 0.44 & 25 & 2.43 & 1.39 & 0.13 & 0.13 & 1.70 & yes \\
\hline 77 & 0 & 0 & 6.64 & 0.32 & 6 & 7.72 & 0.72 & 0.13 & 0.20 & 4.30 & yes \\
\hline 77 & 0 & -1 & 6.65 & 0.31 & 7 & 10.65 & 1.02 & 0.13 & 0.18 & 3.36 & yes \\
\hline 77 & 0 & 1 & 6.62 & 0.28 & 6 & 4.98 & 0.72 & 0.13 & 0.14 & 2.89 & yes \\
\hline 77 & -1 & 0 & 6.68 & 0.26 & 6 & 9.73 & 1.05 & 0.13 & 0.13 & 2.91 & yes \\
\hline 77 & 1 & 0 & 6.62 & 0.39 & 8 & 9.22 & 0.91 & 0.13 & 0.16 & 4.03 & yes \\
\hline 78 & 0 & 0 & 6.67 & 0.27 & 22 & 4.31 & 1.73 & 0.13 & 0.13 & 0.99 & no \\
\hline 78 & 0 & -1 & 6.70 & 0.25 & 26 & 0.10 & 3.48 & 0.13 & 0.15 & 0.81 & no \\
\hline 78 & 0 & 1 & 6.58 & 0.32 & 105 & 1.03 & 0.10 & 0.12 & 0.13 & 1.46 & yes \\
\hline 78 & -1 & 0 & 6.57 & 0.43 & 24 & 2.72 & 1.23 & 0.12 & 0.13 & 1.39 & yes \\
\hline 78 & 1 & 0 & $\ldots$ & $\ldots$ & $\ldots$ & $\ldots$ & $\ldots$ & 0.14 & $\ldots$ & $\ldots$ & $\ldots$ \\
\hline 79 & 0 & 0 & 6.82 & 0.38 & 9 & 9.65 & 1.05 & 0.13 & 0.17 & 4.04 & yes \\
\hline 79 & 0 & -1 & 6.84 & 0.41 & 8 & 13.79 & 1.29 & 0.09 & 0.13 & 2.93 & yes \\
\hline 79 & 0 & 1 & 6.79 & 0.34 & 9 & 6.16 & 0.94 & 0.10 & 0.12 & 2.45 & yes \\
\hline 79 & -1 & 0 & 6.59 & 0.42 & 14 & 5.08 & 0.92 & 0.09 & 0.09 & 1.11 & yes \\
\hline 79 & 1 & 0 & 6.80 & 0.29 & 5 & 9.17 & 0.74 & 0.10 & 0.13 & 3.23 & yes \\
\hline 80 & 0 & 0 & $\ldots$ & $\ldots$ & $\ldots$ & $\ldots$ & $\ldots$ & 0.14 & $\ldots$ & $\ldots$ & $\ldots$ \\
\hline 80 & 0 & -1 & 6.10 & 0.32 & $\ddot{24}$ & 0.10 & 1.09 & 0.13 & 0.14 & 0.88 & no \\
\hline 80 & 0 & 1 & $\ldots$ & $\ldots$ & $\ldots$ & $\ldots$ & $\ldots$ & 0.13 & $\ldots$ & $\ldots$ & $\ldots$ \\
\hline 80 & -1 & 0 & 6.24 & 0.33 & 33 & 4.86 & 2.88 & 0.12 & 0.12 & 0.99 & yes \\
\hline 80 & 1 & 0 & 6.99 & 0.31 & 26 & 0.95 & 2.13 & 0.13 & 0.13 & 1.08 & no \\
\hline 81 & 0 & 0 & $\ldots$ & $\ldots$ & $\ldots$ & $\ldots$ & $\ldots$ & 0.14 & $\ldots$ & $\ldots$ & $\ldots$ \\
\hline 82 & 0 & 0 & $\ldots$ & $\ldots$ & $\ldots$ & $\ldots$ & $\ldots$ & 0.08 & $\ldots$ & $\ldots$ & $\ldots$ \\
\hline 83 & 0 & 0 & $\ldots$ & $\ldots$ & $\ldots$ & $\ldots$ & $\ldots$ & 0.14 & $\ldots$ & $\ldots$ & $\ldots$ \\
\hline 83 & 0 & -1 & $\ldots$ & $\ldots$ & $\ldots$ & $\ldots$ & $\ldots$ & 0.12 & $\ldots$ & $\ldots$ & $\ldots$ \\
\hline 83 & 0 & 1 & 6.60 & 0.32 & 105 & 0.87 & 0.10 & 0.13 & 0.12 & 0.42 & no \\
\hline 83 & -1 & 0 & $\ldots$ & $\ldots$ & $\ldots$ & $\ldots$ & $\ldots$ & 0.13 & $\ldots$ & $\ldots$ & $\ldots$ \\
\hline 83 & 1 & 0 & 6.56 & 0.31 & 15 & 0.10 & 2.79 & 0.13 & 0.12 & 1.17 & yes \\
\hline 84 & 0 & 0 & 6.61 & 0.30 & 6 & 0.10 & 0.45 & 0.13 & 0.11 & 1.57 & yes \\
\hline 84 & 0 & -1 & 6.65 & 0.27 & 7 & 4.61 & 0.72 & 0.14 & 0.19 & 3.11 & yes \\
\hline
\end{tabular}


TABLE 3-Continued

\begin{tabular}{|c|c|c|c|c|c|c|c|c|c|c|c|}
\hline$\#^{\mathrm{a}}$ & $\begin{array}{l}\mathrm{RA}^{\mathrm{b}} \\
\text { offset }\end{array}$ & $\begin{array}{l}\operatorname{dec}^{b} \\
\text { offset }\end{array}$ & $\begin{array}{c}V_{C}^{\mathrm{c}, d} \\
\left(\mathrm{~km} \mathrm{~s}^{-1}\right)\end{array}$ & $\begin{array}{c}\Delta V^{\mathrm{c}} \\
\left(\mathrm{km} \mathrm{s}^{-1}\right)\end{array}$ & $\begin{array}{c}\text { error }^{\mathrm{c}} \\
\left(\mathrm{m} \mathrm{s}^{-1}\right)\end{array}$ & $\begin{array}{l}\text { optical }^{\mathrm{c}} \\
\text { depth }\end{array}$ & error $^{\mathrm{c}}$ & $\begin{array}{c}\mathrm{rms}^{\mathrm{c}} \\
\operatorname{base}(\mathrm{K})\end{array}$ & $\begin{array}{r}\mathrm{rms}^{\mathrm{c}} \\
\mathrm{fit}(\mathrm{K})\end{array}$ & $\underset{\left(\mathrm{K} \mathrm{km} \mathrm{s}^{-1}\right)}{\int \mathrm{I}^{\mathrm{e}}}$ & $\begin{array}{c}\text { secure }^{f} \\
\text { fit? }\end{array}$ \\
\hline 84 & 0 & 1 & $\ldots$ & $\ldots$ & $\ldots$ & $\ldots$ & $\ldots$ & 0.12 & $\ldots$ & $\ldots$ & $\ldots$ \\
\hline 84 & -1 & 0 & $\ldots$ & $\ldots$ & $\ldots$ & $\ldots$ & $\ldots$ & 0.13 & $\ldots$ & $\ldots$ & $\ldots$ \\
\hline 84 & 1 & 0 & $\ldots$ & $\ldots$ & $\ldots$ & $\ldots$ & $\ldots$ & 0.14 & $\cdots$ & $\ldots$ & $\ldots$ \\
\hline 85 & 0 & 0 & 6.41 & 0.41 & 6 & 14.60 & 0.32 & 0.12 & 0.15 & 3.37 & yes \\
\hline 85 & 0 & -1 & 6.43 & 0.39 & 8 & 13.14 & 0.39 & 0.13 & 0.15 & 2.67 & yes \\
\hline 85 & 0 & 1 & 6.33 & 0.51 & 47 & 5.89 & 3.33 & 0.13 & 0.14 & 0.71 & no \\
\hline 85 & -1 & 0 & 6.43 & 0.39 & 20 & 3.82 & 1.67 & 0.13 & 0.14 & 1.29 & yes \\
\hline 85 & 1 & 0 & 6.44 & 0.39 & 5 & 15.56 & 0.35 & 0.13 & 0.18 & 3.91 & yes \\
\hline 86 & 0 & 0 & 6.90 & 0.60 & 5 & 5.35 & 0.25 & 0.11 & 0.16 & 9.62 & yes \\
\hline 86 & 0 & -1 & 6.89 & 0.44 & 8 & 5.08 & 0.51 & 0.12 & 0.17 & 5.05 & yes \\
\hline 86 & 0 & 1 & 7.01 & 0.56 & 16 & 3.27 & 0.76 & 0.13 & 0.14 & 3.72 & yes \\
\hline 86 & -1 & 0 & 6.78 & 0.52 & 5 & 8.14 & 0.37 & 0.12 & 0.18 & 9.05 & yes \\
\hline 86 & 1 & 0 & 6.91 & 0.58 & 21 & 1.76 & 0.85 & 0.13 & 0.13 & 2.91 & yes \\
\hline 87 & 0 & 0 & 5.90 & 0.31 & 24 & 7.13 & 2.86 & 0.13 & 0.14 & 1.10 & no \\
\hline 87 & 0 & -1 & 5.77 & 0.34 & 26 & 0.10 & 0.94 & 0.12 & 0.13 & 0.68 & no \\
\hline 87 & 0 & 1 & $\ldots$ & $\ldots$ & $\ldots$ & $\ldots$ & $\ldots$ & 0.13 & $\ldots$ & $\ldots$ & $\ldots$ \\
\hline 87 & -1 & 0 & $\cdots$ & $\cdots$ & $\cdots$ & $\cdots$ & $\cdots$ & 0.14 & $\cdots$ & $\begin{array}{l}\cdots \\
\ldots\end{array}$ & $\cdots$ \\
\hline 87 & 1 & 0 & 5.88 & 0.21 & 13 & 8.10 & 2.35 & 0.12 & 0.12 & 0.94 & yes \\
\hline 88 & 0 & 0 & $\ldots$ & $\ldots$ & $\ldots$ & $\ldots$ & $\ldots$ & 0.14 & $\ldots$ & $\ldots$ & $\ldots$ \\
\hline 89 & 0 & 0 & $\ldots$ & $\ldots$ & $\ldots$ & $\ldots$ & $\ldots$ & 0.11 & $\ldots$ & $\ldots$ & $\ldots$ \\
\hline 90 & 0 & 0 & 6.93 & 0.38 & 4 & 5.65 & 0.31 & 0.11 & 0.18 & 7.75 & yes \\
\hline 90 & 0 & -1 & 6.76 & 0.42 & 2 & 0.26 & 0.07 & 0.12 & 0.12 & 3.17 & yes \\
\hline 90 & 0 & 1 & 6.96 & 0.44 & 8 & 4.06 & 0.47 & 0.12 & 0.16 & 5.94 & yes \\
\hline 90 & -1 & 0 & 7.01 & 0.60 & 12 & 2.06 & 0.45 & 0.12 & 0.16 & 4.60 & yes \\
\hline 90 & 1 & 0 & 6.97 & 0.31 & 14 & 3.78 & 1.29 & 0.12 & 0.12 & 1.64 & yes \\
\hline 91 & 0 & 0 & 7.83 & 0.37 & 11 & 8.17 & 1.17 & 0.14 & 0.15 & 3.19 & yes \\
\hline 91 & 0 & -1 & 7.72 & 0.47 & 15 & 0.29 & 0.13 & 0.12 & 0.13 & 2.15 & yes \\
\hline 91 & 0 & 1 & 7.84 & 0.37 & 1 & 0.12 & 0.00 & 0.13 & 0.13 & 1.70 & yes \\
\hline 91 & -1 & 0 & 7.72 & 0.44 & 16 & 4.72 & 1.17 & 0.12 & 0.13 & 2.44 & yes \\
\hline 91 & 1 & 0 & 7.86 & 0.37 & 22 & 2.63 & 1.46 & 0.12 & 0.11 & 1.54 & yes \\
\hline 92 & 0 & 0 & 6.08 & 0.37 & 3 & 13.96 & 0.17 & 0.13 & 0.21 & 6.05 & yes \\
\hline 92 & 0 & -1 & 6.00 & 0.36 & 7 & 3.60 & 0.62 & 0.12 & 0.18 & 3.57 & yes \\
\hline 92 & 0 & 1 & 6.06 & 0.37 & 8 & 4.67 & 0.71 & 0.13 & 0.14 & 3.71 & yes \\
\hline 92 & -1 & 0 & 5.95 & 0.46 & 8 & 5.79 & 0.69 & 0.12 & 0.18 & 4.10 & yes \\
\hline 92 & 1 & 0 & 6.13 & 0.31 & 6 & 9.53 & 0.85 & 0.13 & 0.19 & 4.46 & yes \\
\hline 93 & 0 & 0 & 5.94 & 0.57 & 48 & 0.10 & 0.81 & 0.08 & 0.08 & 0.44 & no \\
\hline 94 & 0 & 0 & 5.90 & 0.38 & 8 & 2.51 & 0.50 & 0.13 & 0.20 & 4.71 & yes \\
\hline 94 & 0 & -1 & 5.79 & 0.30 & 5 & 5.11 & 0.51 & 0.13 & 0.16 & 4.60 & yes \\
\hline 94 & 0 & 1 & 5.94 & 0.25 & 6 & 2.21 & 0.60 & 0.13 & 0.15 & 3.21 & yes \\
\hline 94 & -1 & 0 & 5.76 & 0.34 & 15 & 1.50 & 1.23 & 0.12 & 0.12 & 1.46 & yes \\
\hline 94 & 1 & 0 & 5.95 & 0.33 & 6 & 3.03 & 0.48 & 0.13 & 0.18 & 4.26 & yes \\
\hline 95 & 0 & 0 & 8.15 & 0.35 & 4 & 7.30 & 0.43 & 0.11 & 0.24 & 6.28 & yes \\
\hline 95 & 0 & -1 & 8.17 & 0.24 & 4 & 5.25 & 0.57 & 0.12 & 0.17 & 3.35 & yes \\
\hline 95 & 0 & 1 & 8.23 & 0.27 & 5 & 3.26 & 0.52 & 0.12 & 0.14 & 3.86 & yes \\
\hline 95 & -1 & 0 & 8.16 & 0.38 & 8 & 3.57 & 0.59 & 0.12 & 0.21 & 4.25 & yes \\
\hline 95 & 1 & 0 & 8.16 & 0.32 & 0 & 0.12 & 0.00 & 0.12 & 0.16 & 3.63 & $\begin{array}{l}\text { yes } \\
\text { yes }\end{array}$ \\
\hline 96 & 0 & 0 & 7.54 & 0.49 & 6 & 7.27 & 0.50 & 0.10 & 0.22 & 5.62 & $\begin{array}{l}\text { yes } \\
\text { yes }\end{array}$ \\
\hline 97 & 0 & 0 & 7.50 & 0.30 & 3 & 7.27 & 0.41 & 0.11 & 0.15 & 5.92 & yes \\
\hline 97 & 0 & -1 & 7.51 & 0.30 & 13 & 5.69 & 1.38 & 0.12 & 0.13 & 1.79 & yes \\
\hline 97 & 0 & 1 & 7.54 & 0.30 & 4 & 3.04 & 0.38 & 0.12 & 0.16 & 3.36 & yes \\
\hline 97 & -1 & 0 & 7.49 & 0.29 & 5 & 4.46 & 0.50 & 0.12 & 0.13 & 3.53 & yes \\
\hline 97 & 1 & 0 & 7.45 & 0.31 & 5 & 7.32 & 0.63 & 0.12 & 0.14 & 4.20 & yes \\
\hline 98 & 0 & 0 & 7.47 & 0.40 & 9 & 3.78 & 0.62 & 0.10 & 0.14 & 2.73 & yes \\
\hline 99 & 0 & 0 & 7.54 & 0.17 & 16 & 10.79 & 4.34 & 0.10 & 0.12 & 3.36 & yes \\
\hline 99 & 0 & 0 & 6.91 & 0.42 & 6 & 3.22 & 0.18 & 0.10 & 0.12 & 3.36 & yes \\
\hline 99 & 0 & -1 & $\ldots$ & $\ldots$ & $\ldots$ & $\ldots$ & $\ldots$ & 0.13 & $\ldots$ & $\ldots$ & $\ldots$ \\
\hline 99 & 0 & 1 & 7.12 & 0.50 & 25 & 3.21 & 0.40 & 0.12 & 0.11 & 4.01 & yes \\
\hline 99 & 0 & 1 & 7.50 & 0.24 & 7 & 0.10 & 3.18 & 0.12 & 0.11 & 4.01 & yes \\
\hline
\end{tabular}


TABle 3-Continued

\begin{tabular}{|c|c|c|c|c|c|c|c|c|c|c|c|}
\hline$\#^{\mathrm{a}}$ & $\begin{array}{l}\mathrm{RA}^{\mathrm{b}} \\
\text { offset }\end{array}$ & $\begin{array}{l}\operatorname{dec}^{b} \\
\text { offset }\end{array}$ & $\begin{array}{r}V_{C}^{\mathrm{c}, d} \\
\left(\mathrm{~km} \mathrm{~s}^{-1}\right)\end{array}$ & $\begin{array}{c}\Delta V^{\mathrm{c}} \\
\left(\mathrm{km} \mathrm{s}^{-1}\right)\end{array}$ & $\begin{array}{c}\text { error }^{\mathrm{c}} \\
\left(\mathrm{m} \mathrm{s}^{-1}\right)\end{array}$ & $\begin{array}{l}\text { optical }^{\mathrm{c}} \\
\text { depth }\end{array}$ & error $^{c}$ & $\begin{array}{c}\mathrm{rms}^{\mathrm{c}} \\
\operatorname{base}(\mathrm{K})\end{array}$ & $\begin{array}{r}r m s^{c} \\
f i t(K)\end{array}$ & $\underset{\left(\mathrm{K} \mathrm{km} \mathrm{s}^{-1}\right)}{\int \mathrm{I}^{\mathrm{e}}}$ & $\begin{array}{c}\text { secure }^{\mathrm{f}} \\
\text { fit? }\end{array}$ \\
\hline 99 & -1 & 0 & 7.01 & 0.30 & 18 & 1.58 & 1.51 & 0.11 & 0.13 & 1.21 & yes \\
\hline 99 & 1 & 0 & 7.23 & 1.22 & 165 & 0.10 & 1.41 & 0.12 & 0.11 & 1.02 & no \\
\hline 100 & 0 & 0 & 7.52 & 0.32 & 4 & 4.40 & 0.38 & 0.11 & 0.13 & 5.33 & yes \\
\hline 101 & 0 & 0 & 8.21 & 0.86 & 21 & 0.10 & 0.15 & 0.09 & 0.11 & 2.47 & yes \\
\hline 102 & 0 & 0 & 7.84 & 0.60 & 5 & 5.44 & 0.25 & 0.11 & 0.15 & 10.15 & yes \\
\hline 103 & 0 & 0 & 7.15 & 1.25 & 36 & 2.27 & 0.37 & 0.11 & 0.12 & 7.93 & yes \\
\hline 103 & 0 & 0 & 6.79 & 0.54 & 32 & 1.37 & 0.01 & 0.11 & 0.12 & 7.93 & yes \\
\hline 104 & 0 & 0 & 8.59 & 0.53 & 5 & 4.34 & 0.24 & 0.11 & 0.21 & 10.40 & yes \\
\hline 105 & 0 & 0 & $\ldots$ & $\ldots$ & $\ldots$ & $\ldots$ & $\ldots$ & 0.11 & $\ldots$ & $\ldots$ & $\ldots$ \\
\hline 106 & 0 & 0 & 7.49 & 0.97 & 4 & 5.59 & 0.01 & 0.05 & 0.09 & 11.37 & yes \\
\hline 106 & 0 & 0 & 6.73 & 0.70 & 8 & 1.82 & 0.20 & 0.05 & 0.09 & 11.37 & yes \\
\hline 106 & 0 & -1 & 7.59 & 0.92 & 105 & 0.19 & 0.10 & 0.12 & 0.13 & 3.84 & yes \\
\hline 106 & 0 & -1 & 6.73 & 0.55 & 105 & 1.70 & 0.10 & 0.12 & 0.13 & 3.84 & yes \\
\hline 106 & 0 & 1 & 7.81 & 0.60 & 12 & 8.71 & 0.50 & 0.13 & 0.17 & 12.99 & yes \\
\hline 106 & 0 & 1 & 6.94 & 0.70 & 18 & 3.56 & 0.52 & 0.13 & 0.17 & 12.99 & yes \\
\hline 106 & -1 & 0 & 7.71 & 0.52 & 7 & 5.28 & 0.01 & 0.12 & 0.14 & 5.80 & yes \\
\hline 106 & -1 & 0 & 6.55 & 0.51 & 1 & 0.10 & 0.00 & 0.12 & 0.14 & 5.80 & yes \\
\hline 106 & 1 & 0 & 6.93 & 0.75 & 105 & 1.97 & 0.10 & 0.12 & 0.15 & 12.49 & yes \\
\hline 106 & 1 & 0 & 7.75 & 0.59 & 105 & 6.98 & 0.10 & 0.12 & 0.15 & 12.49 & yes \\
\hline 107 & 0 & 0 & 7.93 & 0.74 & 6 & 5.11 & 0.07 & 0.11 & 0.20 & 16.10 & yes \\
\hline 107 & 0 & 0 & 7.24 & 0.31 & 7 & 19.08 & 1.05 & 0.11 & 0.20 & 16.10 & yes \\
\hline 108 & 0 & 0 & $\ldots$ & $\ldots$ & $\ldots$ & $\ldots$ & $\ldots$ & 0.11 & $\ldots$ & $\ldots$ & $\ldots$ \\
\hline 109 & 0 & 0 & 8.48 & 0.53 & 7 & 2.97 & 0.31 & 0.11 & 0.18 & 6.48 & yes \\
\hline 110 & 0 & 0 & 7.97 & 0.91 & 7 & 2.40 & 0.13 & 0.12 & 0.22 & 16.60 & yes \\
\hline 111 & 0 & 0 & 6.82 & 0.80 & 105 & 2.28 & 0.10 & 0.10 & 0.16 & 17.67 & yes \\
\hline 111 & 0 & 0 & 7.74 & 0.86 & 105 & 5.10 & 0.10 & 0.10 & 0.16 & 17.67 & yes \\
\hline 112 & 0 & 0 & 8.40 & 0.68 & 4 & 4.66 & 0.14 & 0.12 & 0.17 & 18.46 & yes \\
\hline 113 & 0 & 0 & 7.97 & 0.60 & 5 & 4.87 & 0.20 & 0.11 & 0.18 & 11.84 & yes \\
\hline 114 & 0 & 0 & $\ldots$ & $\ldots$ & $\ldots$ & $\ldots$ & $\ldots$ & 0.09 & $\ldots$ & $\ldots$ & $\ldots$ \\
\hline 115 & 0 & 0 & 7.16 & 0.64 & $\dddot{7}$ & 3.54 & 0.26 & 0.11 & 0.19 & 8.50 & $\begin{array}{c}\cdots \\
\text { yes }\end{array}$ \\
\hline 116 & 0 & 0 & 7.83 & 0.77 & 9 & 2.18 & 0.23 & 0.12 & 0.14 & 9.89 & yes \\
\hline 117 & 0 & 0 & $\ldots$ & $\ldots$ & $\ldots$ & $\ldots$ & $\ldots$ & 0.12 & $\ldots$ & $\ldots$ & $\ldots$ \\
\hline 118 & 0 & 0 & 7.34 & 0.58 & 9 & 4.26 & 0.36 & 0.11 & 0.15 & 12.37 & yes \\
\hline 118 & 0 & 0 & 7.74 & 1.06 & 17 & 6.49 & 0.18 & 0.11 & 0.15 & 12.37 & yes \\
\hline 118 & 0 & -1 & 7.22 & 0.39 & 3 & 3.93 & 0.24 & 0.13 & 0.26 & 9.29 & yes \\
\hline 118 & 0 & 1 & 7.39 & 0.74 & 11 & 5.74 & 0.23 & 0.12 & 0.16 & 12.16 & yes \\
\hline 118 & 0 & 1 & 8.20 & 0.74 & 37 & 7.43 & 0.41 & 0.12 & 0.16 & 12.16 & yes \\
\hline 118 & -1 & 0 & 7.66 & 0.78 & 14 & 5.10 & 0.38 & 0.12 & 0.15 & 8.37 & yes \\
\hline 118 & 1 & 0 & 7.17 & 0.58 & 17 & 3.77 & 0.39 & 0.12 & 0.12 & 5.02 & yes \\
\hline 118 & 1 & 0 & 8.11 & 0.58 & 31 & 8.42 & 1.53 & 0.12 & 0.12 & 5.02 & yes \\
\hline 119 & 0 & 0 & $\ldots$ & $\ldots$ & $\ldots$ & $\ldots$ & $\ldots$ & 0.08 & $\ldots$ & $\ldots$ & $\ldots$ \\
\hline 120 & 0 & 0 & $\ldots$ & $\ldots$ & $\ldots$ & $\ldots$ & $\ldots$ & 0.11 & $\ldots$ & $\ldots$ & $\ldots$ \\
\hline 121 & 0 & 0 & 7.22 & 0.38 & 4 & 6.22 & 0.36 & 0.10 & 0.14 & 6.03 & yes \\
\hline 122 & 0 & 0 & 7.98 & 0.53 & 4 & 7.49 & 0.27 & 0.10 & 0.18 & 10.32 & yes \\
\hline 123 & 0 & 0 & 8.19 & 0.48 & 4 & 10.59 & 0.37 & 0.10 & 0.19 & 9.12 & yes \\
\hline 124 & 0 & 0 & 7.04 & 0.34 & 4 & 7.05 & 0.40 & 0.11 & 0.17 & 6.34 & yes \\
\hline 125 & 0 & 0 & 7.28 & 0.50 & 105 & 0.10 & 0.10 & 0.10 & 0.21 & 5.76 & yes \\
\hline 125 & 0 & -1 & 7.29 & 0.46 & 19 & 0.62 & 1.03 & 0.11 & 0.13 & 1.80 & yes \\
\hline 125 & 0 & 1 & 7.25 & 0.44 & 9 & 0.10 & 0.63 & 0.12 & 0.12 & 1.91 & yes \\
\hline 125 & -1 & 0 & 7.39 & 0.47 & 7 & 9.14 & 0.63 & 0.12 & 0.17 & 6.26 & yes \\
\hline 125 & 1 & 0 & 7.36 & 0.39 & 40 & 1.04 & 2.45 & 0.12 & 0.12 & 0.67 & no \\
\hline 126 & 0 & 0 & 6.84 & 0.31 & 7 & 3.37 & 0.57 & 0.11 & 0.12 & 3.53 & yes \\
\hline 127 & 0 & 0 & 5.54 & 0.32 & 11 & 1.89 & 0.95 & 0.12 & 0.12 & 1.77 & yes \\
\hline 127 & 0 & -1 & 5.47 & 0.26 & 13 & 0.10 & 1.27 & 0.12 & 0.11 & 0.84 & yes \\
\hline 127 & 0 & 1 & 5.51 & 0.37 & 10 & 0.97 & 0.79 & 0.12 & 0.14 & 2.31 & yes \\
\hline 127 & -1 & 0 & 5.57 & 0.22 & 19 & 3.51 & 2.84 & 0.17 & 0.16 & 0.92 & no \\
\hline 127 & 1 & 0 & 5.44 & 0.29 & 12 & 3.67 & 1.23 & 0.12 & 0.13 & 1.42 & yes \\
\hline 128 & 0 & 0 & 7.21 & 0.38 & 5 & 6.69 & 0.51 & 0.11 & 0.14 & 4.79 & yes \\
\hline
\end{tabular}


TABle 3-Continued

\begin{tabular}{|c|c|c|c|c|c|c|c|c|c|c|c|}
\hline$\#^{\mathrm{a}}$ & $\begin{array}{l}\mathrm{RA}^{\mathrm{b}} \\
\text { offset }\end{array}$ & $\begin{array}{l}\operatorname{dec}^{b} \\
\text { offset }\end{array}$ & $\begin{array}{r}V_{C}^{\mathrm{c}, d} \\
\left(\mathrm{~km} \mathrm{~s}^{-1}\right)\end{array}$ & $\begin{array}{c}\Delta V^{\mathrm{c}} \\
\left(\mathrm{km} \mathrm{s}^{-1}\right)\end{array}$ & $\begin{array}{c}\text { error }^{\mathrm{c}} \\
\left(\mathrm{m} \mathrm{s}^{-1}\right)\end{array}$ & $\begin{array}{l}\text { optical }^{\mathrm{c}} \\
\text { depth }\end{array}$ & error $^{c}$ & $\begin{array}{c}\mathrm{rms}^{\mathrm{c}} \\
\operatorname{base}(\mathrm{K})\end{array}$ & $\begin{array}{r}r m s^{c} \\
f i t(K)\end{array}$ & $\underset{\left(\mathrm{K} \mathrm{km} \mathrm{s}^{-1}\right)}{\int \mathrm{I}^{\mathrm{e}}}$ & $\begin{array}{c}\text { secure }^{\mathrm{f}} \\
\text { fit? }\end{array}$ \\
\hline 128 & 0 & -1 & 7.23 & 0.44 & 26 & 2.57 & 1.42 & 0.11 & 0.12 & 1.38 & yes \\
\hline 128 & 0 & 1 & 7.25 & 0.39 & 7 & 5.61 & 0.69 & 0.11 & 0.14 & 3.79 & yes \\
\hline 128 & -1 & 0 & 7.26 & 0.29 & 5 & 5.09 & 0.52 & 0.11 & 0.17 & 3.73 & yes \\
\hline 128 & 1 & 0 & 7.13 & 0.31 & 6 & 2.99 & 0.58 & 0.12 & 0.14 & 3.15 & yes \\
\hline 129 & 0 & 0 & 4.56 & 0.30 & 16 & 3.94 & 1.66 & 0.13 & 0.12 & 1.31 & yes \\
\hline 129 & 0 & -1 & 4.78 & 0.40 & 7 & 0.11 & 0.00 & 0.11 & 0.15 & 2.07 & yes \\
\hline 129 & 0 & 1 & 4.63 & 0.28 & 14 & 1.77 & 1.42 & 0.12 & 0.12 & 1.13 & yes \\
\hline 129 & -1 & 0 & 4.86 & 0.45 & 11 & 4.33 & 0.81 & 0.12 & 0.14 & 3.13 & yes \\
\hline 129 & 1 & 0 & 4.50 & 0.30 & 31 & 1.32 & 2.30 & 0.12 & 0.12 & 0.61 & no \\
\hline 130 & 0 & 0 & 4.85 & 0.39 & 26 & 2.77 & 1.73 & 0.13 & 0.12 & 1.39 & yes \\
\hline 130 & 0 & -1 & $\ldots$ & $\ldots$ & $\ldots$ & $\ldots$ & $\ldots$ & 0.14 & $\ldots$ & $\ldots$ & $\ldots$ \\
\hline 130 & 0 & 1 & 4.77 & 0.54 & 68 & 2.05 & 2.26 & 0.13 & 0.15 & 0.83 & no \\
\hline 130 & -1 & 0 & 4.60 & 0.31 & 33 & 1.86 & 3.11 & 0.13 & 0.14 & 0.41 & no \\
\hline 130 & 1 & 0 & 4.90 & 0.28 & 7 & 4.26 & 0.79 & 0.15 & 0.14 & 2.78 & yes \\
\hline 131 & 0 & 0 & 4.78 & 0.25 & 10 & 0.10 & 0.44 & 0.13 & 0.12 & 1.24 & yes \\
\hline 131 & 0 & -1 & 4.90 & 0.29 & 12 & 0.52 & 0.99 & 0.11 & 0.12 & 1.20 & yes \\
\hline 131 & 0 & 1 & 4.72 & 0.19 & 5 & 3.73 & 0.78 & 0.12 & 0.13 & 1.81 & yes \\
\hline 131 & -1 & 0 & 4.85 & 0.21 & 8 & 2.66 & 1.04 & 0.11 & 0.11 & 1.33 & yes \\
\hline 131 & 1 & 0 & 4.78 & 0.31 & 15 & 0.10 & 2.50 & 0.12 & 0.11 & 0.99 & yes \\
\hline 132 & 0 & 0 & 4.77 & 0.67 & 9 & 1.91 & 0.54 & 0.12 & 0.13 & 3.55 & yes \\
\hline 132 & 0 & -1 & 4.77 & 0.52 & 0 & 0.12 & 0.00 & 0.13 & 0.16 & 2.01 & yes \\
\hline 132 & 0 & 1 & 4.88 & 0.71 & 7 & 0.20 & 0.00 & 0.13 & 0.14 & 4.12 & yes \\
\hline 132 & -1 & 0 & 4.74 & 0.58 & 13 & 0.26 & 0.51 & 0.13 & 0.16 & 3.73 & yes \\
\hline 132 & 1 & 0 & 5.00 & 0.61 & 25 & 0.98 & 0.96 & 0.14 & 0.15 & 2.11 & yes \\
\hline 133 & 0 & 0 & 5.06 & 0.55 & 7 & 4.64 & 0.35 & 0.11 & 0.15 & 6.80 & yes \\
\hline 133 & 0 & -1 & 4.81 & 0.61 & 10 & 3.15 & 0.39 & 0.12 & 0.14 & 6.38 & yes \\
\hline 133 & 0 & 1 & 5.11 & 0.73 & 49 & 4.39 & 1.38 & 0.12 & 0.14 & 2.19 & yes \\
\hline 133 & -1 & 0 & 4.85 & 0.64 & 9 & 4.07 & 0.36 & 0.12 & 0.14 & 7.32 & yes \\
\hline 133 & 1 & 0 & 5.11 & 0.57 & 8 & 4.11 & 0.42 & 0.12 & 0.17 & 6.26 & yes \\
\hline 134 & 0 & 0 & 4.87 & 0.48 & 3 & 5.96 & 0.08 & 0.13 & 0.36 & 9.53 & yes \\
\hline 135 & 0 & 0 & 4.72 & 0.62 & 5 & 6.61 & 0.28 & 0.11 & 0.24 & 9.41 & yes \\
\hline 136 & 0 & 0 & 5.94 & 0.51 & 105 & 6.92 & 0.10 & 0.11 & 0.16 & 6.56 & yes \\
\hline 136 & 0 & 0 & 4.64 & 0.56 & 105 & 1.91 & 0.10 & 0.11 & 0.16 & 6.56 & yes \\
\hline 136 & 0 & -1 & 4.87 & 0.64 & 46 & 5.38 & 1.79 & 0.11 & 0.12 & 2.29 & yes \\
\hline 136 & 0 & -1 & 5.98 & 0.19 & 23 & 9.67 & 4.46 & 0.11 & 0.12 & 2.29 & yes \\
\hline 136 & 0 & 1 & 4.59 & 0.65 & 19 & 2.75 & 0.62 & 0.12 & 0.14 & 3.75 & yes \\
\hline 136 & -1 & 0 & 4.65 & 0.37 & 11 & 1.84 & 0.69 & 0.12 & 0.15 & 3.00 & yes \\
\hline 136 & 1 & 0 & 5.96 & 0.39 & 42 & 2.65 & 2.70 & 0.12 & 0.13 & 2.86 & yes \\
\hline 136 & 1 & 0 & 4.70 & 0.60 & 33 & 2.60 & 1.26 & 0.12 & 0.13 & 2.86 & yes \\
\hline 137 & 0 & 0 & $\ldots$ & $\ldots$ & $\ldots$ & $\ldots$ & $\ldots$ & 0.09 & $\ldots$ & $\ldots$ & $\ldots$ \\
\hline 138 & 0 & 0 & 5.07 & 0.30 & 11 & 2.75 & 1.10 & 0.12 & 0.14 & 1.75 & yes \\
\hline 138 & 0 & -1 & 5.10 & 0.32 & 17 & 0.71 & 1.28 & 0.12 & 0.12 & 1.06 & yes \\
\hline 138 & 0 & 1 & 5.09 & 0.30 & 15 & 0.10 & 2.16 & 0.11 & 0.12 & 0.76 & yes \\
\hline 138 & -1 & 0 & 5.04 & 0.26 & 9 & 3.10 & 1.02 & 0.12 & 0.10 & 1.47 & yes \\
\hline 138 & 1 & 0 & 5.16 & 0.30 & 20 & 0.10 & 1.75 & 0.11 & 0.11 & 0.79 & yes \\
\hline 139 & 0 & 0 & 5.09 & 0.40 & 17 & 2.48 & 0.98 & 0.14 & 0.18 & 2.61 & yes \\
\hline 140 & 0 & 0 & 5.34 & 0.25 & 10 & 3.35 & 1.20 & 0.13 & 0.14 & 1.53 & yes \\
\hline 140 & 0 & -1 & 5.41 & 0.28 & 2 & 0.82 & 0.00 & 0.11 & 0.13 & 1.13 & yes \\
\hline 140 & 0 & 1 & 5.34 & 0.21 & 22 & 1.81 & 2.91 & 0.11 & 0.11 & 0.22 & no \\
\hline 140 & -1 & 0 & 5.45 & 0.22 & 20 & 1.20 & 2.31 & 0.11 & 0.12 & 0.48 & no \\
\hline 140 & 1 & 0 & 5.30 & 0.21 & 5 & 2.61 & 0.43 & 0.11 & 0.14 & 1.72 & yes \\
\hline 141 & 0 & 0 & $\ldots$ & $\ldots$ & $\ldots$ & $\ldots$ & $\ldots$ & 0.14 & $\ldots$ & $\ldots$ & $\ldots$ \\
\hline 142 & 0 & 0 & $\ldots$ & $\ldots$ & $\ldots$ & $\ldots$ & $\ldots$ & 0.14 & $\ldots$ & $\ldots$ & $\ldots$ \\
\hline 143 & 0 & 0 & 5.09 & 0.29 & 5 & 8.88 & 0.67 & 0.11 & 0.20 & 4.31 & yes \\
\hline 143 & 0 & -1 & 5.07 & 0.31 & 19 & 1.53 & 1.65 & 0.12 & 0.11 & 1.10 & yes \\
\hline 143 & 0 & 1 & 5.23 & 0.37 & 8 & 19.48 & 0.65 & 0.11 & 0.14 & 1.89 & yes \\
\hline 143 & -1 & 0 & 5.10 & 0.28 & 11 & 3.06 & 1.14 & 0.11 & 0.14 & 1.72 & yes \\
\hline 143 & 1 & 0 & 5.08 & 0.33 & 15 & 8.26 & 1.71 & 0.12 & 0.11 & 1.84 & yes \\
\hline
\end{tabular}


TABLE 3-Continued

\begin{tabular}{|c|c|c|c|c|c|c|c|c|c|c|c|}
\hline$\#^{\mathrm{a}}$ & $\begin{array}{r}\mathrm{RA}^{\mathrm{b}} \\
\text { offset }\end{array}$ & $\begin{array}{r}\operatorname{dec}^{b} \\
\text { offset }\end{array}$ & $\begin{array}{r}V_{C}{ }^{\mathrm{c}, d} \\
\left(\mathrm{~km} \mathrm{~s}^{-1}\right)\end{array}$ & $\begin{array}{c}\Delta V^{\mathrm{c}} \\
\left(\mathrm{km} \mathrm{s}^{-1}\right)\end{array}$ & $\begin{array}{c}\text { error }^{\mathrm{c}} \\
\left(\mathrm{m} \mathrm{s}^{-1}\right)\end{array}$ & $\begin{array}{l}\text { optical }^{\mathrm{c}} \\
\text { depth }\end{array}$ & error $^{c}$ & $\begin{array}{c}\mathrm{rms}^{\mathrm{c}} \\
\operatorname{base}(\mathrm{K})\end{array}$ & $\begin{array}{r}\mathrm{rms}^{\mathrm{c}} \\
\mathrm{fit}(\mathrm{K})\end{array}$ & $\begin{array}{c}\int \mathrm{I}^{\mathrm{e}} \\
\left(\mathrm{K} \mathrm{km} \mathrm{s}^{-1}\right)\end{array}$ & $\begin{array}{c}\text { secure } \\
\text { fit ? }\end{array}$ \\
\hline 144 & 0 & 0 & $\ldots$ & $\ldots$ & $\ldots$ & $\ldots$ & $\ldots$ & 0.12 & & $\ldots$ & $\ldots$ \\
\hline 145 & 0 & 0 & 3.42 & 0.24 & 28 & 0.10 & 4.57 & 0.12 & 0.12 & 0.74 & no \\
\hline 146 & 0 & 0 & 4.49 & 0.37 & 6 & 9.10 & 0.56 & 0.12 & 0.28 & 6.18 & yes \\
\hline 147 & 0 & 0 & 4.64 & 0.47 & 8 & 4.61 & 0.52 & 0.10 & 0.14 & 4.27 & yes \\
\hline 148 & 0 & 0 & 5.03 & 0.90 & 105 & 17.34 & 0.10 & 0.11 & 0.20 & 13.00 & yes \\
\hline 148 & 0 & 0 & 5.11 & 0.58 & 105 & 0.11 & 0.10 & 0.11 & 0.20 & 13.00 & yes \\
\hline 149 & 0 & 0 & 4.51 & 0.82 & 5 & 6.40 & 0.14 & 0.12 & 0.21 & 20.20 & yes \\
\hline 150 & 0 & 0 & 4.05 & 0.49 & 3 & 12.99 & 0.11 & 0.12 & 0.20 & 9.41 & yes \\
\hline 151 & 0 & 0 & 4.52 & 0.34 & 1 & 0.44 & 0.00 & 0.12 & 0.14 & 1.80 & yes \\
\hline 152 & 0 & 0 & 4.08 & 0.50 & 5 & 12.75 & 0.44 & 0.12 & 0.18 & 10.85 & yes \\
\hline 153 & 0 & 0 & $\ldots$ & $\ldots$ & $\ldots$ & $\ldots$ & $\ldots$ & 0.13 & $\ldots$ & $\ldots$ & $\ldots$ \\
\hline 153 & 0 & -1 & $\ldots$ & $\ldots$ & $\ldots$ & $\ldots$ & $\ldots$ & 0.14 & $\ldots$ & $\ldots$ & $\ldots$ \\
\hline 153 & 0 & 1 & $\ldots$ & $\ldots$ & $\ldots$ & $\ldots$ & $\ldots$ & 0.14 & $\ldots$ & $\ldots$ & $\ldots$ \\
\hline 153 & -1 & 0 & $\ldots$ & $\ldots$ & $\ldots$ & $\ldots$ & $\ldots$ & 0.14 & $\ldots$ & $\ldots$ & $\ldots$ \\
\hline 153 & 1 & 0 & $\ldots$ & $\ldots$ & $\ldots$ & $\ldots$ & $\ldots$ & 0.14 & $\ldots$ & $\ldots$ & $\ldots$ \\
\hline 154 & 0 & 0 & $\ldots$ & $\ldots$ & $\ldots$ & $\ldots$ & $\ldots$ & 0.12 & $\ldots$ & $\ldots$ & $\ldots$ \\
\hline 155 & 0 & 0 & 4.15 & 0.33 & 11 & 4.47 & 1.05 & 0.12 & 0.11 & 2.16 & yes \\
\hline 156 & 0 & 0 & $\ldots$ & $\ldots$ & $\ldots$ & $\ldots$ & $\ldots$ & 0.12 & $\ldots$ & $\ldots$ & $\ldots$ \\
\hline 157 & 0 & 0 & $\ldots$ & $\ldots$ & $\ldots$ & $\ldots$ & $\ldots$ & 0.13 & $\ldots$ & $\ldots$ & $\ldots$ \\
\hline
\end{tabular}

${ }^{\text {a }}$ See Table 1 for the locations of the targets.

${ }^{\mathrm{b}}$ measured in units of the beam $\left(25^{\prime \prime}\right)$

${ }^{\mathrm{c}}$ Centroid velocity, velocity dispersion (FWHM), optical depth, baseline rms, model rms, and the corresponding errors where appropriate determined using CLASS

${ }^{\mathrm{d}}$ The error was similar in all cases with a mean and standard deviation of $8 \pm 8 \mathrm{~m} / \mathrm{s}$.

${ }^{\mathrm{e}}$ Integrated intensity computed using the tdv function in CLASS.

${ }^{\mathrm{f}}$ Was the fit judged to be good? 
TABLE 4

Parameters of Spectral Fitting for $\mathrm{C}^{18} \mathrm{O}$

\begin{tabular}{|c|c|c|c|c|c|c|c|c|c|c|}
\hline$\#^{\mathrm{a}}$ & $\begin{array}{l}\mathrm{RA}^{\mathrm{b}} \\
\text { offset }\end{array}$ & $\begin{array}{l}\operatorname{dec}^{b} \\
\text { offset }\end{array}$ & $\begin{array}{r}V_{C}{ }^{\mathrm{c}, d} \\
\left(\mathrm{~km} \mathrm{~s}^{-1}\right)\end{array}$ & $\begin{array}{c}\Delta V^{\mathrm{c}} \\
\left(\mathrm{km} \mathrm{s}^{-1}\right)\end{array}$ & $\begin{array}{c}\text { error }^{\mathrm{c}} \\
\left(\mathrm{m} \mathrm{s}^{-1}\right)\end{array}$ & $\begin{array}{c}\mathrm{T}_{A, \text { peak }}^{*}{ }^{\mathrm{c}} \\
(\mathrm{K})\end{array}$ & $\begin{array}{c}\int \mathrm{I}^{\mathrm{c}} \\
\left(\mathrm{K} \mathrm{km} \mathrm{s}^{-1}\right)\end{array}$ & $\begin{array}{c}\mathrm{rms}^{\mathrm{c}} \\
\operatorname{base}(\mathrm{K})\end{array}$ & $\begin{array}{r}\mathrm{rms}^{\mathrm{c}} \\
\mathrm{fit}(\mathrm{K})\end{array}$ & $\begin{array}{c}\text { secure }^{\mathrm{e}} \\
\text { fit? }\end{array}$ \\
\hline 1 & 0 & 0 & $\ldots$ & $\ldots$ & $\ldots$ & $\ldots$ & $\ldots$ & 0.47 & $\ldots$ & $\ldots$ \\
\hline 2 & 0 & 0 & 10.42 & 0.46 & 51 & 2.32 & 1.14 & 0.42 & 0.36 & yes \\
\hline 2 & 0 & 0 & 9.61 & 0.72 & 103 & 1.50 & 1.15 & 0.42 & 0.36 & yes \\
\hline 3 & 0 & 0 & 10.20 & 0.53 & 11 & 3.92 & 2.21 & 0.18 & 0.35 & yes \\
\hline 3 & 0 & -1 & 10.13 & 0.84 & 19 & 3.00 & 2.68 & 0.23 & 0.46 & yes \\
\hline 3 & 0 & 1 & 10.16 & 0.50 & 10 & 4.68 & 2.49 & 0.25 & 0.27 & yes \\
\hline 3 & 0 & 1 & 9.21 & 0.40 & 38 & 1.54 & 0.65 & 0.25 & 0.27 & yes \\
\hline 3 & -1 & 0 & 10.21 & 0.58 & 12 & 4.86 & 3.02 & 0.27 & 0.38 & yes \\
\hline 3 & 1 & 0 & 10.17 & 0.61 & 30 & 2.38 & 1.54 & 0.26 & 0.35 & yes \\
\hline 4 & 0 & 0 & 10.11 & 0.91 & 8 & 4.05 & 3.92 & 0.15 & 0.28 & yes \\
\hline 5 & 0 & 0 & 10.19 & 1.00 & 39 & 2.73 & 2.92 & 0.42 & 0.49 & yes \\
\hline 5 & 0 & -1 & 10.06 & 0.81 & 30 & 3.03 & 2.61 & 0.36 & 0.55 & yes \\
\hline 5 & 0 & 1 & 9.97 & 1.25 & 32 & 2.64 & 3.50 & 0.34 & 0.56 & yes \\
\hline 5 & -1 & 0 & 10.07 & 1.12 & 33 & 3.14 & 3.74 & 0.37 & 0.45 & yes \\
\hline 5 & 1 & 0 & 10.16 & 0.96 & 36 & 3.00 & 3.05 & 0.37 & 0.40 & yes \\
\hline 6 & 0 & 0 & 10.18 & 0.86 & 13 & 3.53 & 3.23 & 0.19 & 0.31 & yes \\
\hline 7 & 0 & 0 & 10.10 & 0.82 & 31 & 3.21 & 2.78 & 0.43 & 0.47 & yes \\
\hline 7 & 0 & -1 & 9.93 & 0.83 & 28 & 3.10 & 2.75 & 0.36 & 0.38 & yes \\
\hline 7 & 0 & 1 & 9.98 & 1.11 & 40 & 2.83 & 3.34 & 0.38 & 0.46 & yes \\
\hline 7 & -1 & 0 & 9.98 & 0.91 & 30 & 3.07 & 2.96 & 0.36 & 0.50 & yes \\
\hline 7 & 1 & 0 & 10.11 & 0.92 & 30 & 3.28 & 3.20 & 0.38 & 0.42 & yes \\
\hline 8 & 0 & 0 & 10.20 & 0.53 & 27 & 3.11 & 1.76 & 0.40 & 0.37 & yes \\
\hline 8 & 0 & -1 & 10.29 & 0.65 & 25 & 3.02 & 2.08 & 0.40 & 0.55 & yes \\
\hline 8 & 0 & 1 & 10.12 & 0.52 & 22 & 3.45 & 1.89 & 0.37 & 0.38 & yes \\
\hline 8 & -1 & 0 & 10.22 & 0.51 & 20 & 3.93 & 2.14 & 0.37 & 0.36 & yes \\
\hline 8 & 1 & 0 & 9.99 & 0.23 & 25 & 2.85 & 0.70 & 0.38 & 0.36 & yes \\
\hline 8 & 1 & 0 & 10.48 & 0.65 & 97 & 1.82 & 1.26 & 0.38 & 0.36 & yes \\
\hline 9 & 0 & 0 & 10.16 & 0.60 & 36 & 2.74 & 1.74 & 0.37 & 0.53 & yes \\
\hline 10 & 0 & 0 & 9.61 & 0.52 & 36 & 2.79 & 1.55 & 0.37 & 0.40 & yes \\
\hline 11 & 0 & 0 & $\ldots$ & $\ldots$ & $\ldots$ & $\ldots$ & $\ldots$ & 0.38 & $\ldots$ & $\ldots$ \\
\hline 12 & 0 & 0 & 10.86 & 0.40 & 20 & 3.54 & 1.52 & 0.43 & 0.38 & yes \\
\hline 12 & 0 & -1 & 10.88 & 0.23 & 5 & 4.35 & 1.07 & 0.22 & 0.24 & yes \\
\hline 12 & 0 & -1 & 10.14 & 0.39 & 32 & 1.49 & 0.62 & 0.22 & 0.24 & yes \\
\hline 12 & 0 & 1 & 10.78 & 0.34 & 14 & 3.43 & 1.24 & 0.27 & 0.28 & yes \\
\hline 12 & -1 & 0 & 10.75 & 0.26 & 25 & 1.57 & 0.44 & 0.25 & 0.20 & yes \\
\hline 12 & 1 & 0 & 10.19 & 0.92 & 26 & 1.00 & 0.98 & 0.23 & 0.34 & yes \\
\hline 12 & 1 & 0 & 10.74 & 0.31 & 26 & 2.83 & 0.93 & 0.23 & 0.34 & yes \\
\hline 13 & 0 & 0 & 10.98 & 0.41 & 20 & 3.26 & 1.44 & 0.37 & 0.44 & yes \\
\hline 13 & 0 & -1 & 10.84 & 0.38 & 16 & 3.23 & 1.31 & 0.27 & 0.36 & yes \\
\hline 13 & 0 & 1 & 11.01 & 0.32 & 18 & 2.82 & 0.95 & 0.28 & 0.29 & yes \\
\hline 13 & -1 & 0 & 10.88 & 0.32 & 12 & 3.99 & 1.35 & 0.27 & 0.33 & yes \\
\hline 13 & 1 & 0 & 11.05 & 0.49 & 22 & 2.86 & 1.50 & 0.25 & 0.49 & yes \\
\hline 14 & 0 & 0 & 8.10 & 1.06 & 81 & 0.76 & 0.86 & 0.20 & 0.19 & yes \\
\hline 15 & 0 & 0 & 9.11 & 0.86 & 11 & 4.12 & 3.77 & 0.21 & 0.36 & yes \\
\hline 16 & 0 & 0 & 9.81 & 1.36 & 13 & 4.10 & 5.95 & 0.17 & 0.18 & yes \\
\hline 16 & 0 & -1 & 9.48 & 0.69 & 16 & 4.69 & 3.43 & 0.30 & 0.30 & yes \\
\hline 16 & 0 & 1 & 9.70 & 0.89 & 20 & 4.14 & 3.93 & 0.29 & 0.38 & yes \\
\hline 16 & -1 & 0 & 9.36 & 0.85 & 23 & 5.28 & 4.80 & 0.38 & 0.52 & yes \\
\hline 16 & 1 & 0 & 9.38 & 0.89 & 17 & 4.59 & 4.35 & 0.29 & 0.44 & yes \\
\hline 17 & 0 & 0 & 7.73 & 0.48 & 21 & 1.62 & 0.82 & 0.20 & 0.23 & yes \\
\hline 18 & 0 & 0 & 9.59 & 1.23 & 17 & 2.91 & 3.82 & 0.17 & 0.29 & yes \\
\hline 18 & 0 & -1 & 8.72 & 1.02 & 140 & 1.46 & 1.59 & 0.29 & 0.35 & yes \\
\hline 18 & 0 & -1 & 9.91 & 0.91 & 61 & 3.10 & 2.98 & 0.29 & 0.35 & yes \\
\hline 18 & 0 & 1 & 9.40 & 1.07 & 17 & 4.09 & 4.66 & 0.26 & 0.41 & yes \\
\hline 18 & -1 & 0 & 9.36 & 0.80 & 15 & 4.44 & 3.80 & 0.26 & 0.24 & yes \\
\hline 18 & -1 & 0 & 8.31 & 0.52 & 54 & 1.18 & 0.65 & 0.26 & 0.24 & yes \\
\hline 18 & 1 & 0 & 9.52 & 0.62 & 18 & 4.02 & 2.65 & 0.30 & 0.36 & yes \\
\hline 19 & 0 & 0 & 8.56 & 0.67 & 6 & 7.03 & 5.03 & 0.19 & 0.33 & yes \\
\hline
\end{tabular}


TABLE 4-Continued

\begin{tabular}{|c|c|c|c|c|c|c|c|c|c|c|}
\hline$\#^{\mathrm{a}}$ & $\begin{array}{l}\mathrm{RA}^{\mathrm{b}} \\
\text { offset }\end{array}$ & $\begin{array}{l}\operatorname{dec}^{b} \\
\text { offset }\end{array}$ & $\begin{array}{r}V_{C}^{\mathrm{c}, d} \\
\left(\mathrm{~km} \mathrm{~s}^{-1}\right)\end{array}$ & $\begin{array}{c}\Delta V^{\mathrm{c}} \\
\left(\mathrm{km} \mathrm{s}^{-1}\right)\end{array}$ & $\begin{array}{c}\text { error }^{\mathrm{c}} \\
\left(\mathrm{m} \mathrm{s}^{-1}\right)\end{array}$ & $\begin{array}{c}\mathrm{T}_{A, \text { peak }}^{*}{ }^{\mathrm{c}} \\
(\mathrm{K})\end{array}$ & $\begin{array}{c}\int \mathrm{I}^{\mathrm{c}} \\
\left(\mathrm{K} \mathrm{km} \mathrm{s}{ }^{-1}\right)\end{array}$ & $\begin{array}{c}\mathrm{rms}^{\mathrm{c}} \\
\operatorname{base}(\mathrm{K})\end{array}$ & $\begin{array}{r}\mathrm{rms}^{\mathrm{c}} \\
\mathrm{fit}(\mathrm{K})\end{array}$ & $\begin{array}{c}\text { secure }^{\mathrm{e}} \\
\text { fit? }\end{array}$ \\
\hline 20 & 0 & 0 & 8.55 & 0.62 & 8 & 6.17 & 4.04 & 0.21 & 0.52 & yes \\
\hline 21 & 0 & 0 & 8.82 & 1.00 & 10 & 4.95 & 5.26 & 0.17 & 0.28 & yes \\
\hline 22 & 0 & 0 & 8.60 & 1.13 & 8 & 4.35 & 5.23 & 0.15 & 0.44 & yes \\
\hline 22 & 0 & -1 & 8.37 & 0.94 & 18 & 4.08 & 4.08 & 0.25 & 0.66 & yes \\
\hline 22 & 0 & 1 & 8.82 & 0.92 & 12 & 4.96 & 4.83 & 0.23 & 0.37 & yes \\
\hline 22 & -1 & 0 & 8.87 & 0.60 & 26 & 5.17 & 3.29 & 0.22 & 0.32 & yes \\
\hline 22 & -1 & 0 & 8.18 & 0.51 & 26 & 2.98 & 1.63 & 0.22 & 0.32 & yes \\
\hline 22 & 1 & 0 & 8.28 & 0.63 & 17 & 5.18 & 3.46 & 0.33 & 0.47 & yes \\
\hline 23 & 0 & 0 & 8.25 & 0.75 & 11 & 7.93 & 6.33 & 0.32 & 0.80 & yes \\
\hline 24 & 0 & 0 & 8.76 & 0.85 & 8 & 5.91 & 5.38 & 0.18 & 0.31 & yes \\
\hline 25 & 0 & 0 & 8.94 & 0.81 & 6 & 7.59 & 6.53 & 0.18 & 0.58 & yes \\
\hline 26 & 0 & 0 & 8.52 & 0.57 & 26 & 4.73 & 2.89 & 0.18 & 0.29 & yes \\
\hline 26 & 0 & 0 & 9.14 & 0.55 & 26 & 2.46 & 1.44 & 0.18 & 0.29 & yes \\
\hline 27 & 0 & 0 & 8.72 & 0.57 & 5 & 7.31 & 4.46 & 0.19 & 0.51 & yes \\
\hline 28 & 0 & 0 & 8.67 & 0.98 & 10 & 4.40 & 4.61 & 0.18 & 0.30 & yes \\
\hline 29 & 0 & 0 & 9.59 & 0.38 & 31 & 1.48 & 0.60 & 0.23 & 0.24 & yes \\
\hline 30 & 0 & 0 & 8.74 & 0.44 & 8 & 7.32 & 3.46 & 0.29 & 0.56 & yes \\
\hline 30 & 0 & -1 & 8.67 & 0.50 & 8 & 7.13 & 3.77 & 0.31 & 0.47 & yes \\
\hline 30 & 0 & 1 & 8.80 & 0.44 & 9 & 6.74 & 3.18 & 0.34 & 0.49 & yes \\
\hline 30 & -1 & 0 & 8.78 & 0.46 & 8 & 7.61 & 3.73 & 0.32 & 0.74 & yes \\
\hline 30 & 1 & 0 & 8.72 & 0.51 & 8 & 6.84 & 3.68 & 0.30 & 0.53 & yes \\
\hline 31 & 0 & 0 & 8.42 & 0.69 & 13 & 4.92 & 3.62 & 0.29 & 0.29 & yes \\
\hline 32 & 0 & 0 & 8.31 & 1.04 & 57 & 0.69 & 0.76 & 0.13 & 0.13 & yes \\
\hline 33 & 0 & 0 & 9.34 & 0.50 & 28 & 2.60 & 1.39 & 0.32 & 0.27 & yes \\
\hline 33 & 0 & 0 & 8.39 & 0.62 & 89 & 0.91 & 0.60 & 0.32 & 0.27 & yes \\
\hline 33 & 0 & -1 & 8.31 & 0.63 & 73 & 0.65 & 0.43 & 0.23 & 0.24 & yes \\
\hline 33 & 0 & -1 & 9.29 & 0.34 & 12 & 3.32 & 1.20 & 0.23 & 0.24 & yes \\
\hline 33 & 0 & 1 & 9.38 & 0.41 & 16 & 2.90 & 1.28 & 0.25 & 0.30 & yes \\
\hline 33 & -1 & 0 & 9.38 & 0.39 & 15 & 3.14 & 1.31 & 0.28 & 0.28 & yes \\
\hline 33 & 1 & 0 & 9.29 & 0.56 & 18 & 3.03 & 1.81 & 0.27 & 0.25 & yes \\
\hline 34 & 0 & 0 & 8.24 & 0.58 & 7 & 7.11 & 4.39 & 0.27 & 0.72 & yes \\
\hline 34 & 0 & -1 & 8.65 & 0.51 & 64 & 1.83 & 1.00 & 0.31 & 0.29 & yes \\
\hline 34 & 0 & -1 & 8.13 & 0.39 & 18 & 5.12 & 2.12 & 0.31 & 0.29 & yes \\
\hline 34 & 0 & 1 & 8.36 & 0.68 & 20 & 3.27 & 2.38 & 0.34 & 0.65 & yes \\
\hline 34 & -1 & 0 & 8.17 & 0.44 & 8 & 6.99 & 3.30 & 0.31 & 0.48 & yes \\
\hline 34 & 1 & 0 & 8.28 & 0.61 & 12 & 6.07 & 3.92 & 0.33 & 0.71 & yes \\
\hline 35 & 0 & 0 & 8.80 & 0.51 & 95 & 0.72 & 0.39 & 0.22 & 0.21 & yes \\
\hline 35 & 0 & 0 & 9.32 & 0.25 & 13 & 2.88 & 0.77 & 0.22 & 0.21 & yes \\
\hline 36 & 0 & 0 & 9.36 & 0.35 & 20 & 3.34 & 1.25 & 0.41 & 0.28 & yes \\
\hline 36 & 0 & -1 & 9.35 & 0.31 & 15 & 3.30 & 1.10 & 0.27 & 0.36 & yes \\
\hline 36 & 0 & 1 & 9.44 & 0.36 & 14 & 2.93 & 1.13 & 0.21 & 0.24 & yes \\
\hline 36 & 0 & 1 & 8.72 & 0.70 & 135 & 0.62 & 0.47 & 0.21 & 0.24 & yes \\
\hline 36 & -1 & 0 & 9.40 & 0.38 & 28 & 2.85 & 1.17 & 0.29 & 0.45 & yes \\
\hline 36 & 1 & 0 & 9.36 & 0.33 & 13 & 3.00 & 1.06 & 0.22 & 0.17 & yes \\
\hline 36 & 1 & 0 & 8.64 & 0.57 & 64 & 0.75 & 0.45 & 0.22 & 0.17 & yes \\
\hline 37 & 0 & 0 & 9.20 & 0.25 & 37 & 1.52 & 0.40 & 0.35 & 0.30 & yes \\
\hline 37 & 0 & 0 & 9.70 & 0.37 & 53 & 1.28 & 0.50 & 0.35 & 0.30 & yes \\
\hline 38 & 0 & 0 & 9.50 & 0.48 & 50 & 1.92 & 0.97 & 0.38 & 0.33 & yes \\
\hline 39 & 0 & 0 & 9.30 & 0.31 & 27 & 2.60 & 0.85 & 0.38 & 0.37 & yes \\
\hline 40 & 0 & 0 & 8.99 & 0.55 & 27 & 2.75 & 1.61 & 0.34 & 0.46 & yes \\
\hline 41 & 0 & 0 & 8.39 & 0.39 & 7 & 6.89 & 2.83 & 0.29 & 0.27 & yes \\
\hline 41 & 0 & 0 & 7.40 & 0.54 & 28 & 2.38 & 1.37 & 0.29 & 0.27 & yes \\
\hline 41 & 0 & -1 & 7.44 & 0.58 & 35 & 2.93 & 1.80 & 0.41 & 0.53 & yes \\
\hline 41 & 0 & -1 & 8.26 & 0.47 & 12 & 6.35 & 3.17 & 0.41 & 0.53 & yes \\
\hline 41 & 0 & 1 & 8.41 & 0.48 & 8 & 8.71 & 4.42 & 0.43 & 0.65 & yes \\
\hline 41 & 0 & 1 & 7.47 & 0.50 & 50 & 1.92 & 1.03 & 0.43 & 0.65 & yes \\
\hline 41 & -1 & 0 & 7.32 & 0.64 & 48 & 2.48 & 1.70 & 0.47 & 0.46 & yes \\
\hline 41 & -1 & 0 & 8.38 & 0.36 & 9 & 8.83 & 3.42 & 0.47 & 0.46 & yes \\
\hline
\end{tabular}


TABLE 4-Continued

\begin{tabular}{|c|c|c|c|c|c|c|c|c|c|c|}
\hline$\#^{\mathrm{a}}$ & $\begin{array}{l}\mathrm{RA}^{\mathrm{b}} \\
\text { offset }\end{array}$ & $\begin{array}{l}\operatorname{dec}^{b} \\
\text { offset }\end{array}$ & $\begin{array}{c}V_{C}^{\mathrm{c}, d} \\
\left(\mathrm{~km} \mathrm{~s}^{-1}\right)\end{array}$ & $\begin{array}{c}\Delta V^{\mathrm{c}} \\
\left(\mathrm{km} \mathrm{s}^{-1}\right)\end{array}$ & $\begin{array}{c}\text { error }^{\mathrm{c}} \\
\left(\mathrm{m} \mathrm{s}^{-1}\right)\end{array}$ & $\begin{array}{c}\mathrm{T}_{A, p e a k}{ }^{\mathrm{c}} \\
(\mathrm{K})\end{array}$ & $\int_{\left(\mathrm{K} \mathrm{km} \mathrm{s}^{-1}\right)}$ & $\begin{array}{c}\mathrm{rms}^{\mathrm{c}} \\
\operatorname{base}(\mathrm{K})\end{array}$ & $\begin{array}{r}\mathrm{rms}^{\mathrm{c}} \\
\mathrm{fit}(\mathrm{K})\end{array}$ & $\begin{array}{c}\text { secure }^{\mathrm{e}} \\
\text { fit? }\end{array}$ \\
\hline 41 & 1 & 0 & 8.37 & 0.32 & 7 & 9.44 & 3.17 & 0.42 & 0.46 & yes \\
\hline 41 & 1 & 0 & 7.46 & 0.64 & 46 & 2.16 & 1.48 & 0.42 & 0.46 & yes \\
\hline 42 & 0 & 0 & 8.89 & 0.74 & 38 & 1.92 & 1.50 & 0.33 & 0.38 & yes \\
\hline 42 & 0 & -1 & 8.86 & 0.78 & 44 & 1.85 & 1.55 & 0.28 & 0.33 & yes \\
\hline 42 & 0 & 1 & 8.98 & 0.60 & 18 & 2.97 & 1.88 & 0.27 & 0.30 & yes \\
\hline 42 & -1 & 0 & 9.00 & 0.65 & 56 & 1.27 & 0.89 & 0.29 & 0.32 & yes \\
\hline 42 & 1 & 0 & 8.98 & 0.55 & 48 & 1.30 & 0.76 & 0.29 & 0.22 & yes \\
\hline 43 & 0 & 0 & 8.70 & 0.53 & 25 & 2.47 & 1.38 & 0.35 & 0.43 & yes \\
\hline 44 & 0 & 0 & 9.16 & 0.71 & 59 & 0.89 & 0.68 & 0.32 & 0.35 & no \\
\hline 44 & 0 & -1 & $\ldots$ & $\ldots$ & $\ldots$ & $\ldots$ & $\ldots$ & 0.37 & $\ldots$ & $\ldots$ \\
\hline 44 & 0 & 1 & 8.98 & 0.44 & $\ddot{61}$ & $\ldots$ & 0.53 & 0.30 & 0.31 & yes \\
\hline 44 & 0 & 1 & 9.62 & 0.39 & 24 & 3.01 & 1.26 & 0.30 & 0.31 & yes \\
\hline 44 & -1 & 0 & $\ldots$ & $\ldots$ & $\ldots$ & $\ldots$ & $\ldots$ & 0.32 & $\ldots$ & $\ldots$ \\
\hline 44 & 1 & 0 & 9.32 & 0.92 & 54 & 1.16 & 1.13 & 0.27 & 0.34 & yes \\
\hline 45 & 0 & 0 & $\ldots$ & $\ldots$ & $\ldots$ & $\ldots$ & $\ldots$ & 0.22 & $\ldots$ & $\ldots$ \\
\hline 46 & 0 & 0 & 8.35 & 0.61 & 13 & 3.00 & 1.95 & 0.19 & 0.19 & yes \\
\hline 46 & 0 & -1 & 8.29 & 0.59 & 11 & 3.01 & 1.90 & 0.17 & 0.25 & yes \\
\hline 46 & 0 & 1 & 8.34 & 0.49 & 9 & 3.61 & 1.89 & 0.17 & 0.17 & yes \\
\hline 46 & -1 & 0 & 8.28 & 0.47 & 9 & 3.01 & 1.50 & 0.16 & 0.17 & yes \\
\hline 46 & 1 & 0 & 8.41 & 0.61 & 12 & 2.97 & 1.92 & 0.18 & 0.17 & yes \\
\hline 47 & 0 & 0 & 10.09 & 0.57 & 15 & 3.53 & 2.15 & 0.28 & 0.30 & yes \\
\hline 48 & 0 & 0 & 9.15 & 0.30 & 11 & 3.40 & 1.10 & 0.29 & 0.29 & yes \\
\hline 49 & 0 & 0 & 7.88 & 0.39 & 23 & 3.14 & 1.30 & 0.37 & 0.31 & yes \\
\hline 49 & 0 & -1 & 8.02 & 0.83 & 38 & 1.75 & 1.55 & 0.26 & 0.28 & yes \\
\hline 49 & 0 & 1 & 7.91 & 0.56 & 28 & 2.51 & 1.49 & 0.27 & 0.35 & yes \\
\hline 49 & -1 & 0 & 7.95 & 0.42 & 17 & 2.99 & 1.35 & 0.26 & 0.26 & yes \\
\hline 49 & 1 & 0 & 7.93 & 0.56 & 19 & 2.94 & 1.76 & 0.24 & 0.36 & yes \\
\hline 50 & 0 & 0 & 9.49 & 0.46 & 47 & 1.42 & 0.70 & 0.34 & 0.26 & yes \\
\hline 51 & 0 & 0 & 9.40 & 0.41 & 17 & 2.46 & 1.08 & 0.22 & 0.24 & yes \\
\hline 51 & 0 & -1 & 9.35 & 0.35 & 21 & 2.16 & 0.79 & 0.26 & 0.20 & yes \\
\hline 51 & 0 & 1 & 9.71 & 0.54 & 33 & 2.56 & 1.47 & 0.30 & 0.33 & yes \\
\hline 51 & -1 & 0 & 9.51 & 0.37 & 22 & 2.03 & 0.79 & 0.26 & 0.23 & yes \\
\hline 51 & 1 & 0 & 9.37 & 0.39 & 15 & 3.18 & 1.32 & 0.25 & 0.29 & yes \\
\hline 52 & 0 & 0 & 8.22 & 0.69 & 50 & 1.62 & 1.19 & 0.35 & 0.32 & yes \\
\hline 52 & 0 & -1 & 8.11 & 0.43 & 17 & 2.75 & 1.26 & 0.27 & 0.35 & yes \\
\hline 52 & 0 & 1 & 8.34 & 0.57 & 42 & 1.65 & 1.01 & 0.30 & 0.27 & yes \\
\hline 52 & -1 & 0 & 7.98 & 0.44 & 20 & 3.59 & 1.70 & 0.33 & 0.40 & yes \\
\hline 52 & 1 & 0 & 8.27 & 0.59 & 39 & 1.71 & 1.07 & 0.29 & 0.27 & yes \\
\hline 53 & 0 & 0 & 9.95 & 0.50 & 15 & 4.20 & 2.26 & 0.33 & 0.34 & yes \\
\hline 54 & 0 & 0 & 9.63 & 0.52 & 20 & 3.01 & 1.67 & 0.32 & 0.28 & yes \\
\hline 55 & 0 & 0 & 9.71 & 0.50 & 13 & 3.60 & 1.93 & 0.24 & 0.24 & yes \\
\hline 55 & 0 & 0 & 8.32 & 0.47 & 64 & 0.96 & 0.48 & 0.24 & 0.24 & yes \\
\hline 55 & 0 & -1 & 9.65 & 0.46 & 8 & 3.53 & 1.72 & 0.17 & 0.18 & yes \\
\hline 55 & 0 & -1 & 8.42 & 0.60 & 59 & 0.59 & 0.37 & 0.17 & 0.18 & yes \\
\hline 55 & 0 & 1 & 8.32 & 0.41 & 36 & 0.92 & 0.40 & 0.20 & 0.23 & yes \\
\hline 55 & 0 & 1 & 9.72 & 0.48 & 10 & 3.80 & 1.95 & 0.20 & 0.23 & yes \\
\hline 55 & -1 & 0 & 9.66 & 0.42 & 10 & 3.23 & 1.46 & 0.18 & 0.19 & yes \\
\hline 55 & 1 & 0 & 9.72 & 0.45 & 10 & 3.37 & 1.62 & 0.20 & 0.22 & yes \\
\hline 56 & 0 & 0 & 9.59 & 0.52 & 30 & 1.55 & 0.86 & 0.21 & 0.32 & yes \\
\hline 57 & 0 & 0 & $\ldots$ & $\ldots$ & $\ldots$ & $\ldots$ & $\ldots$ & 0.31 & $\ldots$ & $\ldots$ \\
\hline 58 & 0 & 0 & 4.78 & 0.67 & 99 & 0.40 & 0.28 & 0.21 & 0.16 & no \\
\hline 59 & 0 & 0 & 7.67 & 0.95 & 38 & 2.18 & 2.20 & 0.31 & 0.28 & yes \\
\hline 60 & 0 & 0 & 8.17 & 0.31 & 38 & 0.61 & 0.20 & 0.15 & 0.13 & yes \\
\hline 60 & 0 & 0 & 7.13 & 0.90 & 45 & 0.87 & 0.83 & 0.15 & 0.13 & yes \\
\hline 61 & 0 & 0 & 7.36 & 1.00 & 77 & 1.21 & 1.29 & 0.29 & 0.32 & yes \\
\hline 61 & 0 & -1 & 7.28 & 0.90 & 54 & 1.35 & 1.29 & 0.28 & 0.30 & yes \\
\hline 61 & 0 & 1 & 7.38 & 0.64 & 53 & 1.15 & 0.79 & 0.25 & 0.25 & yes \\
\hline 61 & -1 & 0 & 7.39 & 0.79 & 45 & 1.46 & 1.23 & 0.28 & 0.34 & yes \\
\hline
\end{tabular}


TABLE 4-Continued

\begin{tabular}{|c|c|c|c|c|c|c|c|c|c|c|}
\hline$\#^{\mathrm{a}}$ & $\begin{array}{l}\mathrm{RA}^{\mathrm{b}} \\
\text { offset }\end{array}$ & $\begin{array}{l}\operatorname{dec}^{b} \\
\text { offset }\end{array}$ & $\begin{array}{r}V_{C}^{\mathrm{c}, d} \\
\left(\mathrm{~km} \mathrm{~s}^{-1}\right)\end{array}$ & $\begin{array}{c}\Delta V^{\mathrm{c}} \\
\left(\mathrm{km} \mathrm{s}^{-1}\right)\end{array}$ & $\begin{array}{c}\text { error }^{\mathrm{c}} \\
\left(\mathrm{m} \mathrm{s}^{-1}\right)\end{array}$ & $\begin{array}{c}\mathrm{T}_{A, \text { peak }}^{*}{ }^{\mathrm{c}} \\
(\mathrm{K})\end{array}$ & $\begin{array}{c}\int \mathrm{I}^{\mathrm{c}} \\
\left(\mathrm{K} \mathrm{km} \mathrm{s}{ }^{-1}\right)\end{array}$ & $\begin{array}{c}\mathrm{rms}^{\mathrm{c}} \\
\operatorname{base}(\mathrm{K})\end{array}$ & $\begin{array}{r}\mathrm{rms}^{\mathrm{c}} \\
\mathrm{fit}(\mathrm{K})\end{array}$ & $\begin{array}{c}\text { secure }^{\mathrm{e}} \\
\text { fit? }\end{array}$ \\
\hline 61 & 1 & 0 & 7.34 & 1.07 & 88 & 1.02 & 1.16 & 0.30 & 0.33 & yes \\
\hline 62 & 0 & 0 & 7.53 & 0.79 & 44 & 1.81 & 1.51 & 0.29 & 0.31 & yes \\
\hline 62 & 0 & -1 & 7.81 & 0.75 & 36 & 2.16 & 1.74 & 0.28 & 0.37 & yes \\
\hline 62 & 0 & 1 & 7.49 & 1.14 & 63 & 1.62 & 1.98 & 0.28 & 0.34 & yes \\
\hline 62 & -1 & 0 & 7.47 & 0.73 & 61 & 1.53 & 1.19 & 0.31 & 0.30 & yes \\
\hline 62 & 1 & 0 & 7.44 & 1.02 & 40 & 1.67 & 1.81 & 0.26 & 0.36 & yes \\
\hline 63 & 0 & 0 & 7.07 & 0.64 & 16 & 2.31 & 1.58 & 0.17 & 0.13 & yes \\
\hline 63 & 0 & -1 & 7.02 & 0.60 & 26 & 1.48 & 0.95 & 0.15 & 0.17 & yes \\
\hline 63 & 0 & 1 & 7.12 & 0.46 & 8 & 3.26 & 1.59 & 0.15 & 0.16 & yes \\
\hline 63 & -1 & 0 & 7.03 & 0.86 & 61 & 0.77 & 0.70 & 0.16 & 0.17 & yes \\
\hline 63 & 1 & 0 & 7.13 & 0.43 & 7 & 3.48 & 1.58 & 0.14 & 0.19 & yes \\
\hline 64 & 0 & 0 & 7.28 & 1.22 & 158 & 0.48 & 0.62 & 0.29 & 0.25 & no \\
\hline 64 & 0 & -1 & $\ldots$ & $\ldots$ & $\ldots$ & $\ldots$ & $\ldots$ & 0.32 & $\ldots$ & $\ldots$ \\
\hline 64 & 0 & 1 & 7.47 & 1.03 & 151 & 0.61 & 0.67 & 0.30 & 0.24 & no \\
\hline 64 & -1 & 0 & $\ldots$ & $\ldots$ & $\ldots$ & $\ldots$ & $\ldots$ & 0.31 & $\ldots$ & $\ldots$ \\
\hline 64 & 1 & 0 & 7.42 & 1.62 & 139 & 0.44 & 0.76 & 0.15 & 0.13 & yes \\
\hline 65 & 0 & 0 & 6.91 & 0.34 & 17 & 3.32 & 1.20 & 0.34 & 0.26 & yes \\
\hline 65 & 0 & -1 & 6.77 & 0.44 & 22 & 3.15 & 1.48 & 0.34 & 0.31 & yes \\
\hline 65 & 0 & 1 & 7.09 & 0.88 & 61 & 1.59 & 1.48 & 0.30 & 0.36 & yes \\
\hline 65 & -1 & 0 & 6.78 & 0.52 & 41 & 1.85 & 1.02 & 0.34 & 0.32 & yes \\
\hline 65 & 1 & 0 & 7.34 & 1.38 & 122 & 0.78 & 1.16 & 0.29 & 0.31 & yes \\
\hline 65 & 1 & 0 & 6.90 & 0.23 & 17 & 2.19 & 0.54 & 0.29 & 0.31 & yes \\
\hline 66 & 0 & 0 & 6.61 & 0.54 & 35 & 2.07 & 1.20 & 0.30 & 0.38 & yes \\
\hline 67 & 0 & 0 & 6.63 & 1.00 & 21 & 3.43 & 3.64 & 0.30 & 0.44 & yes \\
\hline 67 & 0 & -1 & 6.69 & 0.97 & 35 & 3.44 & 3.55 & 0.38 & 0.47 & yes \\
\hline 67 & 0 & 1 & 6.58 & 1.22 & 53 & 1.97 & 2.57 & 0.37 & 0.52 & yes \\
\hline 67 & -1 & 0 & 6.36 & 0.40 & 31 & 3.40 & 1.45 & 0.40 & 0.43 & yes \\
\hline 67 & -1 & 0 & 6.95 & 0.54 & 40 & 3.88 & 2.21 & 0.40 & 0.43 & yes \\
\hline 67 & 1 & 0 & 6.29 & 0.54 & 40 & 3.08 & 1.78 & 0.41 & 0.30 & yes \\
\hline 67 & 1 & 0 & 6.95 & 0.47 & 34 & 3.33 & 1.68 & 0.41 & 0.30 & yes \\
\hline 68 & 0 & 0 & 6.81 & 1.04 & 12 & 5.35 & 5.91 & 0.20 & 0.47 & yes \\
\hline 69 & 0 & 0 & 6.65 & 1.09 & 55 & 1.06 & 1.23 & 0.23 & 0.22 & yes \\
\hline 70 & 0 & 0 & 6.61 & 0.92 & 19 & 2.16 & 2.11 & 0.14 & 0.27 & yes \\
\hline 71 & 0 & 0 & 6.41 & 0.85 & 16 & 4.60 & 4.15 & 0.18 & 0.20 & yes \\
\hline 71 & 0 & 0 & 7.30 & 0.67 & 14 & 4.60 & 3.27 & 0.18 & 0.20 & yes \\
\hline 72 & 0 & 0 & 6.47 & 1.20 & 8 & 5.64 & 7.18 & 0.17 & 0.22 & yes \\
\hline 72 & 0 & -1 & 6.68 & 1.02 & 19 & 4.63 & 5.02 & 0.29 & 0.43 & yes \\
\hline 72 & 0 & 1 & 6.43 & 1.01 & 12 & 5.51 & 5.90 & 0.25 & 0.32 & yes \\
\hline 72 & -1 & 0 & 6.54 & 1.27 & 20 & 3.67 & 4.94 & 0.25 & 0.31 & yes \\
\hline 72 & 1 & 0 & 6.41 & 1.09 & 11 & 6.93 & 8.01 & 0.27 & 0.38 & yes \\
\hline 73 & 0 & 0 & 6.65 & 0.95 & 6 & 5.41 & 5.47 & 0.16 & 0.23 & yes \\
\hline 74 & 0 & 0 & 6.93 & 0.86 & 18 & 2.33 & 2.14 & 0.17 & 0.22 & yes \\
\hline 74 & 0 & -1 & 6.99 & 0.93 & 25 & 2.69 & 2.67 & 0.26 & 0.26 & yes \\
\hline 74 & 0 & 1 & 6.92 & 0.59 & 18 & 2.84 & 1.79 & 0.25 & 0.29 & yes \\
\hline 74 & -1 & 0 & 6.82 & 0.67 & 25 & 2.45 & 1.74 & 0.25 & 0.28 & yes \\
\hline 74 & 1 & 0 & 6.78 & 0.87 & 53 & 2.17 & 2.01 & 0.27 & 0.26 & yes \\
\hline 74 & 1 & 0 & 7.46 & 0.29 & 25 & 1.84 & 0.57 & 0.27 & 0.26 & yes \\
\hline 75 & 0 & 0 & 6.70 & 0.89 & 15 & 3.57 & 3.38 & 0.20 & 0.40 & yes \\
\hline 75 & 0 & -1 & 6.71 & 0.69 & 17 & 4.10 & 3.00 & 0.29 & 0.47 & yes \\
\hline 75 & 0 & 1 & 6.69 & 0.82 & 17 & 3.54 & 3.11 & 0.25 & 0.29 & yes \\
\hline 75 & -1 & 0 & 6.68 & 0.81 & 18 & 3.88 & 3.33 & 0.27 & 0.32 & yes \\
\hline 75 & 1 & 0 & 6.77 & 0.83 & 12 & 4.49 & 3.95 & 0.24 & 0.37 & yes \\
\hline 76 & 0 & 0 & 6.63 & 0.73 & 17 & 4.04 & 3.13 & 0.31 & 0.37 & yes \\
\hline 76 & 0 & -1 & 6.79 & 0.54 & 26 & 3.96 & 2.28 & 0.38 & 0.44 & yes \\
\hline 76 & 0 & -1 & 6.09 & 0.33 & 47 & 2.06 & 0.72 & 0.38 & 0.44 & yes \\
\hline 76 & 0 & 1 & 6.61 & 0.65 & 25 & 3.23 & 2.22 & 0.38 & 0.37 & yes \\
\hline 76 & -1 & 0 & 6.49 & 0.67 & 24 & 3.67 & 2.60 & 0.39 & 0.42 & yes \\
\hline 76 & 1 & 0 & 6.71 & 0.54 & 16 & 4.68 & 2.67 & 0.37 & 0.40 & yes \\
\hline
\end{tabular}


TABLE 4-Continued

\begin{tabular}{|c|c|c|c|c|c|c|c|c|c|c|}
\hline$\#^{\mathrm{a}}$ & $\begin{array}{l}\mathrm{RA}^{\mathrm{b}} \\
\text { offset }\end{array}$ & $\begin{array}{l}\operatorname{dec}^{b} \\
\text { offset }\end{array}$ & $\begin{array}{r}V_{C}^{\mathrm{c}, d} \\
\left(\mathrm{~km} \mathrm{~s}^{-1}\right)\end{array}$ & $\begin{array}{c}\Delta V^{\mathrm{c}} \\
\left(\mathrm{km} \mathrm{s}^{-1}\right)\end{array}$ & $\begin{array}{c}\text { error }^{\mathrm{c}} \\
\left(\mathrm{m} \mathrm{s}^{-1}\right)\end{array}$ & $\begin{array}{c}\mathrm{T}_{A, \text { peak }}^{*}{ }^{\mathrm{c}} \\
(\mathrm{K})\end{array}$ & $\begin{array}{c}\int \mathrm{I}^{\mathrm{c}} \\
\left(\mathrm{K} \mathrm{km} \mathrm{s}{ }^{-1}\right)\end{array}$ & $\begin{array}{c}\mathrm{rms}^{\mathrm{c}} \\
\operatorname{base}(\mathrm{K})\end{array}$ & $\begin{array}{r}\mathrm{rms}^{\mathrm{c}} \\
\mathrm{fit}(\mathrm{K})\end{array}$ & $\begin{array}{c}\text { secure }^{\mathrm{e}} \\
\text { fit? }\end{array}$ \\
\hline 77 & 0 & 0 & 6.68 & 0.79 & 26 & 3.37 & 2.82 & 0.34 & 0.32 & yes \\
\hline 77 & 0 & -1 & 6.70 & 0.56 & 22 & 4.34 & 2.61 & 0.42 & 0.29 & yes \\
\hline 77 & 0 & 1 & 6.62 & 0.74 & 43 & 3.48 & 2.73 & 0.45 & 0.53 & yes \\
\hline 77 & -1 & 0 & 6.63 & 0.73 & 27 & 3.53 & 2.74 & 0.35 & 0.35 & yes \\
\hline 77 & 1 & 0 & 6.71 & 0.67 & 22 & 4.15 & 2.94 & 0.38 & 0.37 & yes \\
\hline 78 & 0 & 0 & 6.68 & 1.09 & 33 & 3.98 & 4.61 & 0.36 & 0.54 & yes \\
\hline 78 & 0 & -1 & 6.66 & 0.83 & 21 & 4.24 & 3.76 & 0.34 & 0.42 & yes \\
\hline 78 & 0 & 1 & 6.72 & 0.98 & 33 & 3.07 & 3.21 & 0.33 & 0.38 & yes \\
\hline 78 & -1 & 0 & 6.65 & 0.75 & 20 & 4.03 & 3.22 & 0.33 & 0.36 & yes \\
\hline 78 & 1 & 0 & 6.89 & 0.86 & 20 & 4.14 & 3.80 & 0.32 & 0.46 & yes \\
\hline 79 & 0 & 0 & 6.57 & 1.02 & 30 & 3.46 & 3.76 & 0.35 & 0.33 & yes \\
\hline 79 & 0 & -1 & 6.50 & 0.94 & 18 & 3.78 & 3.80 & 0.26 & 0.28 & yes \\
\hline 79 & 0 & 1 & 6.68 & 0.77 & 24 & 4.09 & 3.36 & 0.36 & 0.30 & yes \\
\hline 79 & -1 & 0 & 6.47 & 0.72 & 15 & 4.42 & 3.41 & 0.29 & 0.38 & yes \\
\hline 79 & 1 & 0 & 6.62 & 0.82 & 18 & 3.85 & 3.35 & 0.28 & 0.32 & yes \\
\hline 80 & 0 & 0 & 6.74 & 0.63 & 42 & 2.91 & 1.94 & 0.33 & 0.33 & yes \\
\hline 80 & 0 & 0 & 5.93 & 0.72 & 55 & 2.74 & 2.10 & 0.33 & 0.33 & yes \\
\hline 80 & 0 & -1 & 6.87 & 0.46 & 45 & 2.36 & 1.16 & 0.38 & 0.27 & yes \\
\hline 80 & 0 & -1 & 6.20 & 0.69 & 46 & 3.30 & 2.44 & 0.38 & 0.27 & yes \\
\hline 80 & 0 & 1 & 6.59 & 0.62 & 47 & 3.19 & 2.10 & 0.34 & 0.26 & yes \\
\hline 80 & 0 & 1 & 5.89 & 0.60 & 66 & 2.26 & 1.45 & 0.34 & 0.26 & yes \\
\hline 80 & -1 & 0 & 6.39 & 0.88 & 26 & 3.12 & 2.93 & 0.34 & 0.37 & yes \\
\hline 80 & 1 & 0 & 6.03 & 0.61 & 17 & 2.93 & 1.89 & 0.36 & 0.46 & yes \\
\hline 80 & 1 & 0 & 6.82 & 0.90 & 9 & 1.91 & 1.84 & 0.36 & 0.46 & yes \\
\hline 81 & 0 & 0 & 6.67 & 1.26 & 133 & 0.84 & 1.12 & 0.34 & 0.30 & no \\
\hline 82 & 0 & 0 & 6.47 & 1.01 & 27 & 1.38 & 1.48 & 0.15 & 0.15 & yes \\
\hline 83 & 0 & 0 & 6.72 & 0.65 & 31 & 2.39 & 1.66 & 0.32 & 0.38 & yes \\
\hline 83 & 0 & -1 & 6.72 & 0.51 & 33 & 1.85 & 1.01 & 0.32 & 0.35 & yes \\
\hline 83 & 0 & 1 & 6.71 & 0.58 & 25 & 2.56 & 1.57 & 0.31 & 0.45 & yes \\
\hline 83 & -1 & 0 & 6.63 & 0.56 & 36 & 1.57 & 0.94 & 0.31 & 0.32 & yes \\
\hline 83 & 1 & 0 & 6.52 & 0.39 & 16 & 3.33 & 1.37 & 0.31 & 0.34 & yes \\
\hline 84 & 0 & 0 & 6.82 & 0.79 & 29 & 3.01 & 2.53 & 0.35 & 0.42 & yes \\
\hline 84 & 0 & -1 & 6.77 & 0.68 & 23 & 2.97 & 2.13 & 0.31 & 0.43 & yes \\
\hline 84 & 0 & 1 & 6.47 & 0.56 & 67 & 1.51 & 0.90 & 0.34 & 0.28 & yes \\
\hline 84 & -1 & 0 & 6.75 & 0.64 & 80 & 1.28 & 0.87 & 0.34 & 0.32 & yes \\
\hline 84 & 1 & 0 & 6.77 & 0.75 & 24 & 3.02 & 2.40 & 0.33 & 0.53 & yes \\
\hline 85 & 0 & 0 & 6.50 & 0.98 & 32 & 2.60 & 2.72 & 0.30 & 0.40 & yes \\
\hline 85 & 0 & -1 & 6.43 & 0.67 & 21 & 3.20 & 2.30 & 0.32 & 0.35 & yes \\
\hline 85 & 0 & 1 & 6.30 & 0.74 & 45 & 1.90 & 1.51 & 0.32 & 0.36 & yes \\
\hline 85 & -1 & 0 & 6.43 & 0.71 & 31 & 2.77 & 2.09 & 0.35 & 0.34 & yes \\
\hline 85 & 1 & 0 & 6.49 & 0.77 & 23 & 2.90 & 2.39 & 0.31 & 0.34 & yes \\
\hline 86 & 0 & 0 & 6.89 & 0.96 & 13 & 3.73 & 3.82 & 0.18 & 0.28 & yes \\
\hline 86 & 0 & -1 & 6.90 & 0.75 & 22 & 2.72 & 2.16 & 0.25 & 0.25 & yes \\
\hline 86 & 0 & 1 & 6.98 & 0.83 & 26 & 2.09 & 1.85 & 0.23 & 0.27 & yes \\
\hline 86 & -1 & 0 & 6.78 & 0.61 & 20 & 2.84 & 1.85 & 0.26 & 0.23 & yes \\
\hline 86 & 1 & 0 & 6.78 & 0.54 & 13 & 3.93 & 2.26 & 0.26 & 0.28 & yes \\
\hline 87 & 0 & 0 & 5.90 & 0.41 & 19 & 3.60 & 1.56 & 0.37 & 0.27 & yes \\
\hline 87 & 0 & -1 & 5.83 & 0.41 & 17 & 3.41 & 1.50 & 0.33 & 0.31 & yes \\
\hline 87 & 0 & 1 & 5.96 & 0.56 & 18 & 3.56 & 2.12 & 0.31 & 0.37 & yes \\
\hline 87 & -1 & 0 & 5.92 & 0.39 & 25 & 2.69 & 1.12 & 0.35 & 0.26 & yes \\
\hline 87 & 1 & 0 & 5.94 & 0.45 & 23 & 3.03 & 1.46 & 0.34 & 0.45 & yes \\
\hline 88 & 0 & 0 & 6.95 & 0.66 & 26 & 3.14 & 2.22 & 0.34 & 0.35 & yes \\
\hline 89 & 0 & 0 & 7.26 & 1.23 & 197 & 0.56 & 0.73 & 0.19 & 0.20 & no \\
\hline 90 & 0 & 0 & 7.00 & 1.08 & 27 & 1.98 & 2.28 & 0.16 & 0.25 & yes \\
\hline 90 & 0 & -1 & 7.55 & 0.80 & 52 & 1.62 & 1.38 & 0.26 & 0.23 & yes \\
\hline 90 & 0 & -1 & 6.68 & 0.51 & 56 & 1.27 & 0.69 & 0.26 & 0.23 & yes \\
\hline 90 & 0 & 1 & 7.17 & 1.19 & 62 & 1.01 & 1.28 & 0.23 & 0.25 & yes \\
\hline 90 & -1 & 0 & 7.08 & 1.57 & 79 & 1.19 & 1.99 & 0.25 & 0.21 & yes \\
\hline
\end{tabular}


TABLE 4-Continued

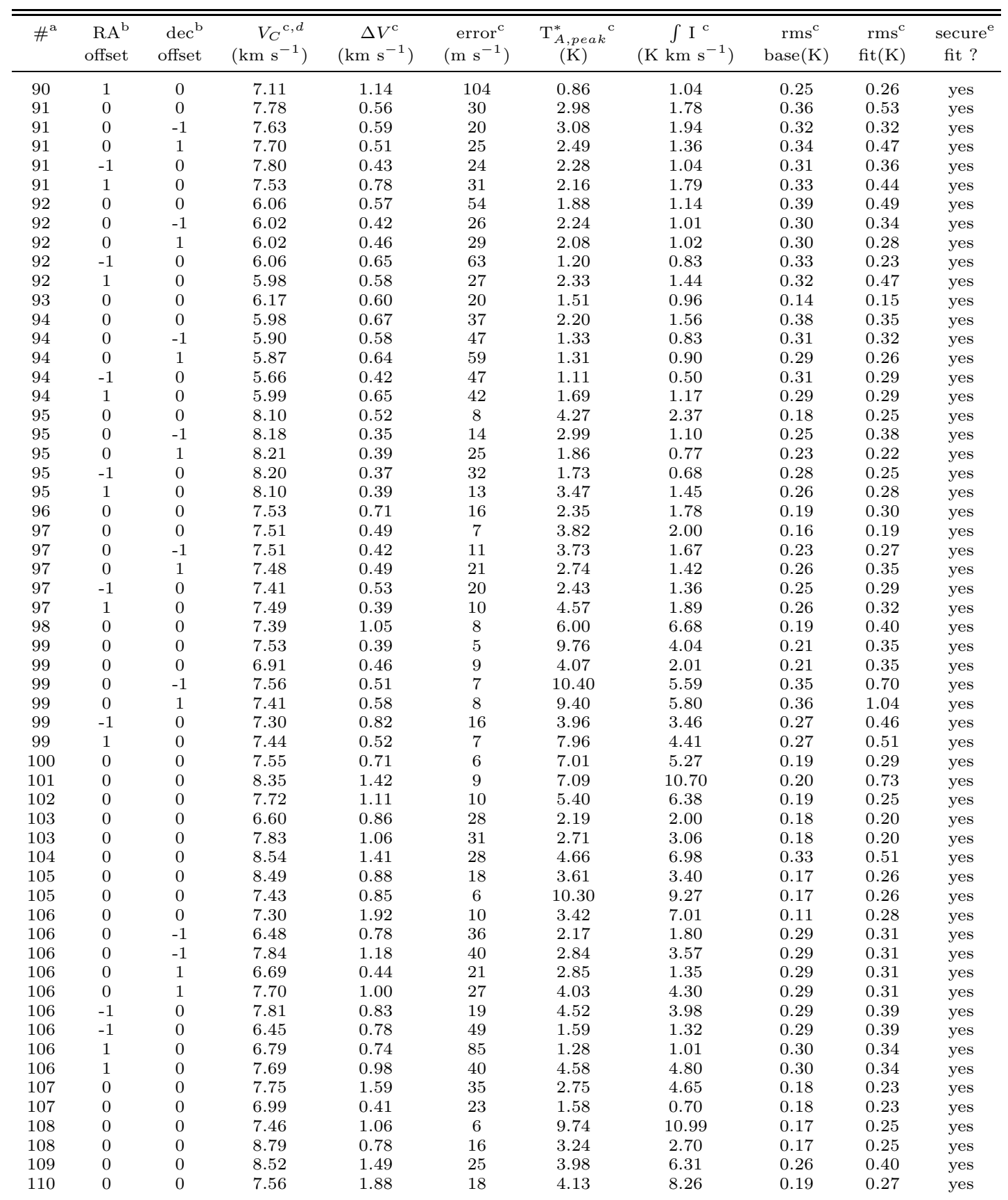


TABLE 4-Continued

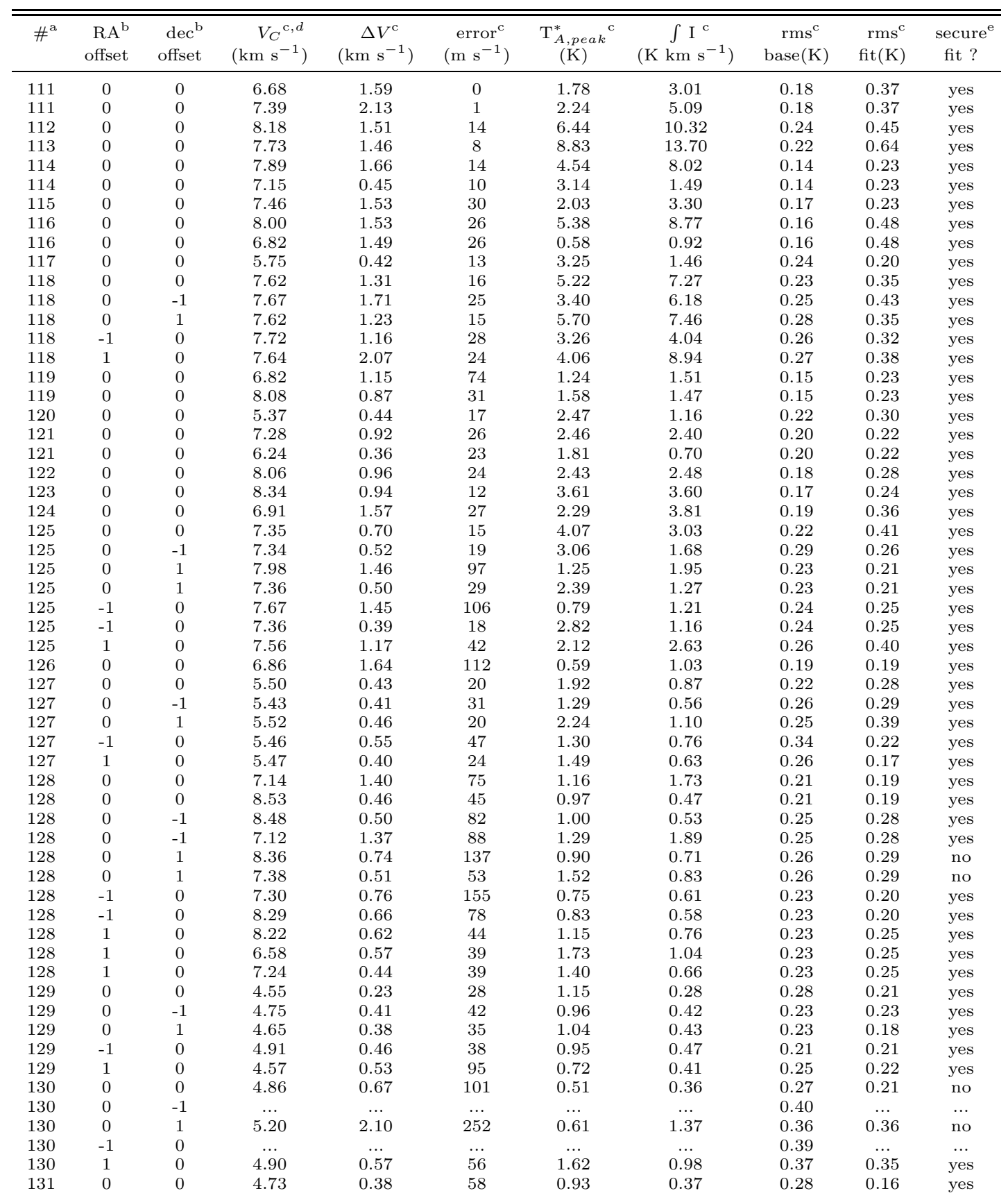


TABLE 4-Continued

\begin{tabular}{|c|c|c|c|c|c|c|c|c|c|c|}
\hline$\#^{\mathrm{a}}$ & $\begin{array}{l}\mathrm{RA}^{\mathrm{b}} \\
\text { offset }\end{array}$ & $\begin{array}{l}\operatorname{dec}^{b} \\
\text { offset }\end{array}$ & $\begin{array}{r}V_{C}{ }^{\mathrm{c}, d} \\
\left(\mathrm{~km} \mathrm{~s}^{-1}\right)\end{array}$ & $\begin{array}{c}\Delta V^{\mathrm{c}} \\
\left(\mathrm{km} \mathrm{s}^{-1}\right)\end{array}$ & $\begin{array}{c}\text { error }^{\mathrm{c}} \\
\left(\mathrm{m} \mathrm{s}^{-1}\right)\end{array}$ & $\begin{array}{c}\mathrm{T}_{A, p e a k}^{*}{ }^{\mathrm{c}} \\
(\mathrm{K})\end{array}$ & $\begin{array}{c}\int \mathrm{I}^{\mathrm{c}} \\
\left(\mathrm{K} \mathrm{km} \mathrm{s}^{-1}\right)\end{array}$ & $\begin{array}{c}\mathrm{rms}^{\mathrm{c}} \\
\mathrm{base}(\mathrm{K})\end{array}$ & $\begin{array}{r}\mathrm{rms}^{\mathrm{c}} \\
\mathrm{fit}(\mathrm{K})\end{array}$ & $\begin{array}{c}\text { secure }^{e} \\
\text { fit? }\end{array}$ \\
\hline 131 & 0 & -1 & 4.81 & 0.54 & 55 & 1.02 & 0.58 & 0.25 & 0.23 & yes \\
\hline 131 & 0 & 1 & 4.89 & 0.78 & 87 & 0.54 & 0.45 & 0.23 & 0.23 & yes \\
\hline 131 & -1 & 0 & 4.93 & 0.83 & 119 & 0.52 & 0.46 & 0.27 & 0.17 & no \\
\hline 131 & 1 & 0 & 4.74 & 0.61 & 233 & 0.65 & 0.42 & 0.24 & 0.29 & no \\
\hline 132 & 0 & 0 & 5.14 & 1.01 & 99 & 0.79 & 0.86 & 0.26 & 0.30 & yes \\
\hline 132 & 0 & -1 & 5.05 & 1.09 & 224 & 0.64 & 0.74 & 0.37 & 0.32 & no \\
\hline 132 & 0 & 1 & 5.07 & 1.10 & 151 & 0.79 & 0.92 & 0.37 & 0.36 & no \\
\hline 132 & -1 & 0 & 5.01 & 1.54 & 204 & 0.67 & 1.10 & 0.35 & 0.29 & no \\
\hline 132 & 1 & 0 & 5.17 & 1.16 & 104 & 1.00 & 1.23 & 0.34 & 0.32 & no \\
\hline 133 & 0 & 0 & 5.22 & 1.07 & 48 & 1.07 & 1.22 & 0.17 & 0.14 & yes \\
\hline 133 & 0 & -1 & 5.01 & 0.94 & 44 & 1.35 & 1.35 & 0.21 & 0.26 & yes \\
\hline 133 & 0 & 1 & 5.15 & 2.49 & 307 & 0.41 & 1.09 & 0.26 & 0.25 & no \\
\hline 133 & -1 & 0 & 4.94 & 1.57 & 110 & 0.69 & 1.15 & 0.24 & 0.25 & no \\
\hline 133 & 1 & 0 & 5.24 & 0.72 & 39 & 1.57 & 1.20 & 0.23 & 0.20 & yes \\
\hline 134 & 0 & 0 & 5.75 & 0.43 & 21 & 1.64 & 0.74 & 0.17 & 0.15 & yes \\
\hline 134 & 0 & 0 & 4.91 & 0.70 & 20 & 2.25 & 1.68 & 0.17 & 0.15 & yes \\
\hline 135 & 0 & 0 & 4.68 & 0.70 & 35 & 1.53 & 1.14 & 0.17 & 0.14 & yes \\
\hline 135 & 0 & 0 & 5.73 & 1.14 & 124 & 0.80 & 0.98 & 0.17 & 0.14 & yes \\
\hline 136 & 0 & 0 & 5.90 & 0.45 & 19 & 1.93 & 0.92 & 0.18 & 0.17 & yes \\
\hline 136 & 0 & 0 & 4.40 & 1.34 & 75 & 0.86 & 1.23 & 0.18 & 0.17 & yes \\
\hline 136 & 0 & -1 & 5.94 & 0.90 & 55 & 1.70 & 1.64 & 0.27 & 0.31 & yes \\
\hline 136 & 0 & 1 & 5.96 & 0.39 & 28 & 1.56 & 0.65 & 0.24 & 0.20 & yes \\
\hline 136 & 0 & 1 & 4.48 & 1.38 & 126 & 0.65 & 0.96 & 0.24 & 0.20 & yes \\
\hline 136 & -1 & 0 & 4.58 & 1.02 & 149 & 0.69 & 0.75 & 0.24 & 0.26 & no \\
\hline 136 & -1 & 0 & 5.80 & 0.52 & 48 & 1.26 & 0.70 & 0.24 & 0.26 & no \\
\hline 136 & 1 & 0 & 5.93 & 1.00 & 26 & 0.83 & 0.88 & 0.24 & 0.29 & yes \\
\hline 136 & 1 & 0 & 4.27 & 1.14 & 26 & 0.67 & 0.82 & 0.24 & 0.29 & yes \\
\hline 137 & 0 & 0 & 5.73 & 0.68 & 68 & 1.20 & 0.87 & 0.15 & 0.16 & yes \\
\hline 137 & 0 & 0 & 4.70 & 0.93 & 112 & 0.79 & 0.78 & 0.15 & 0.16 & yes \\
\hline 138 & 0 & 0 & 5.24 & 0.90 & 68 & 0.99 & 0.95 & 0.27 & 0.27 & yes \\
\hline 138 & 0 & -1 & 5.34 & 0.92 & 76 & 0.93 & 0.90 & 0.23 & 0.26 & yes \\
\hline 138 & 0 & 1 & 5.34 & 0.67 & 52 & 0.94 & 0.67 & 0.24 & 0.28 & yes \\
\hline 138 & -1 & 0 & 5.14 & 0.91 & 110 & 0.67 & 0.65 & 0.24 & 0.22 & no \\
\hline 138 & 1 & 0 & 5.59 & 0.56 & 34 & 1.80 & 1.07 & 0.25 & 0.25 & yes \\
\hline 139 & 0 & 0 & 4.92 & 0.97 & 123 & 0.76 & 0.78 & 0.39 & 0.47 & no \\
\hline 140 & 0 & 0 & 5.34 & 0.27 & 19 & 1.85 & 0.54 & 0.25 & 0.21 & yes \\
\hline 140 & 0 & -1 & 5.43 & 0.36 & 28 & 2.07 & 0.79 & 0.24 & 0.33 & yes \\
\hline 140 & 0 & 1 & 5.37 & 0.27 & 12 & 2.58 & 0.74 & 0.22 & 0.17 & yes \\
\hline 140 & -1 & 0 & 5.42 & 0.36 & 24 & 1.42 & 0.54 & 0.25 & 0.28 & yes \\
\hline 140 & 1 & 0 & 5.27 & 0.34 & 19 & 2.25 & 0.82 & 0.25 & 0.15 & yes \\
\hline 141 & 0 & 0 & 4.76 & 1.34 & 160 & 0.83 & 1.19 & 0.33 & 0.27 & yes \\
\hline 142 & 0 & 0 & $\ldots$ & $\ldots$ & $\ldots$ & $\ldots$ & $\ldots$ & 0.39 & $\ldots$ & $\ldots$ \\
\hline 143 & 0 & 0 & 5.09 & 0.46 & 18 & 1.85 & 0.90 & 0.18 & 0.18 & yes \\
\hline 143 & 0 & -1 & 5.09 & 0.46 & 64 & 0.96 & 0.47 & 0.26 & 0.21 & yes \\
\hline 143 & 0 & 1 & 5.28 & 0.49 & 30 & 1.57 & 0.82 & 0.26 & 0.23 & yes \\
\hline 143 & -1 & 0 & 5.12 & 0.34 & 23 & 1.58 & 0.58 & 0.26 & 0.14 & yes \\
\hline 143 & 1 & 0 & 5.00 & 0.58 & 55 & 0.89 & 0.55 & 0.25 & 0.28 & yes \\
\hline 144 & 0 & 0 & 3.85 & 0.67 & 35 & 1.00 & 0.71 & 0.20 & 0.22 & yes \\
\hline 145 & 0 & 0 & 3.60 & 1.31 & 264 & 1.12 & 1.56 & 0.25 & 0.44 & yes \\
\hline 146 & 0 & 0 & 4.34 & 0.88 & 11 & 3.37 & 3.14 & 0.16 & 0.24 & yes \\
\hline 147 & 0 & 0 & 4.55 & 0.86 & 10 & 4.01 & 3.68 & 0.18 & 0.32 & yes \\
\hline 148 & 0 & 0 & 5.36 & 0.53 & 7 & 3.03 & 1.71 & 0.20 & 0.27 & yes \\
\hline 148 & 0 & 0 & 4.81 & 1.02 & 15 & 3.67 & 3.98 & 0.20 & 0.27 & yes \\
\hline 149 & 0 & 0 & 4.35 & 1.07 & 8 & 6.52 & 7.40 & 0.19 & 0.30 & yes \\
\hline 150 & 0 & 0 & 4.09 & 0.68 & 10 & 4.00 & 2.90 & 0.19 & 0.21 & yes \\
\hline 151 & 0 & 0 & 4.41 & 0.56 & 49 & 1.04 & 0.62 & 0.25 & 0.25 & yes \\
\hline 152 & 0 & 0 & 4.05 & 0.74 & 7 & 5.32 & 4.19 & 0.16 & 0.21 & yes \\
\hline 153 & 0 & 0 & $\ldots$ & $\ldots$ & $\ldots$ & $\ldots$ & $\ldots$ & 0.27 & $\ldots$ & $\ldots$ \\
\hline
\end{tabular}


TABle 4-Continued

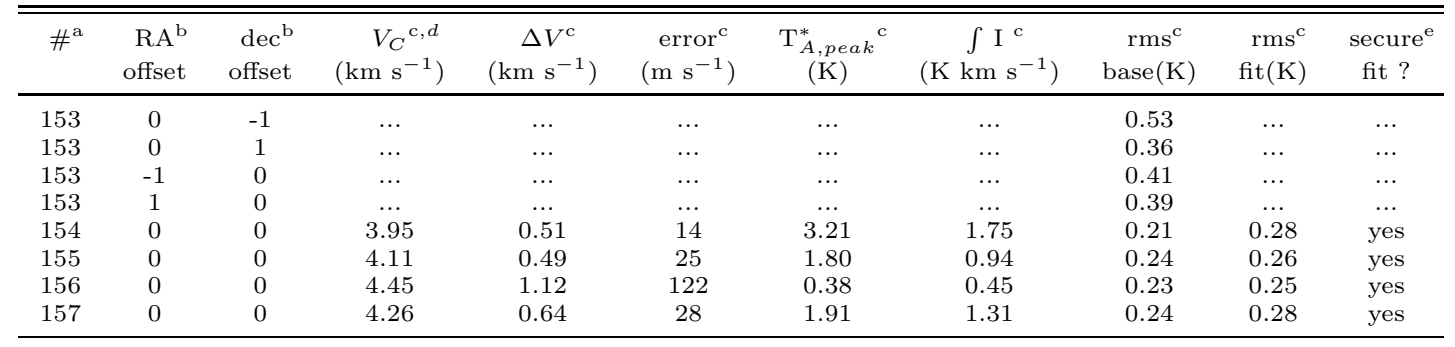

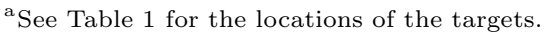

${ }^{\mathrm{b}}$ measured in units of the beam $\left(25^{\prime \prime}\right)$

${ }^{\mathrm{c}}$ Centroid velocity, velocity dispersion (FWHM), peak intensity, integrated intensity, baseline rms, model rms, and the corresponding errors where appropriate determined using CLASS

${ }^{\mathrm{d}}$ The error was similar in all cases with a mean and standard deviation of $16 \pm 15 \mathrm{~m} / \mathrm{s}$.

eWas the fit judged to be good?

TABLE 5

Properties of Extinction Regions.

\begin{tabular}{|c|c|c|c|c|c|c|c|c|c|c|}
\hline Number $^{a}$ & $\begin{array}{c}\mathrm{RA}^{\mathrm{a}} \\
(\mathrm{J} 2000.0)\end{array}$ & $\begin{array}{c}\text { Dec }^{\mathrm{a}} \\
(\mathrm{J} 2000.0)\end{array}$ & $\begin{array}{l}\text { Mass }^{\mathrm{a}} \\
\left(\mathrm{M}_{\odot}\right)\end{array}$ & $\begin{array}{c}\text { Radius }^{\mathrm{a}} \\
\left({ }^{\prime \prime}\right)\end{array}$ & $\begin{array}{c}\sigma V_{\text {grav }}^{\mathrm{b}} \\
\left(\mathrm{km} \mathrm{s}^{-1}\right)\end{array}$ & $\mathrm{N}_{N}{ }^{\mathrm{c}}$ & $\begin{array}{c}\sigma V_{N}^{\mathrm{d}} \\
\left(\mathrm{km} \mathrm{s}^{-1}\right)\end{array}$ & $\mathrm{N}_{C}^{\mathrm{e}}$ & $\begin{array}{c}\sigma V_{C}^{\mathrm{f}} \\
\left(\mathrm{km} \mathrm{s}^{-1}\right)\end{array}$ & Notes ${ }^{g}$ \\
\hline 1 & $3: 47: 45.3$ & $32: 52: 43.4$ & 859.6 & 776 & 0.89 & 7 & 0.39 & 9 & 0.46 & B5 \\
\hline 2 & $3: 43: 57.1$ & $31: 59: 28.7$ & 1938.9 & 1119 & 1.11 & 11 & 0.55 & 25 & 0.51 & IC348 \\
\hline 3 & $3: 39: 27.4$ & $31: 21: 08.6$ & 780.6 & 737 & 0.87 & 2 & 0.20 & 11 & 0.41 & SW of IC348 \\
\hline 4 & $3: 36: 28.9$ & $31: 11: 13.1$ & 560.5 & 670 & 0.77 & 1 & 0 & 5 & 0.42 & $\mathrm{E}$ of $\mathrm{B} 1$ \\
\hline 5 & $3: 32: 35.6$ & $30: 58: 27.7$ & 441.1 & 579 & 0.73 & 9 & 0.28 & 19 & 0.43 & B1 \\
\hline 6 & $3: 30: 28.7$ & $30: 26: 30.2$ & 257.6 & 454 & 0.63 & 3 & 0.09 & 4 & 0.30 & SW of B1 \\
\hline 7 & $3: 28: 56.0$ & $31: 22: 36.4$ & 973.3 & 889 & 0.88 & 8 & 0.54 & 12 & 0.78 & NGC1333 \\
\hline 8 & $3: 28: 53.3$ & $30: 44: 00.5$ & 246.2 & 453 & 0.62 & 0 & 0 & 2 & 0.30 & $\mathrm{~S}$ of $\mathrm{NGC} 1333$ \\
\hline 9 & $3: 27: 36.6$ & $30: 12: 32.8$ & 240.1 & 448 & 0.62 & 8 & 0.32 & 10 & 0.58 & L1455 \\
\hline 10 & $3: 25: 22.8$ & $30: 43: 19.2$ & 173.7 & 386 & 0.56 & 4 & 0.55 & 6 & 0.44 & L1448 \\
\hline 11 & $3: 24: 50.3$ & $30: 23: 10.1$ & 107.4 & 309 & 0.50 & 2 & 0.26 & 4 & 0.30 & $\mathrm{~S}$ of L1448 \\
\hline
\end{tabular}

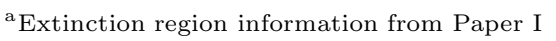

${ }^{\mathrm{b}}$ Velocity dispersion required to support the region

${ }^{\mathrm{c}}$ Number of starless cores detected in $\mathrm{N}_{2} \mathrm{H}^{+}$within the extinction region

${ }^{\mathrm{d}}$ Velocity dispersion of the $\mathrm{N}_{2} \mathrm{H}^{+}$starless cores in the region (uncorrected for the thermal motion of the mean gas)

${ }^{\mathrm{e}}$ Number of non-protostars detected in $\mathrm{C}^{18} \mathrm{O}$ within the extinction region

${ }^{\mathrm{f}}$ Velocity dispersion of the non-protostellar $\mathrm{C}^{18} \mathrm{O}$ detections in the extinction region (uncorrected for the thermal motion of the mean gas)

${ }^{\mathrm{g}}$ Descriptive location of extinction region 
TABLE 6

Properties of the submillimetre cores identified in the Perseus SCUBA map with 3" Pixels.

\begin{tabular}{|c|c|c|c|c|c|c|c|c|c|c|c|c|}
\hline $\begin{array}{r}\text { Name }^{\mathrm{a}} \\
(\mathrm{SMM} \mathrm{J})\end{array}$ & $\#^{\mathrm{b}}$ & $\begin{array}{c}\text { RA }^{\mathrm{c}} \\
(\mathrm{J} 2000.0)\end{array}$ & $\begin{array}{c}\text { Dec }^{\mathrm{c}} \\
(\mathrm{J} 2000.0)\end{array}$ & $\begin{array}{c}\mathrm{f}_{0}{ }^{\mathrm{d}} \\
(\mathrm{Jy} / \mathrm{bm})\end{array}$ & $\begin{array}{c}\mathrm{S}_{850}{ }^{\mathrm{d}} \\
(\mathrm{Jy})\end{array}$ & $\begin{array}{c}\mathrm{R}_{e f f} \mathrm{~d} \\
\left({ }^{\prime \prime}\right)\end{array}$ & Conc $^{\mathrm{e}}$ & $\begin{array}{c}\mathrm{T}_{B E}{ }^{\mathrm{e}} \\
(\mathrm{K})\end{array}$ & $\begin{array}{c}\log n_{\text {cent }} \mathrm{e} \\
\left(\mathrm{cm}^{-3}\right)\end{array}$ & $\begin{array}{c}\mathrm{P}_{e x t} / \mathrm{k}^{\mathrm{e}} \\
\left(\mathrm{cm}^{3} \mathrm{~K}^{-1}\right)\end{array}$ & $\begin{array}{c}\text { Secure }^{\mathrm{f}} \\
\text { Fit? }\end{array}$ & $\begin{array}{l}\text { Assoc }^{g} \\
\text { Protostar }\end{array}$ \\
\hline $034769+32517$ & 1 & $3: 47: 41.5$ & $32: 51: 46.5$ & 0.4 & 1.07 & 22.9 & 0.59 & 11. & 5.68 & 6.00 & yes & 49 \\
\hline $034765+32530$ & 2 & $3: 47: 39.2$ & $32: 53: 01.5$ & 0.2 & 0.26 & 13.7 & 0.20 & 15. & 5.14 & 6.20 & yes & - \\
\hline $034765+32522$ & 3 & $3: 47: 39.2$ & $32: 52: 16.5$ & 0.4 & 0.74 & 18.9 & 0.49 & 12. & 5.54 & 6.20 & yes & - \\
\hline $034481+32005$ & 4 & $3: 44: 48.8$ & $32: 00: 30.5$ & 0.2 & 0.40 & 17.2 & 0.29 & 16. & 4.99 & 6.10 & yes & - \\
\hline $034473+32015$ & 5 & $3: 44: 43.9$ & $32: 01: 33.7$ & 0.6 & 1.08 & 20.8 & 0.62 & 12. & 5.88 & 6.10 & yes & 48 \\
\hline $034461+31588$ & 6 & $3: 44: 36.8$ & $31: 58: 48.8$ & 0.2 & 0.49 & 18.1 & 0.39 & 14. & 5.11 & 6.10 & yes & - \\
\hline $034438+32100$ & 7 & $3: 44: 23.1$ & $32: 10: 01.3$ & 0.1 & 0.30 & 18.6 & 0.32 & 14. & 4.85 & 5.90 & no & - \\
\hline $034410+32022$ & 8 & $3: 44: 06.1$ & $32: 02: 16.4$ & 0.2 & 1.30 & 28.0 & 0.38 & 18. & 4.79 & 5.90 & yes & - \\
\hline $034404+32024$ & 9 & $3: 44: 02.8$ & $32: 02: 25.4$ & 0.3 & 1.87 & 30.3 & 0.40 & 19. & 4.85 & 6.00 & yes & - \\
\hline $034401+32019$ & 10 & $3: 44: 01.2$ & $32: 01: 55.4$ & 0.3 & 1.65 & 28.3 & 0.44 & 16. & 5.10 & 6.00 & yes & - \\
\hline $034396+32040$ & 11 & $3: 43: 58.1$ & $32: 04: 04.5$ & 0.3 & 0.87 & 21.5 & 0.41 & 16. & 5.12 & 6.10 & yes & - \\
\hline $034395+32030$ & 12 & $3: 43: 57.2$ & $32: 03: 04.5$ & 1.3 & 4.20 & 37.1 & 0.79 & 15. & 5.77 & 5.80 & yes & 43 \\
\hline $034394+32008$ & 13 & $3: 43: 56.7$ & $32: 00: 49.5$ & 1.4 & 5.35 & 38.9 & 0.78 & 16. & 5.76 & 5.80 & yes & 44 \\
\hline $034394+32038$ & 14 & $3: 43: 56.7$ & $32: 03: 52.5$ & 0.2 & 0.87 & 23.2 & 0.35 & 19. & 4.80 & 6.00 & yes & - \\
\hline $034384+32034$ & 15 & $3: 43: 50.8$ & $32: 03: 25.5$ & 0.5 & 5.53 & 54.8 & 0.65 & 14. & 5.22 & 5.50 & yes & 41 \\
\hline $034363+32031$ & 16 & $3: 43: 38.0$ & $32: 03: 07.5$ & 0.2 & 1.48 & 32.4 & 0.43 & 15. & 4.89 & 5.80 & yes & - \\
\hline $034180+31574$ & 17 & $3: 41: 48.0$ & $31: 57: 27.3$ & 0.1 & 0.08 & 10.8 & 0.34 & 11. & 5.21 & 6.10 & no & - \\
\hline $034178+31482$ & 18 & $3: 41: 46.8$ & $31: 48: 15.4$ & 0.1 & 0.29 & 20.9 & 0.34 & 13. & 4.73 & 5.80 & no & - \\
\hline $034176+31574$ & 19 & $3: 41: 46.2$ & $31: 57: 24.4$ & 0.1 & 0.18 & 15.6 & 0.44 & 9. & 5.37 & 6.00 & no & - \\
\hline $034167+31503$ & 20 & $3: 41: 40.5$ & $31: 50: 21.4$ & 0.1 & 0.21 & 18.4 & 0.32 & 12. & 4.81 & 5.80 & no & - \\
\hline $034160+31499$ & 21 & $3: 41: 36.2$ & $31: 49: 54.4$ & 0.1 & 0.20 & 18.2 & 0.34 & 12. & 4.81 & 5.80 & no & - \\
\hline $034081+31488$ & 22 & $3: 40: 49.2$ & $31: 48: 48.2$ & 0.1 & 0.79 & 32.9 & 0.35 & 16. & 4.43 & 5.50 & no & - \\
\hline $033979+31349$ & 23 & $3: 39: 47.5$ & $31: 34: 59.5$ & 0.1 & 0.07 & 8.8 & 0.23 & 11. & 5.39 & 6.30 & no & - \\
\hline $033966+31320$ & 24 & $3: 39: 39.9$ & $31: 32: 05.5$ & 0.1 & 0.07 & 9.9 & 0.27 & 11. & 5.29 & 6.20 & no & - \\
\hline $033965+31318$ & 25 & $3: 39: 39.0$ & $31: 31: 53.5$ & 0.1 & 0.11 & 12.9 & 0.29 & 11. & 5.07 & 6.00 & no & - \\
\hline $033963+31312$ & 26 & $3: 39: 38.1$ & $31: 31: 17.5$ & 0.1 & 0.09 & 11.9 & 0.31 & 11. & 5.13 & 6.10 & no & - \\
\hline $033960+31320$ & 27 & $3: 39: 36.4$ & $31: 32: 02.5$ & 0.1 & 0.06 & 9.7 & 0.26 & 10. & 5.28 & 6.20 & no & - \\
\hline $033345+31071$ & 28 & $3: 33: 27.3$ & $31: 07: 09.0$ & 0.2 & 0.19 & 11.7 & 0.32 & 14. & 5.26 & 6.30 & yes & 40 \\
\hline $033335+31074$ & 29 & $3: 33: 21.3$ & $31: 07: 27.2$ & 1.5 & 7.30 & 40.7 & 0.74 & 18. & 5.77 & 5.90 & yes & 39 \\
\hline $033330+31095$ & 30 & $3: 33: 18.0$ & $31: 09: 33.2$ & 1.8 & 5.97 & 43.7 & 0.84 & 16. & 5.66 & 5.70 & yes & 38 \\
\hline $033327+31078$ & 31 & $3: 33: 16.6$ & $31: 07: 51.2$ & 0.3 & 2.27 & 33.9 & 0.38 & 23. & 4.62 & 5.90 & yes & 37 \\
\hline $033327+31069$ & 32 & $3: 33: 16.3$ & $31: 06: 54.2$ & 0.6 & 5.73 & 44.1 & 0.55 & 17. & 5.17 & 5.80 & yes & 36 \\
\hline $033321+31198$ & 33 & $3: 33: 13.2$ & $31: 19: 53.5$ & 0.2 & 0.65 & 20.5 & 0.31 & 18. & 4.88 & 6.00 & yes & 34 \\
\hline $033309+31050$ & 34 & $3: 33: 05.6$ & $31: 05: 00.4$ & 0.2 & 1.04 & 26.6 & 0.35 & 20. & 4.69 & 5.90 & yes & - \\
\hline $033307+31047$ & 35 & $3: 33: 04.7$ & $31: 04: 45.4$ & 0.2 & 0.46 & 18.0 & 0.16 & 17. & 4.96 & 6.10 & yes & - \\
\hline $033303+31043$ & 36 & 3:33:01.9 & $31: 04: 18.4$ & 0.2 & 1.83 & 36.9 & 0.34 & 22. & 4.45 & 5.70 & yes & - \\
\hline $033229+30498$ & 37 & $3: 32: 17.8$ & $30: 49: 48.3$ & 1.8 & 3.41 & 30.6 & 0.82 & 14. & 5.94 & 6.00 & yes & 33 \\
\hline $033134+30454$ & 38 & $3: 31: 20.8$ & $30: 45: 29.4$ & 0.8 & 1.62 & 24.5 & 0.71 & 12. & 6.02 & 6.00 & yes & 32 \\
\hline $033025+30237$ & 39 & $3: 30: 15.3$ & $30: 23: 43.5$ & 0.2 & 0.23 & 13.9 & 0.34 & 14. & 5.11 & 6.20 & no & - \\
\hline $032986+31391$ & 40 & $3: 29: 51.9$ & $31: 39: 07.0$ & 0.3 & 0.74 & 20.5 & 0.53 & 11. & 5.56 & 6.10 & yes & 31 \\
\hline $032942+31282$ & 41 & $3: 29: 25.6$ & $31: 28: 16.4$ & 0.2 & 0.42 & 15.6 & 0.38 & 15. & 5.19 & 6.30 & yes & - \\
\hline $032939+31333$ & 42 & $3: 29: 24.0$ & $31: 33: 19.4$ & 0.3 & 0.69 & 18.8 & 0.43 & 14. & 5.29 & 6.20 & yes & 30 \\
\hline $032935+31255$ & 43 & $3: 29: 21.4$ & $31: 25: 34.4$ & 0.2 & 1.59 & 35.0 & 0.36 & 21. & 4.48 & 5.70 & yes & - \\
\hline $032931+31232$ & 44 & $3: 29: 19.0$ & $31: 23: 13.5$ & 0.4 & 1.89 & 30.6 & 0.55 & 13. & 5.37 & 5.90 & yes & 29 \\
\hline
\end{tabular}


TABLE 6-Continued

\begin{tabular}{|c|c|c|c|c|c|c|c|c|c|c|c|c|}
\hline $\begin{array}{c}\text { Name }^{\mathrm{a}} \\
(\mathrm{SMM} \mathrm{J})\end{array}$ & $\#^{\mathrm{b}}$ & $\begin{array}{c}\mathrm{RA}^{\mathrm{c}} \\
(\mathrm{J} 2000.0)\end{array}$ & $\begin{array}{c}\text { Dec }^{\mathrm{c}} \\
(\mathrm{J} 2000.0)\end{array}$ & $\begin{array}{c}\mathrm{f}_{0}{ }^{\mathrm{d}} \\
(\mathrm{Jy} / \mathrm{bm})\end{array}$ & $\begin{array}{l}\mathrm{S}_{850}{ }^{\mathrm{d}} \\
(\mathrm{Jy})\end{array}$ & $\begin{array}{c}\mathrm{R}_{e f f} \mathrm{~d} \\
\left(^{\prime \prime}\right)\end{array}$ & Conc ${ }^{\mathrm{e}}$ & $\begin{array}{c}\mathrm{T}_{B E}{ }^{\mathrm{e}} \\
(\mathrm{K})\end{array}$ & $\begin{array}{c}\log n_{\text {cent }} \mathrm{e} \\
\left(\mathrm{cm}^{-3}\right)\end{array}$ & $\begin{array}{c}\mathrm{P}_{e x t} / \mathrm{k}^{\mathrm{e}} \\
\left(\mathrm{cm}^{3} \mathrm{~K}^{-1}\right)\end{array}$ & $\begin{array}{c}\text { Secure }^{f} \\
\text { Fit? }\end{array}$ & $\begin{array}{c}\text { Assoc }{ }^{\mathrm{g}} \\
\text { Protostar }\end{array}$ \\
\hline $032930+31251$ & 45 & $3: 29: 18.5$ & $31: 25: 10.5$ & 0.4 & 2.19 & 34.3 & 0.54 & 13. & 5.25 & 5.80 & yes & - \\
\hline $032929+31278$ & 46 & $3: 29: 17.6$ & $31: 27: 49.5$ & 0.3 & 1.07 & 25.8 & 0.54 & 12. & 5.42 & 5.90 & yes & 27 \\
\hline $032925+31205$ & 47 & $3: 29: 15.5$ & $31: 20: 31.5$ & 0.2 & 0.81 & 22.7 & 0.40 & 16. & 5.00 & 6.00 & yes & - \\
\hline $032922+31139$ & 48 & $3: 29: 13.6$ & $31: 13: 55.5$ & 0.7 & 2.04 & 24.8 & 0.58 & 14. & 5.67 & 6.20 & yes & 26 \\
\hline $032920+31131$ & 49 & $3: 29: 12.2$ & $31: 13: 07.5$ & 3.7 & 8.33 & 37.3 & 0.86 & 19. & 5.88 & 6.00 & yes & 25 \\
\hline $032918+31184$ & 50 & $3: 29: 11.3$ & $31: 18: 28.5$ & 1.1 & 5.33 & 39.9 & 0.74 & 16. & 5.74 & 5.80 & yes & 24 \\
\hline $032918+31217$ & 51 & $3: 29: 10.8$ & $31: 21: 43.5$ & 0.5 & 2.77 & 32.8 & 0.51 & 16. & 5.22 & 6.00 & yes & - \\
\hline $032917+31135$ & 52 & $3: 29: 10.6$ & $31: 13: 31.5$ & 8.0 & 13.16 & 32.2 & 0.86 & 24. & 6.11 & 6.40 & yes & 22 \\
\hline $032914+31152$ & 53 & $3: 29: 08.9$ & $31: 15: 16.5$ & 0.6 & 3.08 & 32.5 & 0.60 & 15. & 5.50 & 6.00 & yes & - \\
\hline $032914+31170$ & 54 & $3: 29: 08.7$ & $31: 17: 04.5$ & 0.3 & 0.73 & 19.0 & 0.36 & 19. & 4.98 & 6.20 & yes & - \\
\hline $032913+31219$ & 55 & $3: 29: 08.0$ & $31: 21: 55.5$ & 0.5 & 1.99 & 28.1 & 0.54 & 14. & 5.42 & 6.00 & yes & - \\
\hline $032912+31173$ & 56 & $3: 29: 07.3$ & $31: 17: 22.5$ & 0.3 & 0.71 & 17.5 & 0.40 & 16. & 5.25 & 6.30 & yes & - \\
\hline $032911+31156$ & 57 & $3: 29: 06.8$ & $31: 15: 37.5$ & 0.7 & 2.81 & 27.3 & 0.52 & 16. & 5.47 & 6.20 & yes & - \\
\hline $032909+31221$ & 58 & $3: 29: 05.4$ & $31: 22: 07.5$ & 0.3 & 1.66 & 28.6 & 0.36 & 23. & 4.70 & 6.00 & yes & - \\
\hline $032908+31187$ & 59 & $3: 29: 05.2$ & $31: 18: 43.5$ & 0.2 & 0.22 & 12.8 & 0.26 & 14. & 5.19 & 6.30 & yes & - \\
\hline $032906+31148$ & 60 & $3: 29: 04.0$ & $31: 14: 52.5$ & 0.6 & 4.01 & 34.7 & 0.53 & 17. & 5.31 & 6.00 & yes & 21 \\
\hline $032905+31159$ & 61 & $3: 29: 03.3$ & $31: 15: 55.5$ & 3.0 & 10.46 & 36.5 & 0.77 & 21. & 5.94 & 6.10 & yes & 20 \\
\hline $032902+31204$ & 62 & $3: 29: 01.7$ & $31: 20: 28.5$ & 1.1 & 8.82 & 46.3 & 0.67 & 18. & 5.52 & 5.80 & yes & 19 \\
\hline $032901+31143$ & 63 & $3: 29: 01.0$ & $31: 14: 22.5$ & 0.2 & 0.79 & 24.2 & 0.37 & 18. & 4.75 & 5.90 & yes & - \\
\hline $032901+31119$ & 64 & $3: 29: 00.7$ & $31: 11: 58.5$ & 0.3 & 0.47 & 17.2 & 0.48 & 11. & 5.54 & 6.20 & yes & 18 \\
\hline $032900+31215$ & 65 & $3: 29: 00.0$ & $31: 21: 34.5$ & 0.8 & 3.92 & 37.4 & 0.67 & 14. & 5.60 & 5.80 & yes & 17 \\
\hline $032892+31146$ & 66 & $3: 28: 55.6$ & $31: 14: 37.5$ & 2.5 & 8.61 & 48.6 & 0.87 & 17. & 5.61 & 5.70 & yes & 15 \\
\hline $032871+31062$ & 67 & $3: 28: 43.0$ & 31:06:13.4 & 0.2 & 0.97 & 27.8 & 0.30 & 19. & 4.64 & 5.80 & yes & - \\
\hline $032867+31178$ & 68 & $3: 28: 40.4$ & $31: 17: 52.3$ & 0.4 & 2.18 & 32.1 & 0.51 & 14. & 5.21 & 5.90 & yes & 13 \\
\hline $032866+31184$ & 69 & $3: 28: 39.7$ & $31: 18: 25.3$ & 0.4 & 2.57 & 36.6 & 0.53 & 14. & 5.17 & 5.80 & yes & - \\
\hline $032865+31059$ & 70 & $3: 28: 39.5$ & $31: 05: 55.3$ & 0.2 & 1.06 & 27.7 & 0.32 & 19. & 4.65 & 5.90 & yes & 12 \\
\hline $032861+31134$ & 71 & $3: 28: 37.1$ & $31: 13: 28.3$ & 0.6 & 1.92 & 29.5 & 0.66 & 12. & 5.70 & 5.90 & yes & 11 \\
\hline $032858+31070$ & 72 & $3: 28: 35.0$ & 31:07:04.3 & 0.2 & 0.16 & 10.0 & 0.30 & 14. & 5.39 & 6.40 & yes & 10 \\
\hline $032854+31110$ & 73 & $3: 28: 32.7$ & $31: 11: 04.2$ & 0.2 & 0.36 & 16.4 & 0.27 & 16. & 5.02 & 6.10 & yes & 9 \\
\hline $032785+30241$ & 74 & $3: 27: 51.5$ & $30: 24: 09.3$ & 0.1 & 0.24 & 15.6 & 0.27 & 14. & 5.00 & 6.00 & no & - \\
\hline $032780+30121$ & 75 & $3: 27: 48.2$ & $30: 12: 10.5$ & 0.3 & 1.50 & 30.2 & 0.48 & 13. & 5.13 & 5.90 & yes & 8 \\
\hline $032771+30124$ & 76 & $3: 27: 42.9$ & $30: 12: 28.5$ & 0.4 & 1.51 & 28.4 & 0.57 & 12. & 5.47 & 5.90 & yes & 7 \\
\hline $032766+30122$ & 77 & $3: 27: 39.7$ & $30: 12: 13.5$ & 0.2 & 1.00 & 23.3 & 0.35 & 20. & 4.82 & 6.00 & yes & - \\
\hline $032765+30130$ & 78 & $3: 27: 39.2$ & $30: 13: 01.5$ & 0.6 & 1.20 & 21.1 & 0.59 & 12. & 5.79 & 6.20 & yes & 6 \\
\hline $032763+30139$ & 79 & $3: 27: 38.3$ & $30: 13: 55.5$ & 0.2 & 0.40 & 16.0 & 0.31 & 16. & 5.06 & 6.20 & yes & 5 \\
\hline $032662+30154$ & 80 & $3: 26: 37.6$ & $30: 15: 24.7$ & 0.2 & 0.35 & 14.2 & 0.39 & 14. & 5.32 & 6.30 & yes & 4 \\
\hline $032584+30419$ & 81 & $3: 25: 51.0$ & $30: 41: 55.5$ & 0.5 & 4.03 & 36.3 & 0.44 & 20. & 4.95 & 6.00 & yes & - \\
\hline $032581+30423$ & 82 & $3: 25: 48.9$ & $30: 42: 19.5$ & 0.5 & 4.56 & 44.3 & 0.55 & 16. & 5.13 & 5.80 & yes & - \\
\hline $032564+30440$ & 83 & $3: 25: 38.9$ & $30: 44: 04.5$ & 1.7 & 4.72 & 37.6 & 0.83 & 15. & 5.78 & 5.80 & yes & 3 \\
\hline $032560+30452$ & 84 & $3: 25: 36.3$ & $30: 45: 16.5$ & 4.1 & 12.81 & 45.9 & 0.87 & 21. & 5.74 & 5.90 & yes & 2 \\
\hline $032543+30450$ & 85 & $3: 25: 25.8$ & $30: 45: 04.4$ & 0.2 & 1.21 & 27.4 & 0.41 & 16. & 4.91 & 5.90 & yes & - \\
\hline $032537+30452$ & 86 & $3: 25: 22.4$ & $30: 45: 13.4$ & 1.0 & 1.70 & 22.4 & 0.70 & 13. & 6.08 & 6.10 & yes & 1 \\
\hline $032516+30238$ & 87 & $3: 25: 10.2$ & $30: 23: 51.0$ & 0.2 & 0.17 & 11.1 & 0.28 & 14. & 5.30 & 6.30 & no & - \\
\hline
\end{tabular}




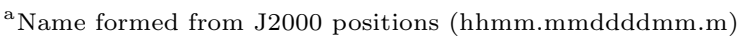

${ }^{\mathrm{b}}$ Reference number used in the text of this paper

${ }^{c}$ Position of peak flux within core (accurate to $3^{\prime \prime}$ )

${ }^{\mathrm{d}}$ Peak flux, total flux, and radius derived from clfind (Williams, de Geus, \& Blitz 1994). The beamsize is 15.7” for the peak flux.

${ }^{e}$ Concentration, temperature, central number density, and external pressure derived from Bonnor-Ebert modelling (see text)

${ }^{\mathrm{f}}$ See text for description of which submillimetre core identificationsare considered to be secure.

${ }^{\mathrm{g}}$ The reference number of any associated Spitzer protostar from the catalog of Jørgensen et al. (2007). Note that if more than one protostar is considered to be associated (within $15^{\prime \prime}$ ), only the closest one is listed. 


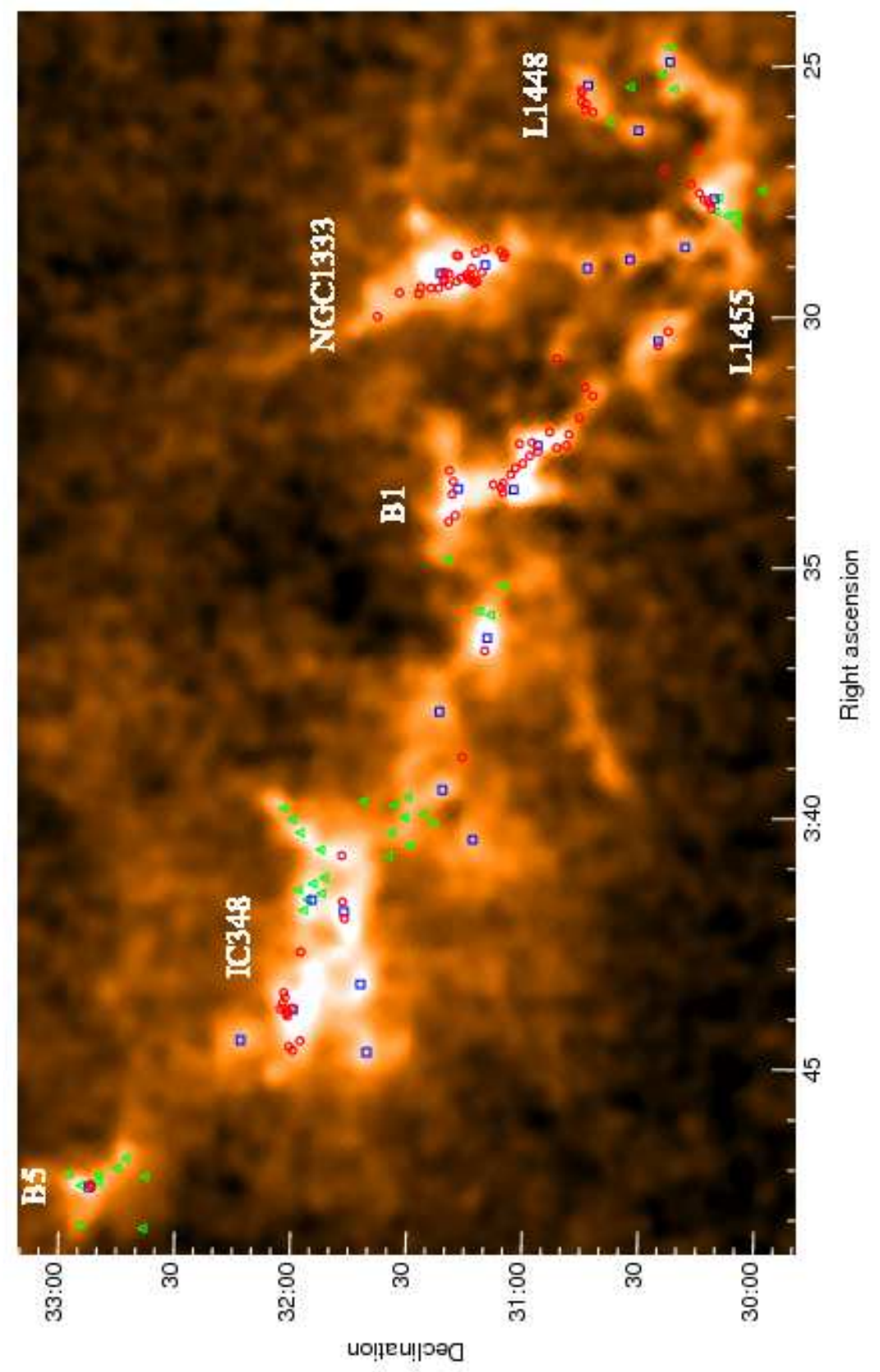

Fig. 1. - 2MASS-derived extinction map of the Perseus molecular cloud overlaid with the positions of our IRAM survey targets. Red circles indicate the SCUBA-selected targets, green triangles indicate the Palomar plate-selected targets, and blue squares indicate the 2MASS-selected targets. Well-known star-formation regions are labelled. 


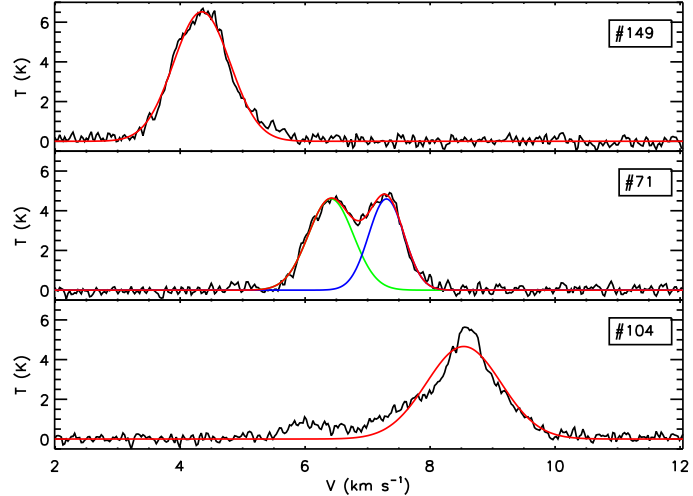

Fig. 2.- Three example $\mathrm{C}^{18} \mathrm{O}$ spectra showing differing spectral profiles. Black indicates the data while the red indicates the model fit. Blue and green indicate the components of a two Gaussian model. The vertical axis is in units of $\mathrm{T}_{A}^{*}$.

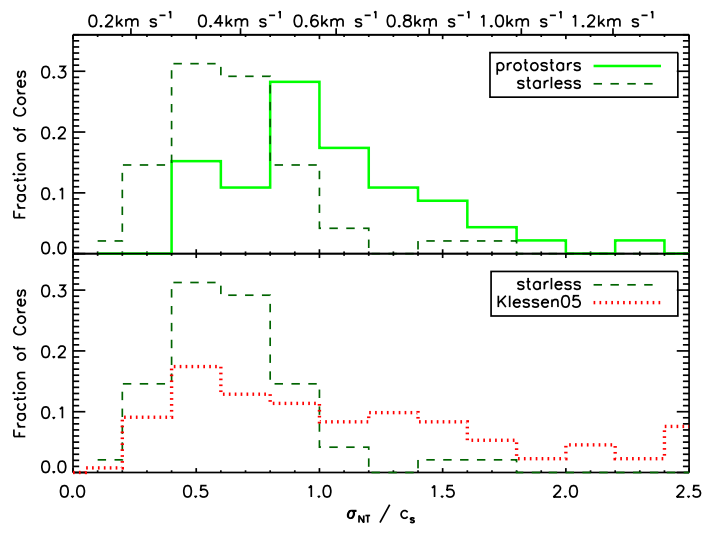

Fig. 3.- Relative level of non-thermal motions within the dense $\mathrm{N}_{2} \mathrm{H}^{+}$cores. The top horizontal axis shows the observed FWHM linewidth in $\mathrm{km} / \mathrm{s}$ while the bottom axis shows the turbulent fraction $\mathrm{f}_{\text {turb }}$ assuming a temperature of $15 \mathrm{~K}$. The top panel shows the protostars (solid green line) and starless cores (dashed green line). The bottom panel shows the starless cores (dashed green line) versus the prediction from a gravoturbulent simulation by Klessen et al. (2005) for starless cores (dotted red line). Note that the final histogram bin for the Klessen et al. (2005) model includes all objects above this turbulent fraction (which extends to 4.3 in their model).

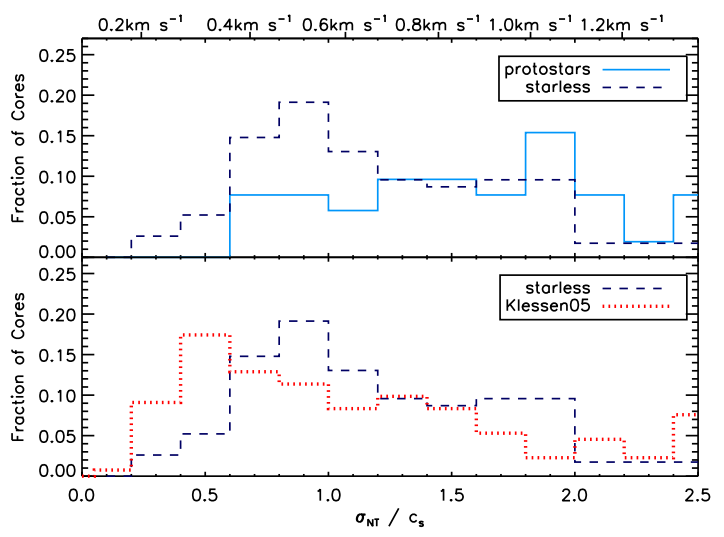

Fig. 4.- Relative level of non-thermal motions measured in $\mathrm{C}^{18} \mathrm{O}$. The top horizontal axis shows the observed FWHM linewidth in $\mathrm{km} / \mathrm{s}$ while the bottom axis shows the turbulent fraction $\mathrm{f}_{\text {turb }}$ assuming a temperature of $15 \mathrm{~K}$. The top panel shows the targets associated with protostars (solid blue line) and those not associated with protostars (dashed blue line). The bottom panel shows the targets not associated with protostars (dashed blue line) versus the prediction from a gravoturbulent simulation by Klessen et al. (2005) (dotted red line). Note that the final histogram bin for the Klessen et al. (2005) model includes all objects above this turbulent fraction (which extends to 4.3 in their model).

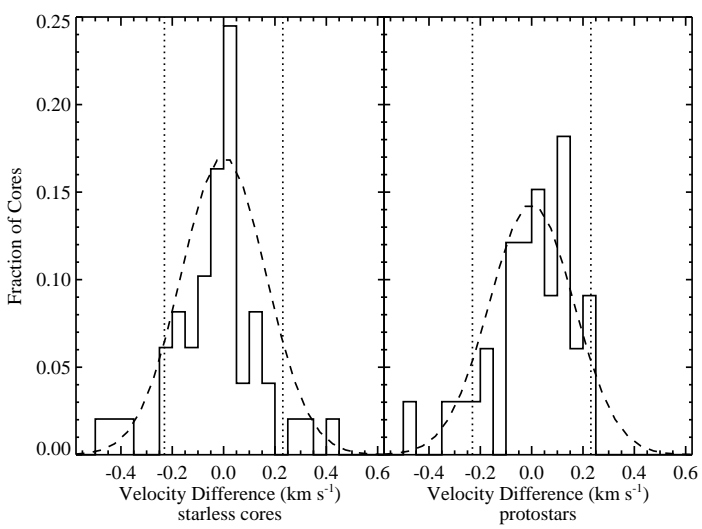

Fig. 5.- Difference in centroid veloicites of $\mathrm{N}_{2} \mathrm{H}^{+}$ to $\mathrm{C}^{18} \mathrm{O}$ for the starless cores (left) and protostars (right). The dotted lines indicate the sound speed of the ambient medium. The dashed lines indicate Gaussian fits to the distributions - the starless cores have $\sigma=0.17 \mathrm{~km} / \mathrm{s}$ while the protostars have $\sigma=0.16 \mathrm{~km} / \mathrm{s}$. 

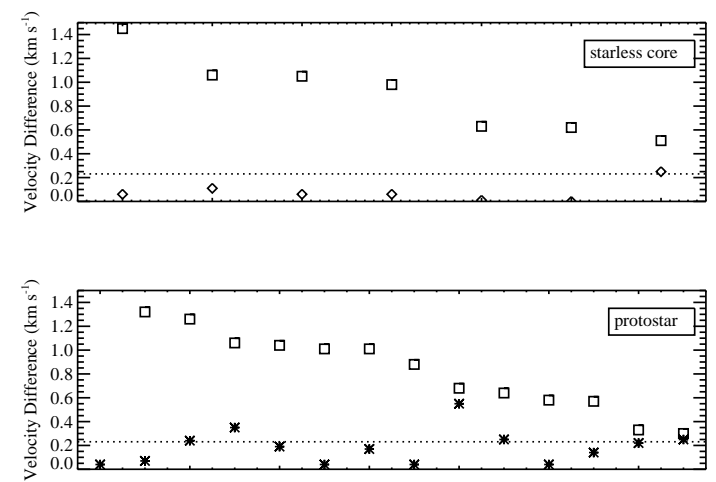

Fig. 6.- Difference in centroid velocities of $\mathrm{N}_{2} \mathrm{H}^{+}$ and $\mathrm{C}^{18} \mathrm{O}$ for starless cores (top) and protostars (bottom). The closest $\mathrm{C}^{18} \mathrm{O}$ velocity components are denoted by diamonds or asterisks while the farther $\mathrm{C}^{18} \mathrm{O}$ velocity components are denoted by squares. In each instance, the cores are ordered from largest to smallest difference in velocity using the farther $\mathrm{C}^{18} \mathrm{O}$ velocity component. The dotted line indicates the sound speed in the ambient medium.

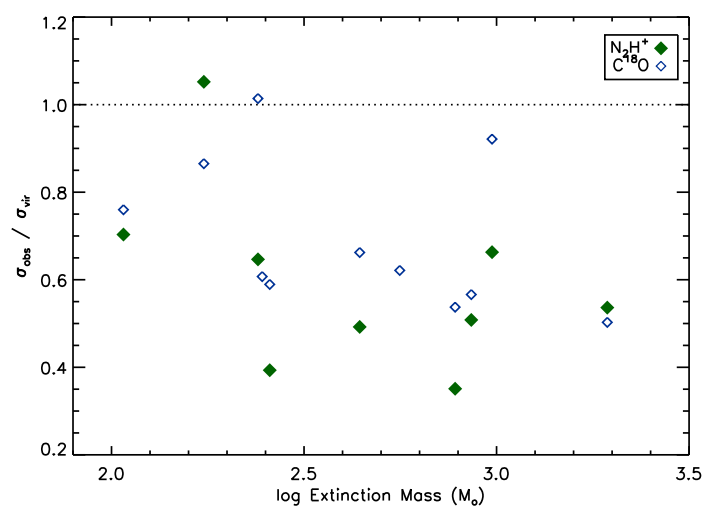

Fig. 7.- Ratio of the measured velocity dispersion to that required to counteract gravity $\left(\sqrt{G M_{e x t} / 5 R_{e x t}}\right)$ versus the mass in the extinction region. The dotted line shows the expected relationship for virial equilibrium. The green filled diamonds denote the dispersion in centroid velocity for $\mathrm{N}_{2} \mathrm{H}^{+}$starless cores. The blue open diamonds denote the dispersion of the summed $\mathrm{C}^{18} \mathrm{O}$ spectra for all starless cores in the extinction region. Two extinction regions have no $\mathrm{N}_{2} \mathrm{H}^{+}$dispersion measured since less than two $\mathrm{N}_{2} \mathrm{H}^{+}$cores were detected.

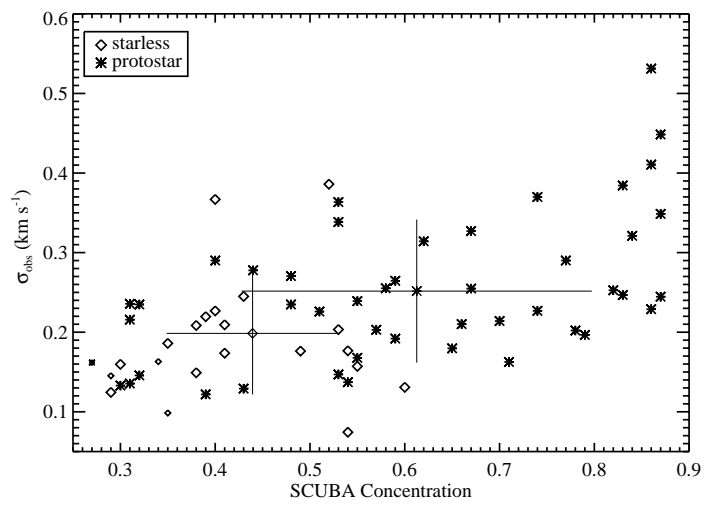

Fig. 8.- Variation of observed velocity dispersion in $\mathrm{N}_{2} \mathrm{H}^{+}$cores versus concentration for starless cores (diamonds) and protostellar cores (asterisks). The large bold crosses indicate the mean and standard deviation for each of the two samples. The smaller symbols indicate SCUBA sources for which the properties derived from clumpfind are less secure (see discussion in Appendix A). These sources were not used in any of the calcuations.

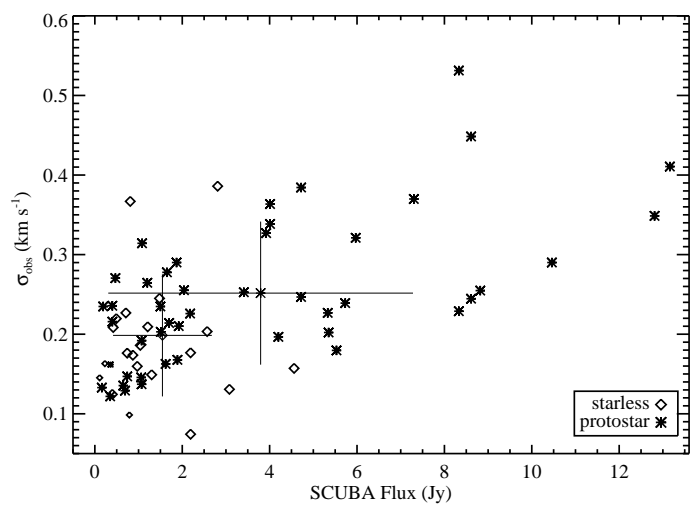

Fig. 9.- Variation of core velocity dispersion with the total flux within a SCUBA core for both protostars and starless cores. The same plotting convention is used as in Figure 8. 


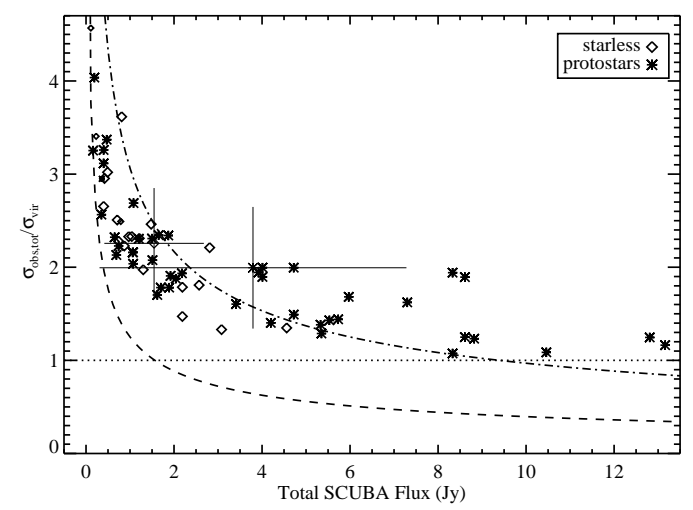

Fig. 10. - Ratio of the mean gas velocity dispersion to the virial velocity dispersion (calculated from SCUBA core flux and radius) squared, versus the observed SCUBA flux. The same plotting conventions are used as in Figure 8 . The dotted line shows the expected relationship for virial equilibrium. The dashed and dot-dashed lines show the relationship for thermal $15 \mathrm{~K}$ cores assuming core radii of $10^{\prime \prime}$ and $60^{\prime \prime}$ respectively.

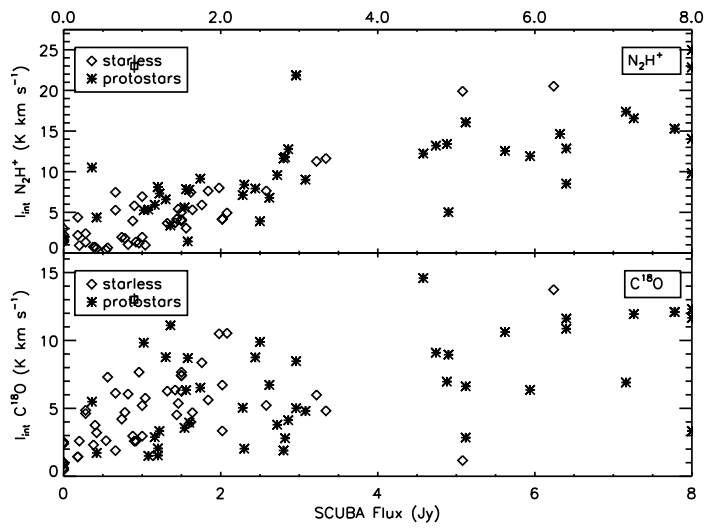

Fig. 11. - Variation in integrated intensity for $\mathrm{C}^{18} \mathrm{O}$ and $\mathrm{N}_{2} \mathrm{H}^{+}$with total SCUBA flux over the region observed by IRAM. Note that cores associated with total SCUBA fluxes of over 8 Jy were included in the plot as having SCUBA fluxes of $8 \mathrm{Jy}$ beam $^{-1}$. The same plotting conventions are used as in Figure 8. The squares with vertical lines indicate the mean size of the error in the integrated intensity. The error bar for the $\mathrm{C}^{18} \mathrm{O}$ integrated intensity has been enlarged by a factor of two.

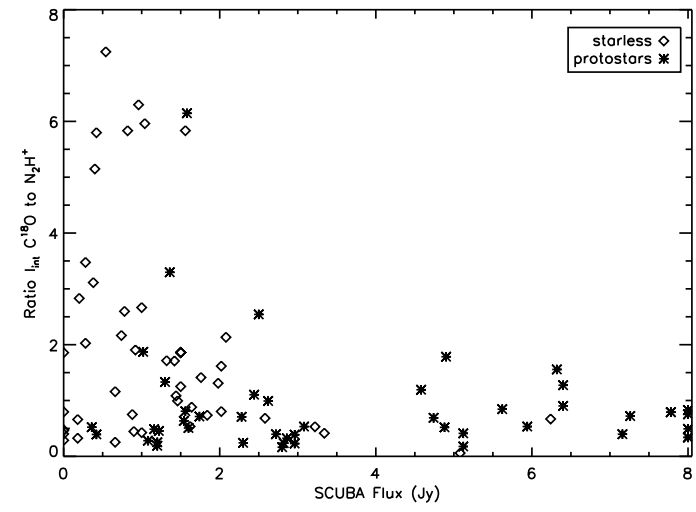

Fig. 12.- Ratio in $\mathrm{C}^{18} \mathrm{O}$ to $\mathrm{N}_{2} \mathrm{H}^{+}$integrated intensity versus total SCUBA flux over the IRAM beam. Note that all cores associated with SCUBA fluxes of over $8 \mathrm{Jy}$ have been included in the plot as having values of $8 \mathrm{Jy}$. The diamonds denote starless cores while the asterisks denote the protostars.

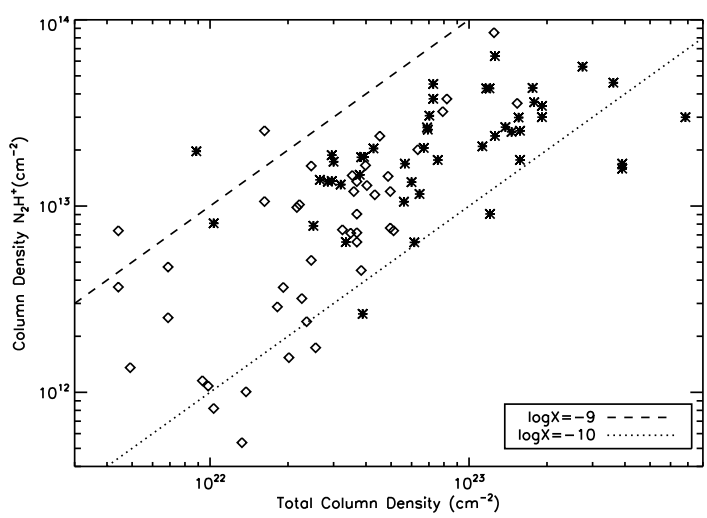

Fig. 13.- Column density of $\mathrm{N}_{2} \mathrm{H}^{+}$versus the total column density (calculated using the SCUBA flux within the IRAM beam). The diagonal lines indicate fractional abundances of $\mathrm{N}_{2} \mathrm{H}^{+}$. Starless cores are diamonds while protostars are asterisks. 


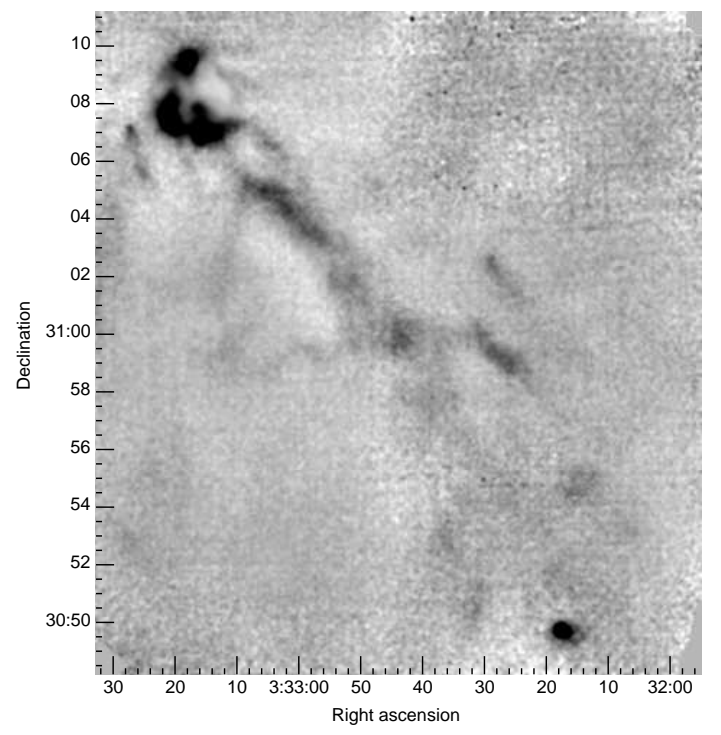

Fig. 14.- The 3" SCUBA map of the B1 star forming region. The image is scaled such that white corresponds to $\sim 0 \mathrm{Jy}^{\text {beam }}{ }^{-1}$ and black to $\sim 0.25 \mathrm{Jy}_{\text {beam }}{ }^{-1}$.

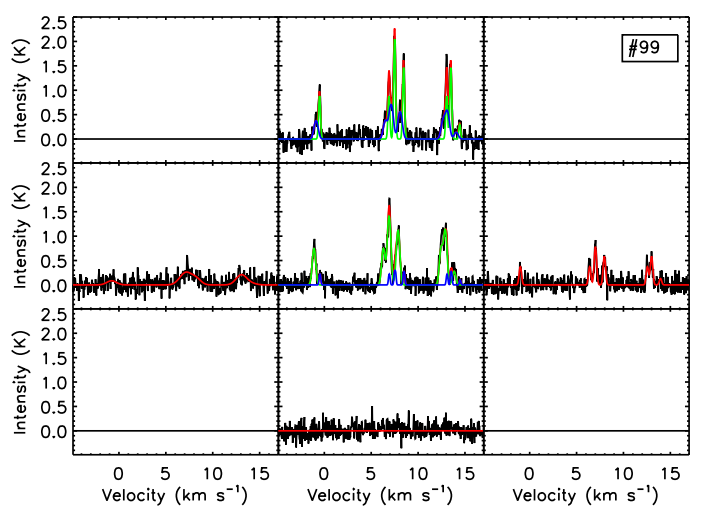

Fig. 15.- Spectrum for source \#99 in NGC1333. The vertical axis is in units of $\mathrm{T}_{A}^{*}$. Red indicates the summed fit while blue and green indicate the two different components fit (where applicable).

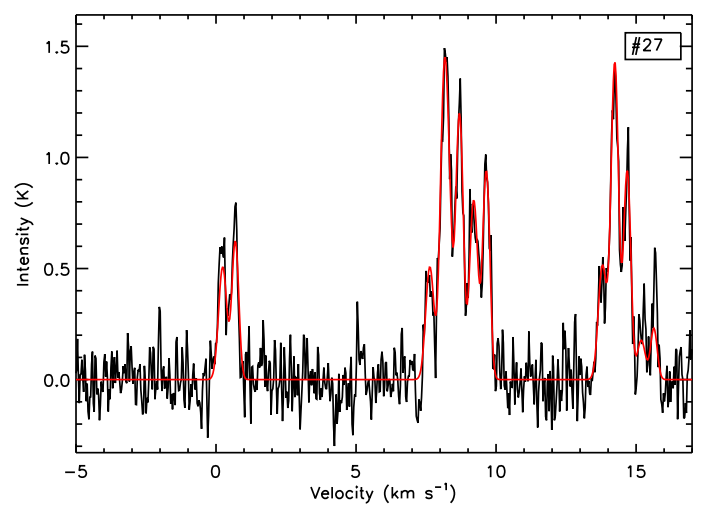

Fig. 16.- Spectrum for source \#27 in IC348. The same plotting convention is used as in Figure 15.

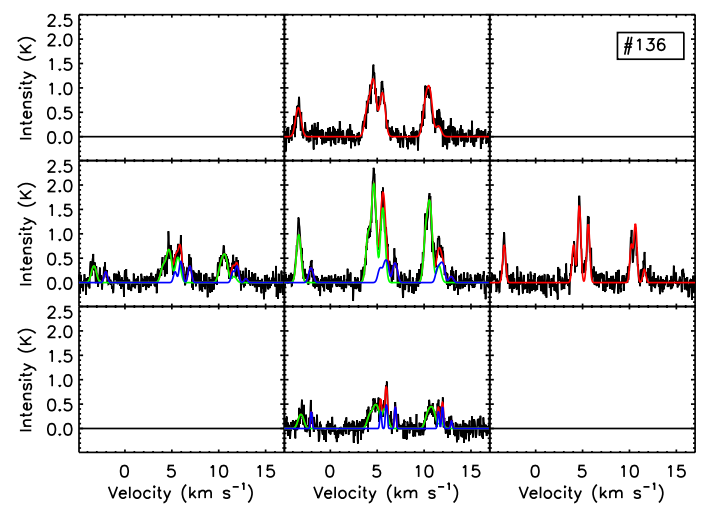

Fig. 17.- Spectrum for source \#136 in L1544. The same plotting convention is used as in Figure 15 .

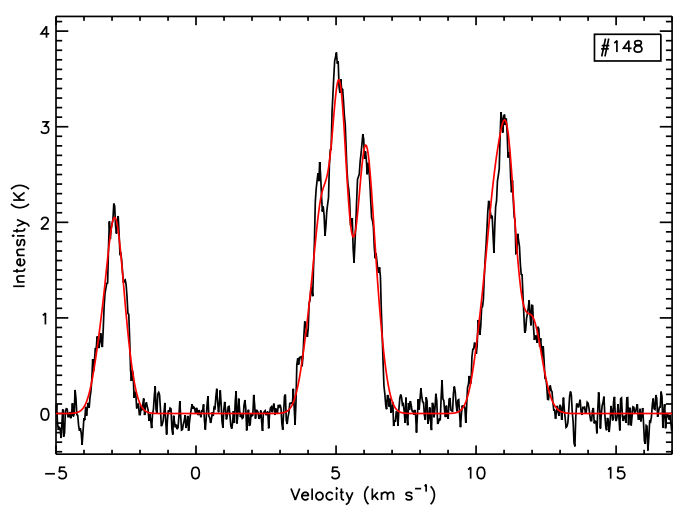

Fig. 18. - Spectrum of source \#148, the two velocity component core in L1448. The same plotting convention is used as in Figure 15. 


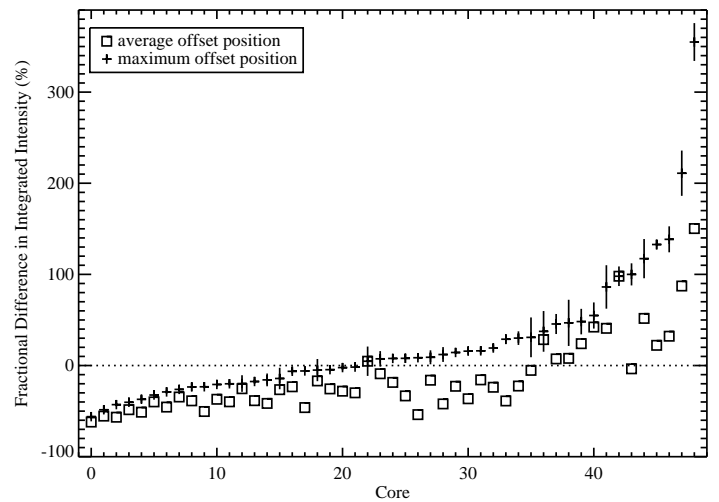

Fig. 19.- Fractional difference in integrated intensity between centre and offset positions in dense $\mathrm{N}_{2} \mathrm{H}^{+}$cores. The pluses denote the maximum difference with the vertical lines indicating the error in this measurement. The squares denote the average difference for all four offset positions versus the centre. The cores are ordered according to the maximum difference.

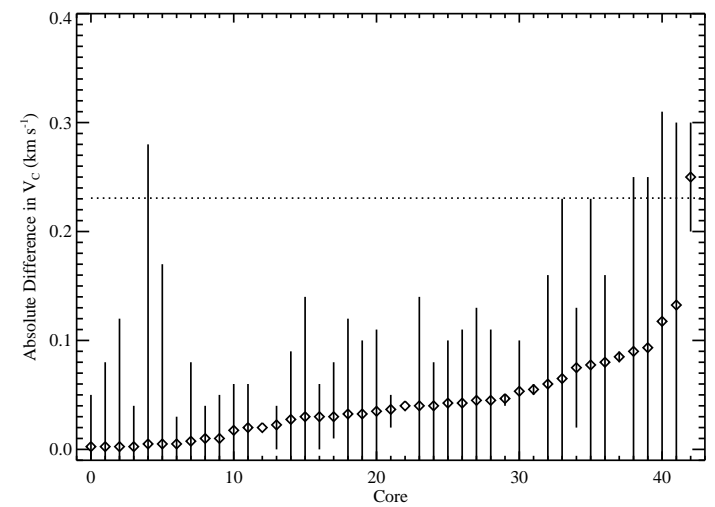

Fig. 20.- Difference in centroid velocity between the cross and central positions, with $\mathrm{N}_{2} \mathrm{H}^{+}$cores ordered in increasing average difference. The diamonds indicate the average cross velocity difference while the vertical lines indicate the range in centroid velocity difference at all cross positions. Cores with two velocity components fit have not been included. The dotted line indicates the sound speed. 